University of San Diego

Digital USD

2004-03-01

\title{
Two Perspectives on the Effectiveness of an Entry-Level Community Rehabilitation Training Program: A Comparison of Student and Supervisorial Perceptions
}

Howard D. Twomey EdD

University of San Diego

Follow this and additional works at: https://digital.sandiego.edu/dissertations

Part of the Leadership Studies Commons

\section{Digital USD Citation}

Twomey, Howard D. EdD, "Two Perspectives on the Effectiveness of an Entry-Level Community Rehabilitation Training Program: A Comparison of Student and Supervisorial Perceptions" (2004).

Dissertations. 738.

https://digital.sandiego.edu/dissertations/738

This Dissertation: Open Access is brought to you for free and open access by the Theses and Dissertations at Digital USD. It has been accepted for inclusion in Dissertations by an authorized administrator of Digital USD. For more information, please contact digital@sandiego.edu. 
Howard D. Twomey

A dissertation submitted in partial fulfillment

of the requirements for the degree of

Doctor of Education

University of San Diego

March 2004

Dissertation Committee

Fred J. Galloway, Ed.D. Chair

Daniel M. Miller, Ph.D. Member

Caren Sax, Ed.D. Member 
(C) Copyright by Howard D. Twomey 2004

All Rights Reserved 


\begin{abstract}
Although a significant amount of attention has focused on the effectiveness of graduate level training programs for rehabilitation counselors, little, if any, research has been devoted to entry-level training programs for Community Rehabilitation Program (CRP) personnel. To remedy this deficiency, this study first developed a survey instrument for both students and their supervisors to measure the change in skills, aptitudes, and attitudes that resulted from participation in a university sponsored training program. After administering the survey to 188 students and 20 supervisors, the perceptions of these two groups were compared and then select demographic measures were used to explain the overall variation in student responses.

Results suggest that both students and supervisors believed the training to be beneficial, although students consistently rated the value of the training higher then did their supervisors, particularly in the area of aptitudes and attitudes. Demographic factors were also found to be important in explaining variation in student responses, although these regressions explained only about 10 percent of the overall variation. However, African Americans and Caucasians appear to have benefited more than Hispanic American and others, while respondents with disabilities benefited less than those without disabilities. In addition, students who both completed their survey on the Internet and received the majority of their instruction in this manner benefited more from the training than those completing both in traditional environments.

Taken together, these results suggest the importance of training for entry-level CRP personnel. Furthermore, results from the regression analysis suggest that
\end{abstract}


certain groups benefited more in some areas than did others, suggesting that curricular reform may be needed if all students are to benefit equally from the training. 


\section{DEDICATION}

This dissertation is dedicated to my mother, Lorna Keith, for her patience and support and to Marie, who continues to be a source of inspiration.

Reproduced with permission of the copyright owner. Further reproduction prohibited without permission. 


\section{ACKNOWLEDGEMENTS}

My deepest appreciation to those who contributed to this work and my personal growth, especially the following: Fred Galloway for being supportive, encouraging, and helping me understand the complexities and simplicities of statistics and an understanding the importance of being genuine and for encouraging me to grow personally. Also for many great rounds of golf and for helping me understand the importance of yelling, "four!" off and on the links.

Caren Sax for her guidance and who demonstrates that you can practice what you preach, and for helping me understand the field of public rehabilitation; Dan Miller who provided critical and thoughtful guidance, and Fred McFarlane who is always supportive, encouraging and quick with a smile; Mari Guillermo for helping me chase down surveys and her encouragement; Dick Koch and Tim Gust who have always encouraged me to achieve; Shelly Valdez who underestimates her own presence, but I do not; Greg Stump who taught me that being genuine is a gift that you give to others

My appreciation goes out to my confidants including my sister Sheila and friends Fran, Mary, Julie and Keith for his technical support. I could not have completed this project without your encouragement and assistance. 


\section{TABLE OF CONTENTS}

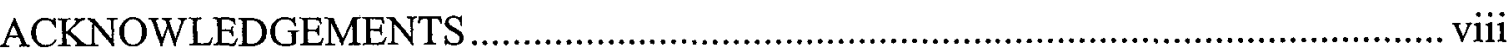

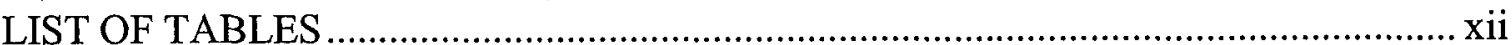

\section{CHAPTER}

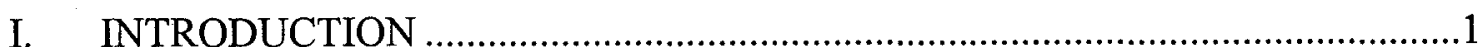

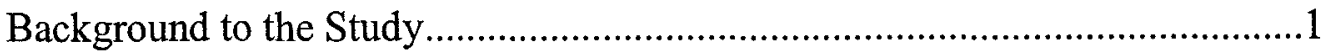

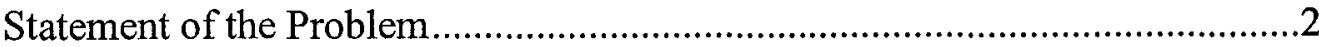

Philosophical Framework .....................................................................

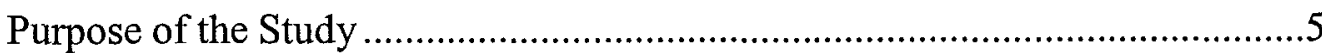

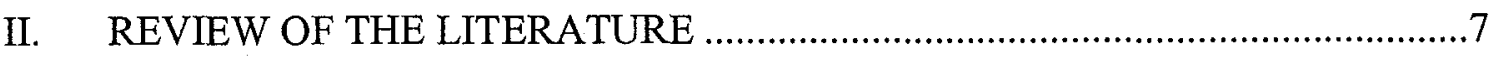

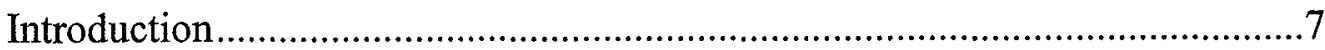

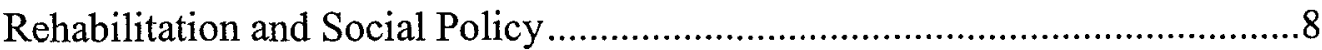

Rehabilitation and the Workplace.........................................................13

Rehabilitation Services Delivery .............................................................19

Rehabilitation Continuing Education...................................................23

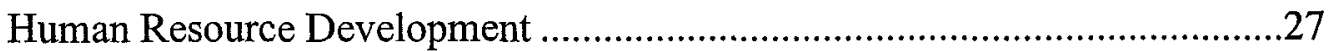

Community Rehabilitation Programs and Evaluation ................................29

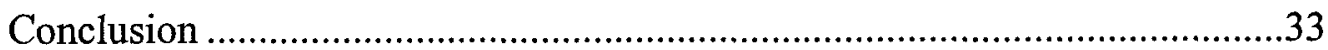

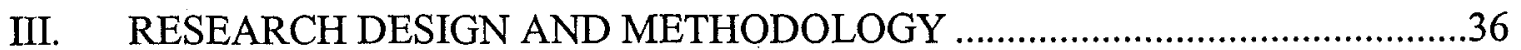

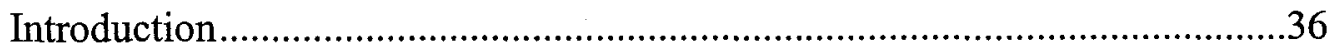

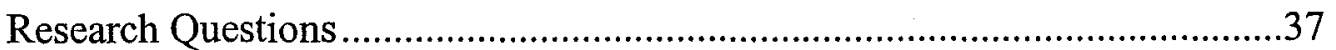

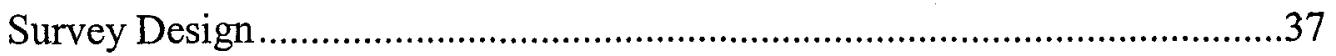

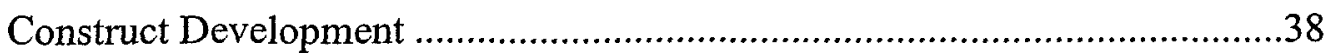




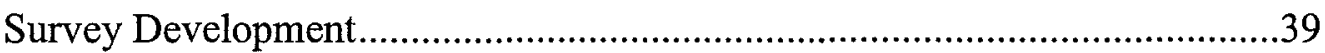

Peer Review of Survey Instrumentation .............................................40

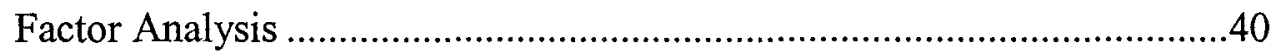

Survey Respondents and Methodology ................................................40

Statistical Analysis of Survey Results ....................................................41

Demographic Data Collection.........................................................42

Comparative Analysis of student and Supervisor Means ............................43

Eliminated Survey Statements .........................................................43

Student Survey Questions and Indices.....................................................44

Supervisor Survey Questions and Indices..............................................45

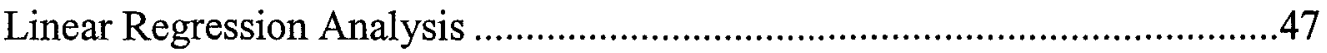

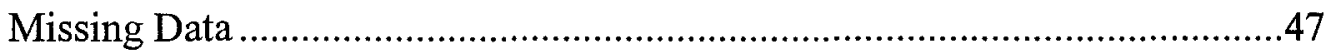

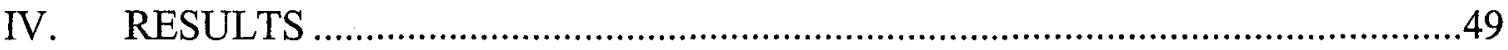

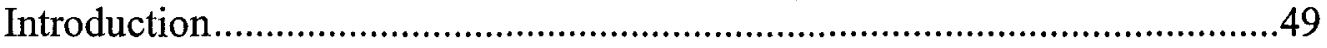

Participants and Survey Procedures..........................................................50

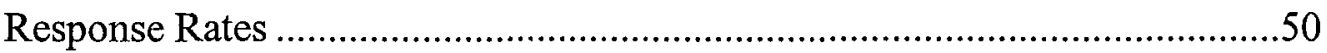

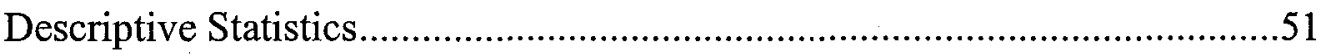

Students Sample Populations ...........................................................55

Supervisor Sample Population ....................................................52

Student Survey Responses by Combined Indices ......................................54

Supervisor Survey Responses by Combined Indices...................................55

Comparison of Student and Supervisor Perception Using Independent T-test .........................................................................56

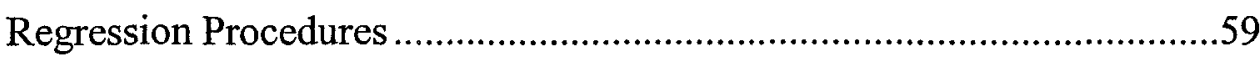

Overall Regression Models....................................................................61 
Regression Results for the Statements that Comprise Student Index 1 (Statement 1-7)

Regression Results for the Statements that Comprise Student Index (Statement 8-13) .64

Regression Results for Student Index 3 (Questions 14-19) ............................66

Qualitative Data ...........................................................................................67

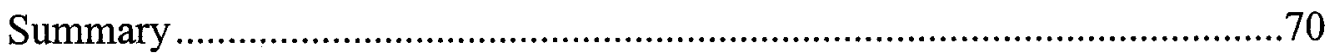

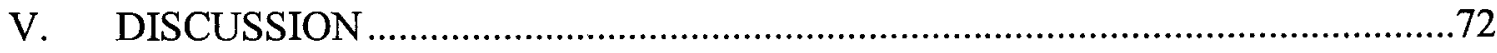

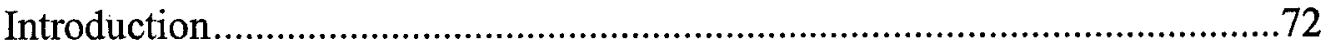

Study Limitations and Biases........................................................................72

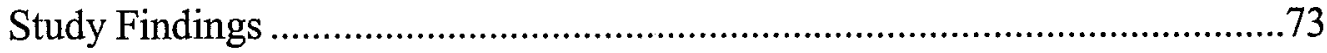

Contributions to the Literature .......................................................................76

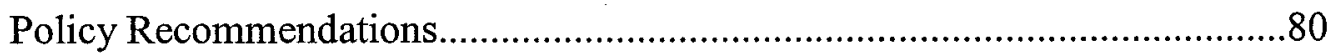

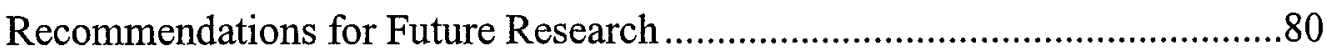

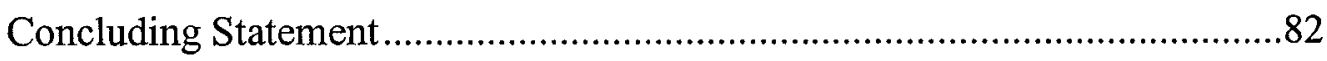

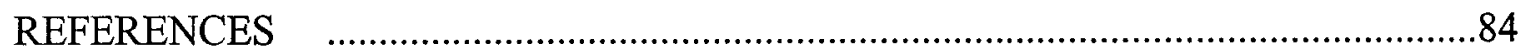

\section{APPENDICES}

A. STUDENT SURVEY WITH COVER LETTER ……………………………......

B. SUPERVISOR SURVEY WITH COVER LETTER …….....................................94

C. STUDENT RESPONSES TO QUALITATIVE QUESTIONS...........................101

D. SUPERVISOR RESPONSES TO QUALITATIVE QUESTIONS .....................151 


\section{List of Tables}

3.1 Independent Variables Description and Coding of Demographics........................42

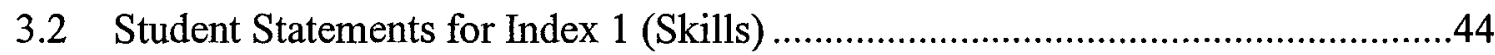

3.3 Student Statements for Index 2 (Aptitude an Attitude) ....................................45

3.4 Student Statements for Index 3 (Organizational Characteristics).........................45

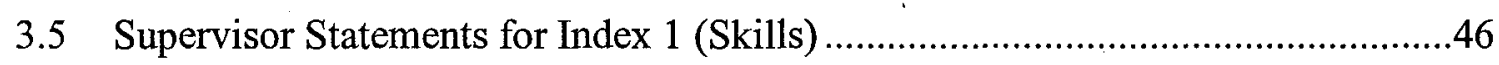

3.6 Supervisor Statements for Index 2 (Aptitude an Attitude) .................................46

3.7 Supervisor Statements for Index 3 (Organizational Characteristics) ....................47

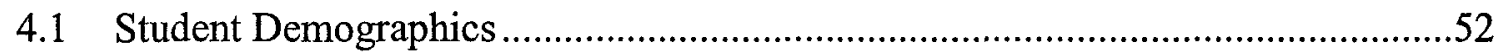

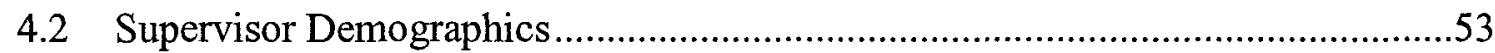

4.3 Student Mean Scores and Standard Deviations Generated from the Survey ...........................................................................54

4.4 Supervisor Mean Scores and Standard Deviations

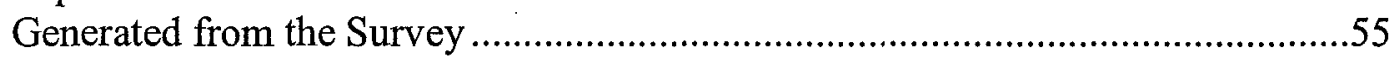

4.5 Student Differences in Mean Score and Standard Deviation Generated from the Survey When Compared to the Supervisors ..........................55

4.6 Result of Mean Comparison Using Independent T-test....................................57

4.7 Result of Mean Comparison Using Independent Sample T-test............................58

4.8 List of Variables and with Abbreviations Used for this Study ............................59

4.9 Adjusted $\mathrm{R}^{2}$ for the Regression Models in the 19 Statements .............................60

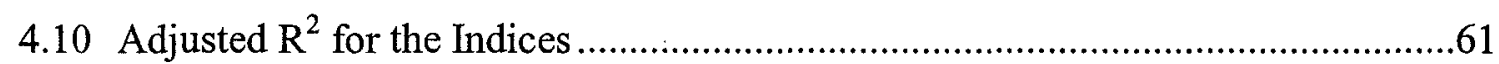

4.11 Indices 1-4 Estimated Coefficients for Selected Demographics..........................62

4.12 Estimated Coefficients for the Statements Comprising Index 1 .......................63

4.13 Estimated Coefficients for the Statements Comprising Index 2 .......................65

4.14 Estimated Coefficients for the Statements Comprising Index 3 ........................66

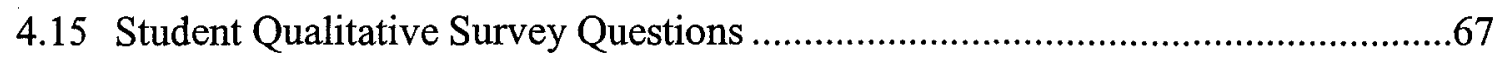


PAGE

4.16 Supervisor Qualitative Survey Questions ...........................................................69 


\section{CHAPTER I}

\section{INTRODUCTION}

\section{Background to the Study}

In 2001, San Diego State University's Interwork Institute received their second five-year Rehabilitation Continuing Education Program for Community Rehabilitation Personnel (CRP-RCEP IX) grant from the U.S. Department of Education (DOE), Office of Special Education and Rehabilitative Services (OSERS), Rehabilitation Services Administration (RSA). The grant purpose is to develop, provide, continue and/or establish educational programs for Community Rehabilitation Program (CRP) personnel whose services are vendored by state vocational rehabilitation (VR) agencies. These educational programs focus on developing the skills of the personnel who help prepare individuals who have disabilities enter the mainstream workforce. Interwork's mission is to provide these educational services within Region IX of the 10 Regions designated by RSA that encompass the United States and Pacific jurisdictions ${ }^{1}$. Although Interwork serves all of Region IX, California and Nevada are the focus of this study. The scope of the CRP-RCEP's responsibilities includes both short-term (1-2 day) training and long-

\footnotetext{
${ }^{1}$ Region IX includes California, Arizona, Nevada, Hawaii and the Pacific Jurisdictions jurisdiction of Guam, Northern Marianas and American Samoa.
} 
term coursework. This study addresses the long-term educational coursework offered to CRP personnel.

During the first five-year grant, the Interwork Institute, in conjunction with the partnership of CRPs in the region, developed curriculum and instruction in five core areas: 1) Leadership and Management; 2) Supported Employment and Natural Supports; 3) Transition to the Workforce; 4) Assistive Technology; and 5) Communication and Rehabilitation. These instructional areas were designed in accordance with the Comprehensive Study of Personnel Development (CSPD). CSPD is a nationwide initiative designed to increase the overall education of persons who work with people who have disabilities, especially in preparing them to enter the labor force. The overall focus of the CSPD is to develop skills, aptitudes and attitudes of persons working with individuals who have disabilities.

The primary focus of this study is to assess the CRP personnel's perceptions of their workplace abilities in measurable terms following classroom instruction. The secondary focus will be an assessment of their skills based on the perceptions and observations of their supervisors. Their perceptions will be measured utilizing surveys designed to assess the workplace in terms of skills, aptitudes, attitudes and selected organizational characteristics. The results will help determine if the Interwork Institute is meeting the workplace needs of Community Rehabilitation Programs personnel.

\section{Statement of the Problem}

The Interwork Institute established curriculum and training goals in concert with the conceptual framework of the Comprehensive System of Personnel Development (CSPD) established by the RSA. CSPD's stated philosophy regarding the educational goals for rehabilitation personnel is focused on developing "knowledge, skills, aptitudes, 
and attitudes empirically established as needed by rehabilitation practitioners to materially affect attainment of desired individual and system outcomes" (Institute on Rehabilitation Issues, 1999 p.6). Curriculum focuses on empowerment strategies that enable students to promote consumer choice and self-advocacy on the part of the individual with disabilities served by the state/federal rehabilitation system. The Interwork Institute evaluation focus stems from these ideas. Simply asked, does the curriculum and instruction meet the needs of the target population and facilitate the organizational requirements of the workplace?

The evaluative criterion utilized in this study is one of effectiveness. The focus is on determining if the educational programs provided to CRP personnel (referred to hereafter as students), designed in accordance with the CSPD and a consumer-focused approach, is positively affecting the organizations that are sending their employees to Interwork sponsored programs.

\section{Philosophical Framework}

The Interwork Institute's philosophical premise relies on analyzing the breadth and depth of their ability to provide academic programs that meet the needs of their constituents. Program development encompassing reflective practices and selfdeterminism are essential ingredients to meeting this principle. Each is a relevant component to a comprehensive evaluation format that tests program effectiveness. Reflective practice is a method that "links thought and action with reflection. It involves thinking about and critically analyzing one's actions with the goal of improving one's professional practice" (Schon, 1983, as described by Sax, 1999, p. 8). Self-determinism is the method of focusing on the ability to "chart one's own course" (Fetterman, Kaftarian \& Wandersman, 1996, p. 8). Literature on adult learning is replete with effective adult 
teaching models that indicate the need for program evaluation in order to meet the goals of a reflective organization (Fetterman, Kaftarian \& Wandersman, 1996; Guba \& Lincoln, 1989; Hirschorn, 1997).

Interwork employs program evaluation surveys as a reflective practice tool to gain insight into it's ability to meet the needs of the persons they serve. Evaluation is also a program necessity based on Interwork's dependence on grant monies. RSA's evaluation process requires accountability for resources and focuses on meaningful demographics (e.g. age, gender, ethnicity, educational level, etc.) of the persons they serve. The Government Performance and Results Act of 1993 notes the importance of formal written program evaluations exceeding the simple gathering of descriptive data. This more recent focus steps away from the traditional data gathering and asks that grantees build and execute deterministic, efficacious and meaningful evaluation processes that measure program effectiveness by the individuals they serve (Kingbury, 2000).

This increasingly complex focal point of grant acquisition can be viewed as a demonstration of organizational competence. Organizational competence is the ability of an organization to deliver a product or service to a group of stakeholders in a manner that demonstrates resourcefulness and encourages growth and leadership (Coplin \& O'Leary, 1998). Organizations receiving government funds must demonstrate their ability to utilize limited resources in a manner that maintains the public's best interest. Kingbury (2000) reports to Congressional Committee:

Program evaluations are objective, systematic, studies that answer questions about program performance and results. By examining a broader range of information than is feasible to monitor on an ongoing basis through performance measures, an evaluation study can explore the benefits of a program as well as ways to improve program performance. (p. 7) 
The Interwork Institute faculty and staff believe that their work during the initial 5-year CRP-RCEP grant was positive. They further believe that they positively affected their target population by providing state-of-the-art, targeted and professionally prepared educational programs. However, the students' perspective is an integral part of Interwork's overall philosophical doctrine and has not been assessed or investigated to determine program effectiveness. Thus, an evaluation of program effectiveness was deemed necessary to assess Interwork's curriculum and instruction over the past five years to measure their ability to meet the needs of the organizations that they serve and specifically the CRP personnel enrolled in the courses.

\section{Purpose of the Study}

The Interwork Institute's framework relies on developing, delivering, and evaluating curriculum, instruction and programs designed for CRP personnel who work with persons who have disabilities. By combining the CSPD conceptual framework, Interwork's philosophy and a student centered educational focus of workplace skill development, the staff of the organization believes that it is meeting the needs of the students. However, this study was developed to empirically evaluate student/employee workplace performance following the completion of instruction. The idea is to measure program effectiveness and establish meaningful inter-organizational dialogue by assessing student and supervisor perceptions of workplace skills derived from the educational format.

This evaluation focuses on comparing self-reports of student performance and observations of students' performance by their supervisors. Two surveys were developed 
for this study to measure the two sources for assessing performance, i.e. students and supervisors (see appendices A and B respectively).

The information collected from these surveys was used to address the following research questions:

1. What are the perceptions of the participants and their workplace supervisors of the training provided by the Interwork Institute?

2. How, if at all, do the perceptions differ between students and their workplace supervisors?

3. To what extent, if any, are the perceptions related to demographics, including age, gender, ethnicity and education?

As with any program evaluation, it is hoped the results of the study could be used to improve upon current practice. More specifically, the findings of this study could be useful to further enhance Interwork's curriculum in ways that are meaningful and produce the desired level of workplace skills that meet the needs of the CRPs and the consumers they serve. 


\section{CHAPTER II}

\section{REVIEW OF THE LITERATURE}

\section{Introduction}

The Interwork Institute is presently administering the second consecutive, fiveyear Rehabilitation Continuing Education Program for Community Rehabilitation Personnel in Region IX (CRP-RCEP IX) grant. RSA and the US Department of Education provide the grant funds to develop and implement educational programs focusing on developing skills, aptitudes and attitudes of persons who work in Community Rehabilitation Programs (CRPs) that provide supported and competitive employment services. This expenditure of public resources for educational program development instills an evaluative necessity, particularly given the scarcity of public resources. Parker, Shaw and McGuire (2003) note "in an era of decreased funding and rising expectations for demonstrable outcomes, postsecondary professionals face a growing need to evaluate the effectiveness of their program's mission and activities using data driven procedures" (p. 3). Consequently, the focus of the literature review includes the mechanisms and implications of this utilization of public resources for individuals with disabilities who focus their lifestyles to include working in an integrated workplace.

The first section, Rehabilitation and Social Policy, focuses on the mission and vision of the rehabilitation worker, outlines legislative decree and sets the background for 
the study on Interwork's program effectiveness. The second section, Rehabilitation and the Workplace, summarizes the research activities conducted within the rehabilitation sector on the educational needs of service providers. The third section, Rehabilitation Services Delivery, explores issues that directly affect persons with disabilities in the pursuit of employment. The fourth section, Rehabilitation Continuing Education, describes the model used by Interwork to address the educational needs of CRP personnel. The fifth section, Human Resource Development (HRD), defines the strategies that provide educational services to rehabilitation workers. The sixth section, Community Rehabilitation Programs and Evaluation, focuses on the organizational mission and evaluation of the training programs to include the utilization of surveys to understand the perceptions of respondents who have completed training and their supervisors who monitor their workplace behavior and skills.

\section{Rehabilitation and Social Policy}

Szymanski (1985), in her presidential address to the $28^{\text {th }}$ American Rehabilitation

Counseling Association (ARCA), described rehabilitation professionals as follows:

I contend that a rehabilitation counselor is a professional visionary. He or she must have the unique ability to see beyond the limitations of a person or a society, toward the individual, the community, and the potential. We must see beyond what is to what can be. The professional rehabilitation counselor believes in and works actively toward a society in which persons with disabilities share equally in all opportunities and benefits. (p. 2)

Szymanski's work focused on rehabilitation counselors who had achieved a Masters degree level of education. However, her visionary principles apply equally to entry-level rehabilitation personnel. In fact, Szymanski's ideas were the cornerstone of legislation that enabled RSA through the US DOE to establish funding for the CRPRCEP grants. Interwork targeted these funds to develop training programs through a 
delivery system that provides CRP personnel with training and education at all educational levels within the workforce. These educational activities are person-centered, i.e., where the educational focus is on the person rather than the process.

Interwork's educational program for front-line staff is directed towards teaching skills to CRP staff who are responsible for working with individuals who have physical, cognitive, psychological, or emotional disabilities as they seek employment, develop selfsufficiency, and create productive lifestyles. Leahy and Szymanski (1995) define a person-centered approach as "a process in which the counselor and the client work together to understand existing problems and potentials and to facilitate the client's effective use of personal and environmental resources" (p.165). Interwork has used this model to build quality educational programs that promote cohesion between the community rehabilitation staff members, their organizations, and the individuals with disabilities who benefit from their services. Interwork's guiding principle is that, with the right training and the appropriate resources, CRPs can operate with clarity of purpose and intent that provides for the best interest of the people they serve.

Over the last century, the rehabilitation profession and the person-centered approach have grown throughout the United States. This growth derived from continued research and advocacy of human potential supported by legislative agenda. Legislative support reaches back more than 80 years as funding increased for educational programs including grants. Realistic employment protection laws were implemented and educational institutional programs focused on instruction in the field of rehabilitation techniques and appropriate services (Schiro-Geist \& Walker, 1992). With this educational focus, the person-centered approach was developed to focus on removing physical, 
psychological and societal occupational barriers. Legislation contributed by implementing pervasive laws making discrimination unlawful. Legislative action provided the legal mandate and subsequent financial means that increasingly leveled the playing field for people with disabilities. In combination with a developing a dedicated rehabilitation community focused on the person first verses the disability, our society benefits from working with and empowering individuals with disabilities.

The Smith-Hughes Act of 1917 and the Soldiers Rehabilitation Act of 1918 provided funding to educate rehabilitation counselors. This led to the Smith-Fess Act, establishing public, federal and state rehabilitation programs (Szymanski \& Leahy, 1993). In 1934, based on the United States' need for workers following World War I, Public Law 113 was enacted to develop strategies and opportunities to enable persons with disabilities to join the work force. In 1954, Public Law 565 increased federal spending for Vocational Rehabilitation Services and research grants. These laws focused on delivery of rehabilitation services that focused entirely on effectively employing persons with disabilities. Public Law 333, enacted in 1965, doubled federal financial support for vocationally related services in an attempt to reduce the negative financial economical impact of disability on the nation (Oberman, 1967).

The Smith-Fess Act institutionalized the practice of rehabilitating persons with disabilities and created educational resources for this underserved population of potential workers. However, legislative regulations cannot alter the public perception of person with disabilities and the attitudes regarding their attempts to attain employment. Similar to the civil rights movement, the rights of the disabled continue to be a difficult concept for the American public to grasp. Martin Luther King, as quoted by the National 
Clearinghouse of Rehabilitation Training Materials, Oklahoma State University (2000), stated:

It is an historical fact that the privileged groups seldom give up their privilege voluntarily. Individuals may see the moral light and voluntarily give up their unjust posture, but as we are reminded, groups tend to be more immoral than individuals. We know through painful experience that freedom is never voluntarily given by the oppressor, it must be demanded by the oppressed. (p. 3)

The ideas that Dr. King proclaimed are relevant for those with disabilities seeking equal employment and treatment under the law. The disabled population is only one of many minority groups who has benefited from legislative mandate. The most recent legislation affecting people with disabilities over approximately the last 40 years as described by The National Clearinghouse of Rehabilitation Training Materials (2000) includes:

1. 1968, Architectural Barriers Act: Prohibits architectural barriers in all federally owned or leased buildings.

2. 1970 , Urban Mass Transit Act: Requires that all new mass transit vehicles be equipped with wheelchair lifts.

3. 1973, Rehabilitation Act (particularly title 5 B, Section 501, 503 \& 504): Prohibits discrimination in federal programs and services and all other programs or services receiving federal funding for the disabled.

4. 1975, Developmental Disabilities Bill of Rights Act: Among other things, establishes protection and advocacy services.

5. 1975, Education of All Handicapped Children Act (PL 94-142): Requires free appropriate public education in the least restrictive environment possible for children with disabilities. This law is now called The Individuals with 
Disabilities Education Act (IDEA). This act was most recently amended in 1997.

6. 1978, Amendment to the Rehabilitation Act: Provides for consumercontrolled Centers for Independent Living for adults who are disabled.

7. 1983, Amendment to the Rehabilitation Act: Provides for the Client Assistance Program (CAP), an advocacy program for consumers requiring rehabilitation and independent living services.

8. 1985, Mental Illness Bill of Rights Act: Requires protection and advocacy service for individuals with mental illness.

9. 1988, Civil Rights Restoration Act: Counteracts bad case law by clarifying Congress' original intention that under the Rehabilitation Act, discrimination in any program or services that is a part of an entity receiving federal funding - not just the part that actually directly receives the funding - is illegal.

10. 1988, Air Carrier Access Act: Prohibits discrimination with respect to air travel; provides for equal access to air transportation services.

11. 1988, Fair Housing Amendment Act: Prohibits discrimination in housing against people with disabilities and families with children. Provides for architectural accessibility for certain new housing units, renovation of dwellings, and modifications for accessibility.

12. 1990, Americas with Disabilities Act (ADA): Provides comprehensive civil rights protection for people with disabilities. Closely modeled after the Civil Rights Act, Section 504, title B of the Rehabilitation Act and its regulations. 
As demonstrated through this extensive (but not complete) legislative history, our society is replete with legislation that mandates the protection of the rights of persons with disabilities. The vast majority focus on the rights of disabled persons to be free of discrimination in the workplace. Many others provide the means for persons with disabilities to seek equal access into the workforce and housing in order to gain equality within the society. However, our society continues to have trouble accepting and understanding the needs of those with disabilities; their ability, willingness and desire to be active in the workplace, and to become productive members of our society.

Rehabilitation professionals require a multitude of skills and knowledge to facilitate persons with disabilities to seek and identify employers and bridge social barriers. As stated by Szymanski (1993) and restated by Mullins, Roessler and Bellini (1997), the need for the rehabilitation worker to develop a vision is clear. They are required to help people with disabilities create their own vision of themselves when they are "often unable to imagine themselves two years down the road" (p. 10). The rehabilitation professional creates opportunities for persons with disabilities by educating employers, defining and reducing barriers, and applying legislative redress in a society that has difficulty overcoming its social barriers.

\section{Rehabilitation and the Workplace}

Clark, Xie, Becker, and Drake (1998) indicated that a publicly financed rehabilitation program is viewed from three perspectives: "The individuals who participate in the program; taxpayers who pay for the services; and society, which ultimately benefits from enhanced productivity of its citizens" (p. 24). The actual pecuniary advantages of rehabilitating persons with disabilities cannot be calculated. One simple reason according the authors is the "uneasiness about translating clinical and 
functional outcome into monetary units" (p. 23). However, important variables in the social calculus include wages earned or lost, dollars expended by the society to provide training to rehabilitation workers and clients, the cost of publicly financed rehabilitation programs and tax incentives, and related governmental expenditures.

Human capital theory suggests that education can enhance a person's skills and marketability, and that achievements derived from both influence competitive wages. Gullason (1998) stated, “schooling directly enhances one's skills, and positively affects one's job-related productivity, which in turn enhances earnings"' (p. 13). However, the cost of rehabilitation is not easily quantified in terms of productivity and financial investment. Gullason's study suggests that the benefit of employment is not exclusively wages and productivity but human factors must be considered as part of the equation. These considerations include the effects of unemployment on the human psyche. The economic standpoint is just one perspective; the value of human dignity is another (Charlton, 1998).

Hartenstein and Waugh (1994) offered an interesting perspective on human dignity. They stated, "unemployment too often exacts a terrible toll on human beings. Further, a valuable and perishable resource is wasted...[unemployment] logically describes a state of idleness" (p. 36). Considering that most disabled individuals are chronically unemployed and these same persons are not included in the unemployment statistics in the United States, this human resource appears to be overlooked (Charlton, 1998). The recent survey conducted by Louis Harris and Associates (1998) reported: 
1. 29 percent of disabled persons of working age (18-64) work full or part-time verses 79 percent of the non-disabled population and most of the disabled of that age group (18-64) state they would prefer to work.

2. 34 percent of the disabled adults live in households with $\$ 15,000$ or less in total annual income verses 12 percent of non-disabled adults.

3. 20 percent of disabled adults have not completed high school versus 9 percent of non-disabled adults.

4. 69 percent of disabled adults socialize with close friends, neighbors or relatives at least once a week versus 84 percent of the non-disabled.

These statistics confirm that, "America's disabled [persons] are far less likely to be working and more likely to live in poverty and isolation than non-disabled workers" (Harris \& Associates, 1998, p. 8). A follow-up study conducted by the National Organization on Disability (NOD) together with Harris and Associates confirmed these results in 2000. This second report indicates that "of those aged 18-64 [the primary employment market] people with disabilities are much less likely to be employed (either full-time or part-time) than people without disabilities" (Harris \& Associates, 2000, p. 1). Specifically in 2000,81 percent of the non-disabled population was working versus 32 percent of the disabled population.

Disabled persons seeking meaningful employment encounter multifaceted problems. Persons with disabilities, with the help of their rehabilitation counselors, must identify appropriate vocational objectives, access employment opportunities, and then be capable of sustaining their position regardless of health concerns, fatigue, transportation, and circumstances relevant to their disabilities. The employers' perspectives are as 
complex, as they must identify the means to provide employment, facilitate the disabled person's individual needs (generally exceeding the non-disabled workforce), and reduce workplace bias and negative reactions from others towards that person. Employers do this while they conduct business, maintain/increase profitability, and maintain employee moral. Although achieving employment is not an impossible task, it can be frustrating and time-consuming for both employer and potential employee and requires complex rehabilitative skills and planning to overcome physical, emotional and societal obstacles. An organization that overcame these difficulties is Michigan's Macomb-Oakland Regional Center, Inc. (MORC). Partnered with Marriott Corporation, MORC began placing persons with disabilities within the organization's hotel workforce. By 1996, Marriott's work force included six percent disabled employees. Marriott reportedly instituted a "disability-neutral" policy acknowledging receptivity towards individuals with disabilities and encouraging fair hiring practices.

MORC developed an inclusion policy that incorporated three requirements for potential employers. The first requirement was that of "zero exclusion or zero reject" (Conyers, Ellwanger, Ferguson, Nemeth et al., 1999). This policy stems from the organization's position that all people, regardless of severity of disability, have the right to engage in meaningful work. The second requirement provided placement of disabled workers in socially meaningful vocational activities. The third requirement was that all available job opportunities would involve employment situations where non-disabled people worked. The overall philosophical position was that rehabilitation services provided in a socially meaningful vocational activity must foster the participant's selfesteem and enhance quality of life (Conyers et al., 1999). 
The statistics provided by MORC are impressive. "During the past ten years, the number of developmentally disabled people placed in employment by MORC increased from 120 in 1988 to 376 in 1998, a 313 percent increase" (Conyers, et al., 1999, p. 33). This success was attributed to rehabilitation professionals who had knowledge of governmental subsidies, services, tax incentives and person centered-planning, and who were able to educate employers on the benefits, both social and financial, of hiring people with disabilities. By applying person centered-planning techniques that identified and utilized the potential employees' interests and abilities in combination with workplace incentives and employer education, a better opportunity for employment was provided.

MORC's experience represents the positive effect of a delivery system by qualified community-based organization employees. Yet the work performed by the rehabilitation professionals is questioned when the economic perspective is considered. Questions regarding the best method to provide rehabilitation services relative to cost efficiency remain a source of societal dialogue. The stakeholders include persons with disabilities, taxpayers, employers, educators and society. Theoretically, the entire nation and individual communities benefit from the enhanced productivity of its citizens. Seemingly, then the transition of persons with disabilities from the roles of being chronically unemployed to being employed seemingly would be readily embraced by society. However, given social, economic and physical barriers, legislation continues to be enacted to allay pecuniary damages on employers who do not hire people with disabilities as a means to curtail discrimination in the workplace.

Despite the codification of United States legislation to protect the rights of the disabled, these citizens remain either unemployed or underemployed. The most recent 
legislation that directly speaks to the issue of workplace discrimination is the Americans with Disabilities Act (ADA). This act strengthened the Rehabilitation Act of 1964 and 1973 that attempted to overcome workplace discrimination. The ADA is the legislative response to an overwhelming and persistent problem for persons with disabilities in their attempt to secure employment. This legislation mandated fair treatment and accessibility to the work environment. In effect, it continued the efforts to combat workplace discrimination by applying substantial monetary penalties for persons convicted of workplace discrimination, a step that was not taken until the ADA was adopted in 1990.

Gopal and Bailey (1995) noted key relationship difficulties regarding the attitudes that create barriers between the disabled workforce and workplace stating that the problem resides within organizational Human Resource (HR) departments. They note that the personnel within HR (an inter-organizational department) have very little information regarding employing people with disabilities. Gopal and Bailey use an illustrative example that indicated that persons with disabilities view work quality, customer satisfaction, on-time delivery, and competitive prices similarly to those who are not disabled. "In general [people with disabilities] have been shown to have a stronger work ethic, a higher motivation to work, greater dependability, better work performance, and a higher regard for quality of work" (p. 54). This is a predominate theme in the literature in this subject area (Caldwell \& Fishbien, 1994: Charlton, 1998; Clark, Haiya, Becker, \& Drake, 1998). A few examples of organizations that have successfully developed inclusion projects for person with disabilities are the previously mentioned Marriott, and others to include Japan Sun Industries, Center Industries, Omoron, Sony, Pizza Hut, and Honda. The overall perception within these organizations is that persons 
with disabilities are excellent long-term employees and mirror other long-term nondisabled employees in their longevity and commitment.

\section{Rehabilitation Services Delivery}

The need for effective outcomes and qualified rehabilitation service providers is a significant research topic in both the rehabilitation and public policy forum. The National Institute on Disability and Rehabilitation Research (NIDRR) funds the majority of research conducted in this area (Daneck, Parker, \& Szymanski, 1991). NIDRR's focus is on client-centered services measured by successful outcome or vocational placements. A contrasting point, illustrated by Daneck, Parker, and Szymanski (1991) was that a dominant legislative focus is the "flavor of the month" method for funding. The authors use this term to refer to a specific disability or illness that receives legislative attention or priority based on what appears to be the "fashionable" disability at that time. Daneck et al. (1991) explained that special interest groups sway government focus and resources toward a particular area of disability, depending on the groups' affiliations and sponsors.

Every research dollar is precious...the era of abundant resources and of lavishing dollars on every problem is over. The question now is:

How do we maximize our rehabilitation and disability-related research dollars so that policy makers are better informed by research and that research allocations are made through rational policy decisions? (p. 7)

University students and faculty, along with practitioners from public, private, state and federal rehabilitation who work in mandated and compulsory rehabilitation programs conduct research in an exhaustive effort to promote effective rehabilitation services and delivery strategies. The impetus should be on determining if the services provided by the rehabilitation community are effective. Szymanski's (1991) research indicates that education in rehabilitation practices accounts for better client outcome than 
services provided by individuals without specific rehabilitation training. She emphasized her previous research regarding rehabilitation counselors who completed a Masters Degrees demonstrate better overall employment outcomes when working with people who have significant disabilities. The statistical model employed was an aptitude treatment interaction (ATI) that determined the relationship between variables that acted as traits. In this study, the academic degree possessed by the subjects was the trait (independent variable), which was then compared to the service outcomes (dependent variable). Master level rehabilitation counselors had higher successful case closure rates where successful employment was obtained for people with severe disabilities than their colleagues with Bachelors or unrelated Masters Degrees (Szymanski, 1991). This study clearly demonstrated the importance of training for practitioners in the rehabilitation field when employment is the desired outcome. Cook and Bolton (1992) derived the same conclusion as Szymanski noting that "better educated and more experienced counselors will perform at higher levels and will generate better client outcomes than a less. educated counselor with less experience" (p. 42).

Szymanski's research regarding the need for highly educated rehabilitation practitioners resulted in raising the required educational level for rehabilitation counselors funded through Federal programs. Reliance on Szymanski's work was clearly demonstrated by the Institute on Rehabilitation Issues (1999) publication, in which the Comprehensive System of Personnel Development (CSPD) was published. The CSPD raised the educational requirements for persons working as rehabilitation counselors in federally funded rehabilitation programs to a Master's degree in Rehabilitation Counseling. Those persons already employed by state or federal programs who do not 
meet this requirement must be actively seeking a master's degree. This clear statement made by CSPD created an agenda by RSA to develop academic programs focused on increasing the educational standards for rehabilitation professionals to the Master's Degree level (e.g., Cook \& Bolton, 1992; Mullins, Roessler, \& Bellini, 1997; Szymanski, 1991; Szymanski, Leahy, \& Linkowski, 1993a, 1993b). Discretion in imposing this requirement was prudent given the needs of the estimated 54 million people in the United States who have disabilities. Comparatively speaking, the number of persons requiring direct hands-on services and assistance of the rehabilitation service provider is considerably higher than the number of persons who presently have Master's Degrees in Rehabilitation Counseling. Many graduates of Rehabilitation Counseling programs find employment in community rehabilitation; however, the requirement for a Masters degree has not been applied to CRPs. In fact, most CRPs do not have the financial resources to pay competitive wages for those who have attained this rigorous educational requirement. Thus, a need was created for educational and workplace skill development and training programs that enhance the skills of CRP employees to insure the delivery of quality services. If Rehabilitation Counselors generate better outcomes when they have more education, it follows that other rehabilitation professionals, including those employed in community rehabilitation would also benefit from education and training in order to produce similar outcomes. From the employment perspective, education should focus on developing workplace social supports and establishing realistic employment goals (Story \& Certo, 1996).

Rehabilitation education, in step with the employers' needs, focuses on developing skills in terms of social integration and personal empowerment or person- 
centered service planning. However, the person-centered educational perspective was not always the normative education policy or employer perspective, as the focus of services was not always facilitating the employment needs of persons with disabilities. From the historical perspective, Wehmeyer (2000) suggested that there have been three "waves" in rehabilitation. These have spurred the issues of self-reliance and self-advocacy that led to the issue of person-centered planning. The "waves" have increasingly focused on providing individuals the opportunity to establish their own needs and less on overcoming manufactured constraints imposed by others. Wehmeyer noted that the first wave was the rehabilitation professional establishing and defining the required services of the disabled person. The second wave was establishment of the "parental movement." This wave consisted of parents advocating for what they perceived were their children's needs. The most current, or third wave, is the recognition of the disabled person's need to determine the services required. Simply stated, rather than a system or "professional" making decisions, the person-centered approach empowers the individual to advocate for their own needs, known as self-determination.

The curriculum developed by Interwork for sponsored programs follows the third wave and provides instruction in the areas of self-advocacy, self-determination, social integration and social equality within the workplace. Quality indicators for personcentered planning and integration are described by the Association of Persons in Supported Employment (APSE, 2000). The following examples are consistent with Interwork's approach: 
1. Individuals explore career opportunities based on their interests, abilities, and needs via such experiences as vocational education classes, job shadowing, job tryouts, and actual employment.

2. Individuals direct their transition plan to include employment, education from school to adult life to the maximum extent possible, with support as needed.

3. Individuals are assisted as needed to secure employment according to individual desires, including the type of work environments, activities, hours, pay, natural supports, etc.

4. Individuals have necessary and appropriate accommodations, assistive technology and individualized supports within and outside of their jobs.

5. Individuals develop satisfying relationships within and outside of their jobs.

\section{Rehabilitation Continuing Education}

Interwork provides continuing education training for individuals serving the disabled population at any educational level that the person chooses. Using a concept of a career ramp verses a career ladder (Sax, 1999), this effort is viewed as one of accessibility and inclusion. The ramp concept is a more accessible rendition of progressive educational steps that allows both students and practitioners to ascend from certificate to the degree programs of their choosing. Any individual, irrespective of his/her present educational level or academic need, is able to access their chosen educational program so that they can build workplace skills or complete an educational degree in the manner of their choosing.

The idea of developing accessible educational steps toward the development of skills in a specialty area is not a new concept. Academic institutions have used this theory over the years to develop programs that envision logical steps towards academic 
achievement leading to skill mastery. The academic ladder is a "unified educational system designed to facilitate upward mobility for students to progress from an Associates degree to a Baccalaureate degree and on to graduate level" (Caldwell \& Fishbien, 1994, p. 56). Caldwell and Fishbien describe this methodology as applied to the human services as a logical and methodological approach to developing professionals in the human service sector who promote a caring, professional work force focused on the needs of the population they serve.

A unique aspect of human services, including the rehabilitation sector, is that the service providers require continuing education. Serving persons with disabilities requires continued support, education and professional development. Academic institutions continue to develop and update curriculum and educational strategies to meet the changing needs of human service providers. The ability to balance the needs of persons with disabilities with the emotional and educational needs of the service provider is an ongoing challenge. The pursuit of skill advancement, continuing education, and personal and professional growth provides the direction for person-centered interventions in the human services professions (Lewis \& Patterson, 1998).

The US Department of Education, Rehabilitation Services Administration (RSA) acknowledged a need to train community-based program personnel to support the needs of persons with disabilities. The RSA instituted the Regional Rehabilitation Continuing Education Program for community rehabilitation personnel (CRP-RCEP) to "provide a broad integrated sequence of training activities that focus on the need of employed rehabilitation personnel" (2001 RRCEP grant application kit). Interwork, the recipients of the Region IX RRCEP grant, and their cohort of CRPs developed a continuing education 
program to serve community-based program personnel. The educational programs comply with the Rehabilitation Act and the overall need for qualified personnel to provide rehabilitative services. Interwork houses San Diego State Universities' Rehabilitation Counseling program, nationally accredited by the Council of Rehabilitation Educators (CORE). CORE authorizes accreditation based on a review of faculty, qualifications, academic coursework, supervised practicum/internships, and viability of the program to recruit students (University of Arkansas Press, 1999-2000). The CRP-RCEP classroom instruction and training by instructors who are professionals in the field and provide for educational and professional development in accordance with CORE guidelines.

The collaboration between community-based rehabilitation programs and the academic sector has created a bridge for program development. This collaboration is the foundation for the development of training programs that provide upward mobility via the career ladder or "ramp" devised by the marriage between academia and service providers. One specific example is the development of certificate and degree programs with the California Community College System. Since 1996, Interwork has worked cooperatively with three Community College districts in California to develop entry-level rehabilitation classroom curricula and certificate degree programs.

Rehabilitation workers' training needs vary according to their specialty, workplace and consumers they serve. These may include skills within the community rehabilitation sector that focus on: (a) job and interview skill development, (b) independent living skills, (c) transportation, and (d) adaptive or assistive technologies. The range of disabilities with which rehabilitation professionals work includes 
developmental and cognitive disabilities, degenerative diseases, blindness/low vision, brain injured and deafness/hard of hearing; or those derived from work including back injuries, carpal tunnel syndrome and related musculoskeletal disorders that result in disabling conditions. There is no clear training regime that works for all persons within this broad service sector (Billett, 1998).

The lists of procedures and methods regarding educational practices derived from scholarly literature and study are endless. Godlad, as described by Shen (1997), denotes four educational goals for individuals working with people with disabilities:

1. Academic Goals: including mastery of basic skills and intellectual development.

2. Vocational Goals: including career education.

3. Social Civic and Cultural goals: including moral and ethical character.

4. Personal Goals: including emotional, physical, creative, aesthetic, and selfrealization.

Interwork focuses on the adult learning model in the delivery of their educational programs that expands the essence of Godlad's typologies. Inherent in this model is the premise that adult learners are mature, task-oriented, self-supporting, pragmatic, lead independent lives, and are generally family-oriented (MacKinnon-Slaney, 1994). Adult educators must respect the independence and foster trust and equal relationships with the active or adult learner. Just as important is the development of psychological safety to insure that the adult learner can experiment with new ideas and thoughts within the educational environment (Britton, 1996). In a psychologically safe environment, adults trust the instructor to maintain each individual's personal identity and self-respect and 
facilitate self-directed motivation to learn (Lee, 1998; MacKinnon, 1993; More, 1997;

Nilson, 1997, 1998, 1999; Ryckman, 1985; Schraw, 1998 ).

\section{Human Resources Development}

Both continuing education and training have permeated the human service professions since Carl Rogers first audio taped his counseling sessions in 1954. These tapes were used to train aspiring counselors on the "effective ingredients in the therapist's attitude and behavior" or "facilitative conditions" (Baker \& Daniels, 1990, p. 357). These sessions inspired the Human Resource Training (HRT) model, originally described as the Integrated Didactic-Experiential Training, which has been re-packaged as Human Resource Development (HRD). HRD is a method of managing a work environment that respects the human desire to better oneself and one's abilities in the workplace. The HRD model has been determined to be of long-term benefit when applied in an educational process (Baker \& Daniels, 1990; Caldwell \& Fishbien, 1994; Gill, 1995). The HRD perspective has been demonstratively effective in changing the behaviors of graduate students receiving systematic counselor training (Baker \& Daniels, 1990). However, Cormier (1990), in response to Baker and Daniels, indicates that the need for systemic training carries over to all persons and not strictly to graduate students.

McGregor's theory, as described by Bowman and Deal (1997) in Reframing Organizations, places emphasis on respecting the human compulsion to grow and be treated with dignity and respect. According to McGregor, skills and abilities, including development of personal growth and independence, require cultivation and respect. The idea that a person is a resource bringing to the work environment their need to be perceived in a positive and growth-enhancing manner recognizes the inter-organizational value and a person's potential and desire to grow. The HRD thought process includes the 
utilization of training and/or learning across the lifetime as a method of investing and recognizing human resources. Therefore, the HRD model is viewed as a systemic interorganizational philosophy that contributes to a cohesive fit between an organizational mission and human potential. The HRD model suggests that the work environment operationalizes training as a tool to develop and expand the human potential with the organization. This humanistic business practice promotes life-long learning as an organizational philosophical construct and enjoins educational pursuits and individual growth with human development.

Interwork implements a Human Resource Development (HRD) paradigm during program development with three goals. The first goal is to increase knowledge of the issues permeating the field of rehabilitation and affect the daily lives of persons with disabilities. The second goal is to provide meaningful services that improve the community-based organizations providing rehabilitation service. The third goal is to expand and enhance the services provided to persons with disabilities (Sax, 1999). The human resource model operationalized combines the three goals with the educational processes, completing the HRD model. These three ideas - a rehabilitation worker's need for lifelong learning, learner-centered education, and experiential learning - combined with workplace skill building enables rehabilitation workers to experience better outcomes driven by increased skills, aptitudes and attitudes.

Training to meet the needs of the workforce is a changing paradigm based on the constant change in our society. Traditionally, training or education was considered to have a beginning and an ending. Gill (1995) addresses concerns that this method failed to account for the continued need for humans to self-actualize. The changing view asserts 
that humans have the need to continue to learn and develop new skills that enhance workplace behaviors providing personal and educational fulfillment. Gill further noted that continued education creates workplace diversity and autonomy leading to enhanced productivity, performance and positive organizational outcomes. The HRD perspective used by Interwork contrives the idea of continued education with the diverse needs of the rehabilitation service providers into multiple programs for the unique needs of each individual served.

\section{Community Rehabilitation Programs and Evaluation}

Community Rehabilitation Programs (CRP) directly or indirectly provide rehabilitation services to individuals with disabilities. Their focus is to maximize an individual's ability and access meaningful employment opportunities that will lead to self-support. This includes opportunities that allow for career advancement that lead to self-sufficiency.

The Rehabilitation Act Amendment of 1998 (SEC. 7(5)(A-Q)) mandates that CRPs provide medical, psychiatric, sociological, social and vocational services with their affiliates in centrally located areas within the communities they serve. Services include, but are not limited to, vocational, aptitude, and interest testing; fitting or training in the use of prosthetic and orthotic devices; recreational, physical and occupational therapy; speech, language and hearing therapy; psychiatric, psychological and social services; and behavior management. Other services include: assessment for determining eligibility, vocational rehabilitation needs, and technology; job development, placement and retention services; orientation strategies and training for persons who are blind; extended employment; psycho-social rehabilitation services; supported employment services; and services to family members when necessary. 
The Rehabilitation Services Administration (RSA) conducted a longitudinal study regarding the perception of consumers (i.e., individuals with disabilities) receiving services from CRPs (Shaw, 1998). The 1998 interim report indicated that persons with disabilities who had received services from a CRP generally believed that they were receiving the services that they needed. The following statistics were provided in this report:

1. 69 percent indicate that they were a part of the decision-making process for services.

2. 76 percent indicated they thought that the counselors provided information to make appropriate choices.

3. 54 percent were very satisfied with available choice of providers; an additional 26 percent were somewhat satisfied.

4. 5 percent reported being dissatisfied with the available choices.

The RSA training budget that funds each of the CRP-RCEPs across the nation has remained level for over 12 years. Over the same time period, the training needs of the CRPs have continued to increase. As competition for grant funds grows more intense, the need for effective evaluation becomes even more critical. For example, Osborn and House (1995) report that academic program evaluations are becoming more prevalent, given funding cutbacks and reductions. The authors note that program evaluations are needed to demonstrate institutional responsiveness to the needs of their constituents. Further, they suggest that evaluation criteria include the perspectives of the students, employers, and the public when assessing educational program results and efficacy, similar to the model used by the Council for Accrediting Counseling and Related 
Programs (CACREP). The CACREP evaluation process includes faculty evaluations, peer review of instruments and findings, and program graduate evaluation.

CACREP, as an organization, was developed in response to a need to strengthen the counseling profession and is recognized by the American Counseling Association (ACA). Presently, CACREP is the preeminent accrediting organization for counseling or human service programs in the United States. Although CACREP does not accredit specialized programs such as rehabilitation counselor training, (i.e., rehabilitation counseling programs are accredited by the Commission on Rehabilitation Education (CORE)), the organization has developed specific evaluation protocols for its members. CACREP's evaluation process and recommendation are employed in this study to formulate a reasonably close approximation of the empowerment strategies as described by Guba and Lincoln (1989). CACREP's program evaluations include:

1. Review by faculty of programs and specialization;

2. Studies of program graduates to assess their perceptions of major aspects of a programs;

3. Assessment of the perceptions of the employers of program graduates.

The remaining sections of CACREP's evaluation descriptors include the availability of the results of studies for review by the student and faculty participants. CACREP also recognizes the importance of disseminating the results of the evaluations and materials for public knowledge (CACREP Standards, 1994). However, CACREP does not provide a recommended model or evaluative format and relies on the knowledge of the accredited organization to provide evaluation models. 
Student and supervisor feedback is important to Interwork's evaluation process. Thus, using an evaluation process that would compliment the HRD model was a priority. Guba and Lincoln (1989) included empowerment strategies that required naturalistic observations (physically watching and assessing the behaviors of others). They encouraged the use of a sociopolitical and collaborative process encompassing empowerment and moving away from the traditional paper and pencil assessment. Using this model can become problematic when evaluating an extended sample population. Fetterman, Kaftarian and Wandersman (1996) note the importance of a process that “fosters improvement and self-determinism" (p.4), offering another sociopolitical process of collaboration and self-analysis. CACREP's evaluation recommendations provide a strategy for integrating the empowerment evaluation strategies and developing instrumentation that captures the essence of meaningful inter-group dialogue.

Ewell (as cited by Osborne \& House, 1995) suggested that self-report questionnaires are an effective method to "gather data about student knowledge, skill development, and job performance" (p. 255). He suggests the following reasons for using survey instruments:

1. They are relatively inexpensive to develop.

2. They are flexible and can be used to gather more than one kind of data.

3. They are one of the few available methods of obtaining information from graduates.

4. The information gathered by survey questionnaires has external face validity. Using surveys in the classroom pose their own unique set of problems. Baldwin and Blattner (2003) note these problems, or factors that influence student perception, to 
include student grade point average, time of day, and student interest. However, in an effort to minimize these issues, evaluative efforts in this study, that included survey development, were redirected to the workplace (Fink, \& Kosecoff, 1995; Holcomb, 1997; Rea, \& Parker, 1997). These efforts were made in an attempt to elicit responses that were free from the "classic" educational evaluation biases and directed towards the recognized abilities of students having completed courses of study.

\section{Conclusion}

The opportunities available for creating an evaluation model to assess the curriculum, instruction and program delivery are boundless. However, certain principles require careful consideration. The Human Resource Development (HRD) model used by Interwork begs for an empowerment strategy. The empowerment methodology suggested by Guba and Lincoln $(1989)$, Fettereman et al. $(1989,1996)$ and practitioners that inspire reflective practices and self-actualization merit consideration. In addition, a need exists to develop user-friendly methodological structures that are efficient and provide measurements that are both quantitative, to ensure a robust study, and also qualitative, to enjoin the human voice within the evaluation strategy.

Interwork's philosophical premise stems from HRD and adult learning models focusing on person-centered training modalities in classroom instruction. The evaluation process must embrace these concepts and combine a mode of inquiry that compliments the organization's philosophical doctrine. Conceptualizing evaluation criteria that would meet Interwork's philosophy employing a quantitative and qualitative component was difficult. However, as Interwork operates in a heavily regulated environment relying on governmental resources and grant funding cycles, the evaluation criteria included quantitative measures augmented with qualitative data through the use a survey. The 
evaluation survey also provides a method to evaluate large groups and compare inter and intra agency findings with limited public resources. This methodological choice was based not only on the need to develop substantive and generalizable data, but that provided information that was easily disbursed to government entities and did not deviate from Interwork's philosophical doctrine.

As CACREP has become a leading accrediting body within the human services training, this organization's recommendations were used to facilitate this study and were the basis for developing the second employer survey. As the organization does not provide a methodology, but rather a rationale for self-study, the convertible characteristics to include a comparative model were employed and survey instruments were developed to obtain the perspectives of the student employee who participate in training and those of their supervisors.

1. The study focuses on three distinct research questions to examine the effectiveness of the training provided by Interwork. The research questions are as follows:

2. What are the perceptions of the participants and their workplace supervisors of the training provided by the Interwork Institute?

3. How, if at all, do the perceptions differ between students and their workplace supervisors?

4. To what extent, if any, are the perceptions related to demographics, including age, gender, ethnicity and education?

CRPs emphasize employment training/facilitation and independent living skills development that focus on positive outcomes for individuals with disabilities. The 
educational programs provided by Region IX's CRP-RCEP must incorporate an evaluation mechanism that measures effectiveness of the collaborative curriculum and instruction developed by Interwork. Consequently, Interwork's ability to develop, implement, and evaluate meaningful educational programs is the focus of this study. 


\section{CHAPTER III}

\section{RESEARCH DESIGN AND METHODOLOGY}

\section{Introduction}

The purpose of the study was to determine if classroom instruction contributed to the workplace skills of students completing coursework. Based on the suggestions of Osborn and House (1995), comparative survey instruments were created to measure respondent perceptions of their workplace skills following classroom instruction. These results were then compared to Community Rehabilitation Program (CRP) supervisors who were surveyed using a similar instrument. This model used the comparative format as recommended by CACREP. However, given the low number of supervisor responses, the study focused primarily on student perceptions, and secondarily on the comparison model.

Three types of statistical techniques were used to analyze the data collected from the surveys. However, in order to determine if the survey questions actually measured the intended constructs, a factor analysis was used with a sample group of 104 students from classes at Grossmont College in Southern California. Based on the results of this analysis, several redundant questions were dropped from the original survey instrument, and then the finalized survey was distributed to students and supervisors. The first statistical techniques used aggregated the scores from the survey across subcategories and the 
demographics of the sample populations were compiled. Next, the mean scores by question and category for both students and supervisors were compiled and compared. Finally, a regression analysis was used to estimate the extent to which variation in student responses could be explained by select demographic measures.

\section{Research Questions}

The following research questions guided the study:

1. What are the perceptions of the students and their workplace supervisors of the training provided by the Interwork Institute?

2. How, if at all, do the perceptions differ between students and their workplace supervisors?

3. To what extent, if any, are student perceptions related to demographics, including age, gender, ethnicity and education?

\section{Survey Design}

To address the study's research questions, the two surveys created specifically for this study were separated into five distinct sections. The first three sections of the surveys were designed to measure workplace aptitudes, attitudes and organization knowledge utilizing a five-point Likert scale. This scale deviated from standard Likert scaling (Strongly Disagree to Strongly Agree) because the statements involved the value of the training provided to the students, and the worst possible outcome was that the students experienced no change in their workplace behaviors. As such the Likert scaling used for the purpose of this study was a five point scale where 5 is "Very Strongly Agree", 4 "Strongly Agree", 3 “Agree", 2 "Disagree", and 1 "No Change".

The first section was separated into 3 indices. The first index, measured job effectiveness and focused on workplace skills; the second index assessed consumer 
support and vocational/employment issues involving aptitude and attitude; the third section examined defined organizational changes and course satisfaction. The fourth section of the survey was divided into two separate parts. The first is an open-ended question format that asks students and their supervisors to provide three responses to each question, while the second part requires respondents to provide single responses to specific questions. The fifth, and final section of the survey, collects demographic information that provides a basis for the independent variables used in the regression analysis.

\section{Construct Development}

Constructs that provide meaningful insight into the development of workplace skill, aptitude and attitude of students in entry-level training programs within the rehabilitation sector, are largely unavailable. In fact, the only relevant literature in this area focuses on assessing master degree rehabilitation counselor competencies and training standards as established by the Council on Rehabilitation Counseling Education (CORE).

The constructs used in this study were designed to assess the respondents' perceptions of their workplace skills, or perceived effectiveness following training, and primarily focus on the students' ability to effectively work with consumers to meet their needs. In addition, a measure of the perceptions of organizational competencies was included to assess the respondents' overall perception of their organizations, and thus their ability to recognize workplace organizational characteristics. The three constructs developed and measured using the five-point Likert scale are:

1. Employee job effectiveness: This construct focuses on the perception of the respondents regarding specific skills and issues of communication following 
classroom instruction. This construct includes statements designed to elicit perceptions regarding the perceived worthiness of training, rehabilitation strategies, willingness to share new skills with co-workers, as well as setting realistic personal performance goals.

2. Employment issues: This construct focuses on assessing the student's ability to empower persons with disabilities to achieve their goals. These statements are directed toward issues of employment as the CRP-RCEP grant focuses on integrating persons with disabilities into the workplace.

3. Organizational changes and competencies: The third construct is the assessment of organizational characteristics. This is a knowledge-based construct that attempts to associate training with the ability of the student to recognize organizational characteristics.

The qualitative survey questions were designed to gather information from respondents in order to better understand their perceptions of classroom activities, specifically curriculum and instruction (Foddy, 1983; Fowler, 1995). This information was used to illuminate and contextualize the quantitative data generated from the study and was divided into two parts. First, respondents were asked to provide three suggestions regarding the strengths of the classes they attended and to provide suggestions for improvement of curriculum and instruction. The second part asks the respondents to provide information about employment and future educational plans (Appendix C).

\section{Survey Development}

Since the survey was developed specifically for this study, it was put through a rigorous four-part process to ensure its reliability and validity. This process involved peer 
review, pilot study, factor analysis and subsequent revisions described in detail in this section. The final survey was administered between May and November 2003.

Peer Review of Survey Instrumentation. A peer review of the original survey instrument was conducted during a meeting of the Association for Persons in Supported Employment (APSE) research conference at the University of Maryland. Assessing the face validity of the survey was at the core of this review. This group of experts made suggestions pertaining to the type and construction of the Likert scale, as well as the relevance of certain questions. Based on this group's recommendations, many questions were eliminated from the original survey based on relevance or identified redundancies. Also during this meeting, the Likert scale was modified from the standard scale to one that measured degree of change.

Factor Analysis._Following the peer review, a factor analysis was conducted based on the results of the pilot study involving 104 students in Southern California selected for convenience and expediency. This Factor Analysis used a Varimax rotation method to see what extent the original survey questions represented the constructs intended by the researcher. While the constructs developed in the survey maintained their integrity, the survey was consolidated into 20 questions through the process of eliminating questions that failed to render a correlation or comparable score to the other questions in the same section (Tabachnick \& Fidell, 1999).

\section{Survey Respondents and Methodology}

Following the peer review and the factor analysis, the final survey was distributed to primarily two groups of students. The first group of students was from Grossmont Community College in San Diego, California. These students were participating in Internet-based curriculum sponsored by the Interwork Institute. The majority of these 
students work in Community Rehabilitation Programs (CRP) throughout California. Because the Grossmont classes are considered a transferable general education course (i.e., transferable for credit to a four-year University), a small percentage of students completing the survey where not employed in a rehabilitation setting. Their completed surveys were incorporated into the aggregate of student responses and the regression analysis. However, these completed student surveys were eliminated from the comparison study between the students and the supervisors as their supervisor were not surveyed.

The second group of students were CRP staff working in Nevada who participated in a certificate program provided by the Interwork Institute. All of these students were employed as rehabilitation service providers and employees of a CRP. The Grossmont students were asked to complete the survey during the last week of instruction, and the Nevada certificate group completed the survey following 35 hours of instruction (a period of instructional time deemed comparable to the Grossmont classes).

CRP supervisors or managers were contacted by telephone calls or in-person visits. Depending on the circumstances, the surveys were either hand delivered to the organizations or mailed via US Postal Service. To increase supervisor responses at approximate one-month intervals, telephone calls were made to elicit additional responses. However, the number of supervisors surveyed was limited due to the scarcity of supervisory staff and failure of many organizations to respond. Statistical Analysis of Survey Results

The aggregate scores, means and standard deviations for all variables collected were calculated, and independent sample t-tests were used to compare the results of the student responses with those of supervisors. To answer research question three, a multiple 
regression model was used to measure the extent to which age, gender, and education explained the variation in student responses. The data from the final survey results were analyzed using SPSS software.

Demographic Data Collection. Table 3.1 represents the original demographic variables and an explanation of the how the information was coded in the actual survey.

Table 3.1

Independent Variables Description and Coding of Demographics.
Description
Coding
Explanation

1. Birth Date (age)

2. Gender

3. Ethnicity

4. Disability

5. Veteran

6. Education

7. Language

8. Years Organizational Service

9. Years working with people who have disabilities

10. Presently in a California (CA) Disability Certificate Program

\begin{tabular}{|c|c|}
\hline Numeric-Scale & Number of years \\
\hline Natural Dichotomous & 0 Female, 1 Male \\
\hline Natural Dichotomous & $\begin{array}{l}1 \text { for persons ethnicity, } \\
0 \text { all other (e.g. Caucasian, } \\
\text { African American, Asian } \\
\text { American/Pacific Islander, all } \\
\text { other) }\end{array}$ \\
\hline Natural Dichotomous & 1 for Disability, 0 for none \\
\hline Natural Dichotomous & 1 for Veteran, 0 for no \\
\hline Natural Dichotomous & $\begin{array}{l}1 \text { for person highest degree } \\
\text { attained, } 0 \text { for all other (e.g. High } \\
\text { School, Associate, Bachelors, } \\
\text { Masters, other) }\end{array}$ \\
\hline Natural Dichotomous & $\begin{array}{l}0 \text { for English as first language, } 1 \\
\text { for all other }\end{array}$ \\
\hline Numeric-Scale & Number of years \\
\hline Numeric-Scale & Number of years \\
\hline Natural Dichotomous & $\begin{array}{l}1 \text { if in a CA certificate program, } 0 \\
\text { if no }\end{array}$ \\
\hline
\end{tabular}

Numeric-Scale

Number of years

0 all other (e.g. Caucasian, African American, Asian American/Pacific Islander, all other)

1 for Disability, 0 for none

Natural Dichotomous attained, 0 for all other (e.g. High School, Associate, Bachelors, Masters, other) for all other if no 

11. Completed Nevada Certificate
Natural Dichotomous 1 if yes, 0 if no
12. Survey on Web
Natural Dichotomous 1 if yes, 0 if no

Comparative Analysis of Student and Supervisor Means

For each of these groups, means and standard deviations were derived for each of the 20 questions as respondents were asked to score each statement using a five-point Likert scale, where 1 was the lowest, or "No Change", and 5 was the highest score, "Very Strongly Agree". These scores were then aggregated to form an overall score, or index, for each of the three survey sections. The three sections were then aggregated into an overall survey score.

After the means and standard deviations were derived, independent sample t-tests were used to compare the mean responses of the students and supervisors for these 24 categories. To ensure a robust statistical inference, the null hypothesis of no differences between the groups were measured at the 90 percent level of confidence.

\section{Eliminated Survey Statements}

Survey statement 20, "I would recommend this class to others", received an incredibly positive response. In fact, it was so positive that the question was eliminated from the indices since there was essentiality no variation in the question and it added nothing in terms of explanatory power. Based on the initial findings, there is no dispute that both supervisors and students believed the classes were worthwhile. However, the question of differences in perceptions between students and supervisors remains, as well as issues pertaining to the extent that the demographics influence perception. 
Consequently, the extent of those perceptions and the between-group differences guided the study.

Student Survey Questions and Indices

The following tables are the actual survey questions separated into the specific indices. The first two sets of questions were developed to assess a specific workplace constructs to be congruent with the Comprehensive Study of Personnel Development (CSPD) that focuses on rehabilitation personnel training. Specifically, the statements in

Table 3.2 focus on skill development following classroom activities. Table 3.3 concentrates on aptitude and attitude development, while the statements in Tables 3.4 examine the importance of organizational characteristics.

Table 3.2

Student Statements for Index 1 (Skills).

1. I am more capable of completing assigned work-related tasks following educational activities.

2. I am better able to participate in discussions with coworkers about appropriate rehabilitation strategies.

3. I feel more comfortable discussing rehabilitation strategies with coworkers.

4. I discuss consumer empowerment issues with supervisors.

5. I am willing to share new skills with my coworkers.

6. I demonstrate a more thoughtful application of knowledge in the work environment.

7. Following instruction, I am better able to establish performance goals for myself. 
Table 3.3

Student Statements for Index 2 (Aptitude and Attitude).

8. I am better able to support/assist consumer goals.

9. I am better at facilitating dialogue with the consumer regarding their individual assessment.

10. I am better able to facilitate self-advocacy.

11. I am better able to facilitate the dialogue with the consumer regarding living strategies.

12. I am better able to facilitate employment outcomes.

13. I am better able to facilitate the establishment of visionary statements with the consumer.

Table 3.4

Student Statements for Index 3 (Organizational Characteristics).

14. Resource utilization (financial)

15. Respect of consumer needs

16. Employee retention

17. Accomplishment of set goals

18. Organization of workload

19. Decreased need for supervision

Supervisor Survey Questions and Indices

The tables that follow are the statements used in the supervisor survey and each question corresponds exactly to a question on the student survey. Table 3.5 and 3.6 focus on the skills, aptitudes and attitude as prescribed by the CSPD, although they are focused 
in an observational context. Table 3.7 focuses on supervisor observations on students' ability to understand each organizational characteristic.

Table 3.5

Supervisor Statements for Index 1 (Skills).

1. Employee(s) are more capable of completing assigned work-related tasks following educational activities

2. Employees appear to participate in discussions with coworkers about appropriate rehabilitation strategies.

3. Employees appear more comfortable discussing rehabilitation strategies with coworkers.

4. Employee(s) discuss consumer empowerment issues with supervisors

5. Employee(s) are willing to share new skills with my coworkers

6. Employee(s) demonstrate a more thoughtful application of knowledge in the work environment

7. Following instruction, Employee(s) are better able to establish personal performance goals.

Table 3.6

Supervisor Statements for Indices 2 (Aptitude and Attitude).

8. Employee(s) are better able to support/assist consumer goals.

9. Employee(s) appear better able to facilitate dialogue with the consumer regarding their individual assessment.

10. Employee(s) are better able to facilitate self-advocacy.

11. Employee(s) appear better able to facilitate the dialogue with the consumer regarding living strategies.

12. Employee(s) appear better able to facilitate employment outcomes.

13. Employee(s) appear better able to facilitate the establishment of visionary statements with the consumer. 
Table 3.7

Supervisor Statements for Indices 3 (Organizational Characteristics).

14. Resource utilization (financial)

15. Respect of consumer needs

16. Employee retention

17. Accomplishment of set goals

18. Organization of workload

19. Decreased need for supervision

\section{Linear Regression Analysis}

The multiple regression models were developed to estimate the effect that participants' demographics, including age, gender, and education had on their answers to the statements in the first three sections of the survey. The utilization and aggregation of the survey results was the same as the steps conducted in the independent mean testing. For each of the 23 regression models, the following evaluation criteria was used:

1. Goodness-of-fit statistics such as $\mathrm{R}^{2}$ and $\mathrm{R}^{2}$ adj. were used to investigate the overall fit of the models.

2. The relevance of each variable to the model was investigated by the significance of their t-statistic.

3. The overall significance of the models was investigated through the use of the F statistic.

Missing Data

Missing or incomplete data were handled using zero-order correction method. This method allowed for the utilization of all surveys by substituting missing data with 
the average derived from all other data. For dummy or binary variables, the mode was substituted to complete the survey (Mertens, 1998). 


\section{CHAPTER IV}

\section{RESULTS}

\section{Introduction}

As previously noted, two surveys were developed specifically for this study, one for students and one for their supervisors. These surveys were used to measure the perceptions of students and supervisors on 19 questions describing work-related behaviors, which would allow for comparison between these two groups. Multiple regression analysis was then used to observe the extent that variation in these responses might be attributed to select demographic measures.

To measure the perceptions of both students and supervisors, means and standard deviations are presented by question and then index. These means are then compared statistically to determine the extent to which supervisors' perceptions are congruent with the perceptions of students regarding the knowledge, skills and aptitudes demonstrated or observed in the workplace. Finally, an estimation of the effect of demographic measures on the dependent variables (survey questions) was completed using regressions analysis. Using these statistical measures, this study explored the perceptions of workplace performance of both students and supervisors in a comparative format to assess programmatic effectiveness of the programs developed by Interwork. 


\section{Participants and Survey Procedures}

The surveys were distributed to the students and supervisors and completed between May and November of 2003. The target population were students in Interworksponsored instructional programs that focused on developing rehabilitation workplace skills in California and Nevada. The students completed the surveys in two ways, either by paper and pencil hand or over the Internet. Instructions were provided via a cover letter for those on the Internet, while the classroom participants received the same written instructions with the caveat that the evaluator was there to respond to any directional questions. The majority of students who took the survey on the Internet were located throughout California, but all were registered at Grossmont College in San Diego. This group took the class primarily on the Internet-based or "hybrid" version of the course that included face-to-face instruction. A small percentage took the survey in a traditional classroom. The second group of students was from Nevada and participated in a certificate program. This entire group took the survey by paper and pencil. Each group completed the survey at the end of their class or certificate program.

Supervisors of Community Rehabilitation Programs (CRP) received the survey from their manager's and had only the cover letter as instructions. The evaluator was not provided the opportunity to meet with the supervisors. The limited number of supervisor surveys reflects the difficulty in obtaining responses from some of the organizations contacted.

Response Rates

Of the 243 students who were provided the survey, 188 completed the instrument, for a response rate of 77 percent. These students worked at eight organizations that could be verified and their supervisors were provided the survey and requested to assess the 
students that they supervised. From the eight organizations, four of these responded with 20 completed surveys, for an approximate 50 percent institutional response rate.

Descriptive Statistics

Descriptive statistics were obtained from the surveys in order to understand the sample population and to eventually fulfill the regression models. This section first discusses the student sample and then the supervisor sample.

Students sample population. As shown in Table 4.1, one hundred and eighty-eight $(n=188)$ students participated in the study. The respondents included 36 males (19 percent) and 152 females ( 81 percent). The average age of the respondents was 37 . The majority were Caucasian Americans (52 percent), followed by Hispanic Americans (14 percent), African American (13 percent), Asian Americans [including Pacific Islanders] ( 8 percent) and all others (13 percent), including those participants who failed to respond to this question. Of the sample population, thirty respondents (16 percent) reported having a disability and sixteen ( 9 percent) indicated veteran status.

The majority of students ( 64 percent) reported the highest completed degree or diploma was from High School, followed by Associate degrees (20 percent), Bachelors degree (12 percent) and Masters degree (4 percent). Twenty-three (12 percent) of the respondents indicated English was their second language. Seventy-nine (42 percent) were enrolled in a California disability-related certificate program and forty-seven ( 25 percent) participated in the Nevada certificate program. The remaining 62 who participated at Grossmont College either did not answer this question or were taking the class for another reason. With respect to the students taking the survey, either on the Internet or in person, seventy-five ( 40 percent) completed the survey by hand and one hundred thirteen (60 percent) completed the survey on the Internet. The average number of years working 
in their respective organization was 4.6 , and the average number of years working with people who have disabilities was 8 .

Table 4.1

Student Demographics.

\begin{tabular}{lcc} 
Demographic Variables & Number & Percentage \\
\hline Survey Respondents & 188 & 100 \\
Female & 152 & 81 \\
Male & 36 & 19 \\
Asian/Pacific Islander & 15 & 8 \\
Caucasian & 98 & 52 \\
Hispanic & 26 & 14 \\
African American, & 24 & 13 \\
Other & 25 & 13 \\
Disability & 30 & 16 \\
Veteran & 16 & 9 \\
High School, & 120 & 64 \\
Associate & 37 & 20 \\
Bachelors & 23 & 12 \\
Masters & 7 & 4 \\
English (first language) & 165 & 88 \\
Pres. in a CA certificate & 79 & 42 \\
Nevada Certificate & 47 & 25 \\
Survey on Web & 113 & 60 \\
& & \\
\hline
\end{tabular}

Supervisor sample population. As described in Table 4.2 twenty supervisors $(n=20)$ responded to the survey. The respondents included twelve females ( 60 percent) and eight males (40 percent). The supervisors' average age was 37 years old. The majority of supervisors were Caucasian ( 75 percent), followed by African Americans (15 
percent), and Hispanic Americans and Native Americans were each represented by a single respondent ( 5 percent). Of the sample population of supervisors, one reported having a disability and one reported being a veteran.

Table 4.2

Supervisor Demographics

\begin{tabular}{lcc}
\hline Demographic Variables & Number & Percentage \\
\hline Survey Respondents & 20 & 100 \\
Female & 12 & 60 \\
Male & 8 & 40 \\
Asian/Pacific Islander & 0 & 0 \\
Caucasian & 15 & 75 \\
Hispanic & 1 & 5 \\
African American, & 3 & 15 \\
Native American & 1 & 5 \\
Other & 0 & 0 \\
Disability & 1 & 5 \\
Veteran & 1 & 5 \\
High School, & 11 & 55 \\
Associate & 2 & 10 \\
Bachelors & 4 & 20 \\
Masters & 3 & 15 \\
English & 20 & 100 \\
\hline
\end{tabular}

The majority of supervisors reported that their highest completed degree was a High School diploma ( 55 percent). This was followed by Bachelors degree ( 20 percent), Masters degree (15 percent) and Associates degrees (10 percent). The supervisors reported that the average number of years working with the organization was 7.3 , with a range of 1 to 17 years, while the average years working with people with disabilities was 
14.6. The lowest number of years working with people with disabilities was 5 and the highest 27 years.

Student Survey Responses by Combined Indices

Table 4.3 provides the mean and standard deviation for all four indices constructed from the student data. There are separate indices corresponding to each of the three constructs, as well as an overall index representing all 19 questions. The overall average of the responses ranged between "Agree" and "Strongly Agree". Although the smallest standard deviation (SD) overall was in the composite Index 4, among the individual indices there was little difference with the SD ranging from a high of 1.13 in Index 3 to a low of .95 in Index 1.

The means and standard deviations suggest that on average, students reported consistent perceptions of their workplace skills following training confirmed by Index 4, the aggregate of all 19 questions. The findings in Table 4.3 also suggest more of an agreement between students in the area of increased Skills (Index 1), verses the scores for Organizational Changes (Index 3), followed by the aggregate scores in the Aptitude and Attitude (Index 3).

Table 4.3

Student Mean Scores and Standard Deviations (SD) Generated from the Survey.

Statements

Index 1-questions 1-7 (Skills Development)

Index 2-questions 8-13 (Aptitude and Attitude)

Index 3-questions 14-19 (Organizational Characteristics)

Index 4-questions 1-19 (Overall Survey Score)
Mean

3.83

3.70

3.42

3.65
SD .95

1.05

1.13

.93 
Supervisor Responses by Combined Indices

Supervisors' perceptions of the students who completed training were also favorable. As shown in Table 4.4, the scores are similar to those of the students with index averages again between "Agree" and "Strongly Agree". However, the average scores were significantly lower (ranging from .06 to .45 ) than the student scores (Table 4.5), suggesting that students perceived the value of training to be greater than the supervisors, in some cases by almost half a point.

Table 4.4

Supervisor Mean Scores and Standard Deviation Generated by from the Survey.

Statements

Index 1-questions 1-7 (Skills Development)

Index 2-questions 8-13 (Aptitude and Attitude)

Index 3-questions 14-19 (Organizational

Characteristics)

Index 4-questions 1-19

\section{Mean Standard Deviation}

$3.60 \quad .68$

$3.25 \quad .80$

$3.36 \quad .95$

3.41

\section{Table 4.5}

Student Differences in Mean Score and Standard Deviation

Generated from the Survey When Compared to the Supervisors.

Statements

Index 1-questions 1-7 (Skills Development)

Index 2-questions 8-13 (Aptitude and Attitude)

Index 3-questions 14-19 (Organizational Characteristics)

Index 4-questions 1-19

\section{Mean Standard Deviation}

$\begin{array}{ll}.23 & .27 \\ .45 & .25 \\ .06 & .18 \\ .23 & .24\end{array}$


Specifically, the supervisor means and standard deviations are approximately onequarter of a point lower than the student scores with the exception of Index 2, where the mean is .45 lower. Index 1 is again the lowest of the three indices, followed by 3 and 2 , while index 4 has the absolute lowest standard deviation.

Taken together, the students and the supervisors agreed that the educational program was beneficial to their workplace skills. However, these findings demonstrate that a difference does exist between student and supervisor perceptions. This difference in some cases is almost one-half of a point, suggesting that students perceive their skills to be better than did their supervisors following training activities. The following section provides additional insight into whether or not these findings are statistically meaningful and if inferences can be made based on these findings.

Comparison of Student and Supervisor Perception

Using Independent T-test

In this section independent sample t-tests are used to compare the perceptions of students and supervisors on a question-by-question basis. These tests were conducted at the 90 percent confidence level. Thirty-two surveys were excluded based on the respondents failure to report working in a CRP or simply failing to answer the employment related question. As shown in Table 4.6, significant differences occurred in 7 of the 19 statements; however, in all cases students felt that they benefited more from the training than did the supervisors.

Specifically, in Index 1, students benefited more in terms of sharing new skills with fellow employees and setting realistic goals (questions 5 and 7), where students scored almost one-half of a point higher than the supervisors. However, the most significant findings occurred in Index 2 (statement 8-13) where, with the exception of 
statement 8, students reported scores at least one-half a point higher then supervisors in facilitating consumer issues such as self-advocacy and visionary statements. Within this index, the biggest difference was in statement 11 where student rated themselves .83 higher than supervisors regarding their abilities to facilitate living strategies. In fact, this is the only average score outside of the "Agree" to "Strongly Agree" range for supervisors and is instead in the "Somewhat Agree" to "Agree" range. This finding suggests that the greatest disparity between supervisors and students is within the area of facilitating consumer dialogue regarding living strategies.

Table 4.6

Result of Mean Comparison using Independent T-test.

\begin{tabular}{lcrrrrr}
\hline Statement & Mean & SD & Mean & SD & Dif. of Mean & Sig.(2-tailed) \\
\cline { 1 - 5 } & \multicolumn{2}{c}{ Supervisor } & \multicolumn{2}{c}{ Student } & & \\
\cline { 2 - 5 } & & & & & & \\
Statement 5 & 3.70 & .73 & 4.19 & .94 & .49 & $.012^{* *}$ \\
Statement 7 & 3.40 & 1.05 & 3.99 & 1.05 & .59 & $.027^{* *}$ \\
Statement 9 & 3.30 & 1.03 & 3.81 & 1.03 & .51 & $.046^{* *}$ \\
Statement 10 & 3.30 & 1.22 & 3.91 & 1.07 & .61 & $.043^{* *}$ \\
Statement 11 & 2.95 & 1.10 & 3.78 & 1.15 & .83 & $.004^{* * *}$ \\
Statement 12 & 3.05 & 1.15 & 3.58 & 1.15 & .53 & $.065^{*}$ \\
Statement 13 & 3.05 & 1.10 & 3.64 & 1.16 & .59 & $.034^{* *}$ \\
& & & & & & \\
\hline$* \mathrm{P}<.10 * * \mathrm{P}<.05 * * * \mathrm{P}<.01$ & & & & &
\end{tabular}

Within the four indices, (Table 4.7) only two indices displayed statistically significant differences between students and supervisors. For these indices, measuring skills, attitudes and aptitudes, the supervisors' rating of the students was up to one-half a point lower than the students rated themselves. 
Table 4.7

Result of Mean Comparison using Independent Sample T-test.

\begin{tabular}{|c|c|c|c|c|c|c|}
\hline Statement & Mean & SD & Mean & SD & Dif. of Mean & Sig.(2-tailed) \\
\hline & \multicolumn{2}{|c|}{ Supervisor } & \multicolumn{2}{|c|}{ Student } & & \\
\hline Index 1 & 3.59 & .68 & 3.94 & .84 & .34 & $.048 * *$ \\
\hline Index 2 & 3.25 & .80 & 3.78 & .97 & .53 & $.012^{* *}$ \\
\hline Index 3 & 3.36 & .95 & 3.64 & .99 & .28 & .226 \\
\hline Index 4 & 3.41 & .68 & 3.51 & 1.08 & .009 & .577 \\
\hline
\end{tabular}

Additional evidence regarding student and supervisor perceptions comes from the qualitative sections of the survey. Overall, the statements made by the students and supervisors regarding their workplace skills following training were positive, although there were some difficulties with respect to certain classes, specifically workload and length. However, the supervisors did not have the degree of reverence for training as the students. Additionally, there was some indication from the supervisors that it was too soon to determine if the classroom instruction had a lasting effect on the students, as the survey was distributed, in some cases, right after class completion, allowing for very little time for the supervisors to make their assessments. A more detailed discussion of the qualitative findings of the study can be found at the end of this chapter.

Taken together, the qualitative and quantitative evidence suggests definitive answers to the first two research questions in this study. Specifically, both students and supervisors agreed that the students benefited from the training (research question 1), but on at least some of the measures students appeared to have benefited more than their supervisor (research question number 2) thought that they did. 
Regression Procedures

Following the assessment of differences in means, regression analyses were used to explain variation in the individual indices as well as the 19 questions used to construct the indices. After a lengthy preliminary analysis, the following four demographic variables-- age, gender, highest degree completed and veteran status--were found not to be statistically significant and were removed from the final regression models. The remaining variables are shown in Table 4.8 along with the way they were defined in this study.

Table 4.8

List of Variables and Abbreviations Used for this Study.

Variable Explanation of Abbreviation

$\begin{array}{ll}\text { Asn } & \text { Asian American } \\ \text { Cauc } & \text { Caucasian } \\ \text { Af Am } & \text { African American } \\ \text { English } & \text { English was reported to be first language } \\ \text { Yrs/dis } & \text { Years working with people who have disabilities } \\ \text { CA Cert } & \text { Persons participating in disability related California Certificate } \\ \text { Web yes } & \text { Person who took the Survey on the web } \\ \text { Disable } & \text { Persons reporting having a disability }\end{array}$

The adjusted $\mathrm{R}^{2} \mathrm{~s}$ associated with each of the final regression models are presented in Table 4.9 and Table 4.10 , and show that the amount of variance explained by the demographic variables ranges from 3 percent to 14 percent. 


\section{Table 4.9}

Adjusted $\mathrm{R}^{2}$ for the Regression Models in the 19 Statements.

1. I am more capable of completing assigned work-related tasks following $\quad .06$ ed activities

2. I am better able to participate in discussions with coworkers about rehab strategies

3. I feel more comfortable discussing rehabilitation strategies with coworkers

4. I discuss consumer empowerment issues with supervisors $\quad .10$

5. I am willing to share new skills with my coworkers .03

6. I demonstrate a more thoughtful application of knowledge in the work $\quad .06$ environment

7. Following instruction, I am better able to establish performance goals $\quad .06$ for myself

8. I am better able to support/assist consumer goals .05

9. I am better at facilitating dialogue with the consumer regarding .08 individual assessment

10. I am better able to facilitate self-advocacy .05

11. I am better able to facilitate the dialogue with the consumer regarding $\quad .07$ living strategies

12. I am better able to facilitate employment outcomes .02

13. I am better able to facilitate the establishment of visionary statements $\quad .06$ with consumer

14. Resource utilization (financial) $\quad .07$

15. Respect of consumer needs $\quad .09$

16. Employee retention $\quad .09$

17. Accomplishment of set goals $\quad .14$

18. Organization of workload $\quad .12$

19. Decreased need for supervision $\quad .14$

In particular, the statement associated with Index 3 (Table 4.10) showed the best fit (12 percent) while those used to construct Index 1 showed the worst. Taken together, 
this suggests that the demographic variables used in this study explained only a small portion of the overall variance in respondents' answers.

Table 4.10

Adjusted $\mathrm{R}^{2}$ for the Indices.

$\begin{array}{ll}\text { Index 1-Questions } 1 \text { through } 7 & .07\end{array}$

Index 2-Questions 8-13

Index 3-Questions 14-19 12

Index 4-Question 1-19 $\quad .10$

Overall Regression Models

Table 4.11 displays the estimated coefficients associated with the regression models for the four indices and the use of either one or two asterisks denoting the statistical significance associated with the independent variable. Examination of the ethnicity variables shows that in three of the four indices, African Americans were more likely to have benefited from the training than the omitted categories of Hispanic Americans and others. The magnitude of this difference ranged from slightly more than four-tenths of one percent (Index 2) to more than eight-tenths of a point (Index 3). Similarly, Asian Americans benefited three-quarters of a point more on Index 3 than Hispanic Americans and others, while Caucasians benefited between a quarter and half a point more than Hispanic Americans and others in Indices 3 and 4. Within the English category, significant differences were found only in Index 4, indicating that English speakers overall scored up to .4 lower compared to persons whose first language was not English. 
Table 4.11

Indices 1-4 Estimated Coefficients for Selected Demographics.

\begin{tabular}{lllllllll}
\hline Statement & Asn & Cauc & $\begin{array}{l}\text { Af } \\
\text { Am }\end{array}$ & English & Yrwkdis & $\begin{array}{l}\text { CA } \\
\text { Cert }\end{array}$ & Webyes & Disab \\
\hline Index 1 (q. 1-7) & .32 & .15 & .32 & -.34 & .01 & .23 & $.37^{* *}$ & $-.46^{* *}$ \\
Index 2 (q. 8-13) & -.17 & .20 & $.43^{*}$ & -.40 & .01 & $.36^{* *}$ & $.28^{* *}$ & $-.46^{* *}$ \\
Index 3 (q. 14-19) & $.75^{* *}$ & $.42^{* *}$ & $.83^{*}$ & -.34 & $.04^{*}$ & .10 & .10 & $-.49^{* *}$ \\
Index 4 (q. 1-19) & .28 & $.26^{*}$ & $.52^{* *}$ & $-.37^{*}$ & $.02^{* *}$ & $.23^{* *}$ & $.26^{* *}$ & $-.47^{* *}$ \\
\hline
\end{tabular}

$* \mathrm{P}<.10 * * \mathrm{P}<.05$

For those students who reported working with individuals who have disabilities, there was a small but significant increase in the value of the training, ranging from .02 in Index 4 to .04 in Index 3, suggesting that statistically meaningful differences were found when comparing them to persons with no experience. However, individuals with a disability who received training benefited almost half a point less in all four indices compared to non-disabled students. Interestingly, students enrolled in a California disability-related certificate program benefited more on Indices 2 and 4 than those not . enrolled in a certificate program, while those who took their classes on the Internet benefited about a third of a point more on three of the four indices when compared to persons who took the survey by hand.

Regression Results for the Statements that

Comprise Student Index 1 (Statement 1-7)

In the first index (Table 4.12), different ethnic groups appeared to respond differently to the survey statements. African American scores were statistically meaningful in questions 1,2 and 7 when compared to Hispanic and other ethnic groups. In statement 7, Asian American and Pacific Islanders rated themselves almost one-half 
point higher than Hispanic Americans and others, and as much as .67 higher than

Caucasians, and .28 higher than African Americans in their ability to establish

performance goals for themselves.

Table 4.12

Estimated Coefficients for the Statements Comprising Index 1

\begin{tabular}{lcccccccc}
\hline Statement & Asn & Cauc & Af Am & English & Yrwk dis & Disab & CA Cert & Web yes \\
\hline Statement 1 & .37 & .20 & $.37^{* *}$ & -.23 & .01 & $-.49^{* *}$ & $.30^{* *}$ & .23 \\
Statement 2 & .46 & .30 & $.45^{* *}$ & $-.61^{* *}$ & .02 & $-.40^{* *}$ & .17 & $.34^{* *}$ \\
Statement 3 & .35 & $.33^{* *}$ & .20 & $-.65^{* *}$ & .00 & -.36 & .00 & $.52^{* *}$ \\
Statement 4 & .09 & .02 & .06 & .14 & $.03^{* *}$ & $-.51^{* *}$ & $.42^{* *}$ & $.50^{* *}$ \\
Statement 5 & -.10 & .13 & .14 & -.40 & .01 & $-.52^{* *}$ & .09 & .24 \\
Statement 6 & .22 & -.06 & .15 & -.30 & .04 & $-.55^{* *}$ & $.37^{*}$ & $.35^{* *}$ \\
Statement 7 & $.83^{* *}$ & .16 & $.55^{* *}$ & -.34 & .01 & -.37 & .20 & $.39^{* *}$ \\
\hline
\end{tabular}

$* \mathrm{P}<.10 * * \mathrm{P}<.05$

Individuals who reported that English was their first language scored significantly less than those whose English was a second language in two areas, specifically in statements 2 and 3 where English speakers reported being .66 and .65 lower, respectively, in these areas than persons whose second language was English. This suggests that this group's perception of their skills following training improved less than their counterparts whose first language was not English.

In addition to the findings regarding race/ethnicity and English as their first language, those folks with experience working with individuals who have disabilities scored significantly higher in one statement, discussing empowerment issues with supervisors, when compared to those without similar experience. Examination of the questions comprising this index also revealed that persons taking the survey on the 
Internet (Webyes) scored .23 to .55 higher in all the questions when compared to those who took the survey by hand. In this category, the statistically meaningful differences were found in 5 of 7 of the statements (excluding statements 1 and 5). Of those who reported being in a California certificate (CA Cert) program, statistically significant differences were found in 3 of the 7 statements $(1,4$ and 6) suggesting that those in certificate programs gained more from the training than others.

Another interesting finding from this index is that persons reporting a disability (Disab) rated themselves almost half a point lower (bounded by -.36 and -.52 ) when compared to those who did not report a disability. In 5 of 7 statements these differences were statistically significant, suggesting that persons with disabilities perceived less overall change in their workplace skills following training than individuals who did not report a disability.

\section{Regression Results for Statements that Comprise}

Student Index 2 (Statement 8-13)

In Index 2 (Table 4.13), the only racial/ethnic difference was in statements 11 and 12 where African Americans reported benefiting by more than a half of a point higher than the omitted groups, Hispanic Americans and others. English speakers (first language) reported themselves almost one-half of a point lower in all of the statements in Index 2 (bounded by -.13 and -.56), suggesting persons who speak English as their second language received more from the training, although only in one statement regarding the ability to facilitate dialogue was the difference statistically significant.

The majority of persons in a California certificate (CA Cert) program and those who took classes on the Internet (Webyes) scored themselves higher when compared to those who did not fit one of these categories. Persons who reported being in a CA Cert 
program or completing a class on the Internet, reported statistically significant differences on several statements. In fact, with the exception of statement 12 (facilitation of dialogue), persons taking a CA Cert reported higher scores than their counterparts. Those individuals who took the class on the Internet reported benefiting more in all of the statements except 10 and 11, scoring a third of point higher when compared to those taking the survey by hand.

Table 4.13

Estimated Coefficients for the Statements Comprising Index 2

\begin{tabular}{lcccccccc}
\hline Statement & Asn & Cauc & Af Am & English & Yrwkdis & Disab & CA Cert & Webyes \\
Statement 8 & -.24 & .27 & .38 & -.50 & .01 & $-.41^{* *}$ & $.33^{* *}$ & $.36^{* *}$ \\
Statement 9 & -.35 & .21 & .31 & $-.56^{* *}$ & .01 & $-.53^{* *}$ & $.40^{* *}$ & $.35^{* *}$ \\
Statement 10 & .00 & .18 & .37 & -.26 & .01 & $-.56^{* *}$ & $.38^{* *}$ & $.33^{* *}$ \\
Statement 11 & -.28 & .10 & .40 & -.42 & .02 & $-.57^{* *}$ & $.45^{* *}$ & .15 \\
Statement 12 & .25 & .18 & $.51^{* *}$ & -.13 & $.02^{* *}$ & $-.40^{* *}$ & .21 & .12 \\
Statement 13 & -.41 & .25 & $.63^{* *}$ & -.49 & .02 & $-.27^{* *}$ & $.37^{* *}$ & $.35^{* *}$ \\
\hline
\end{tabular}

$* \mathrm{P}<.10 * * \mathrm{P}<.05$

Respondents who reported a disability scored significantly lower than those who didn't report a disability, ranging from .27 and .56 lower. This suggests that these folks perceived a smaller change in their aptitudes and attitudes following training compared to their counterparts who did not report a disability. This response also parallels the findings from Index 1 where individuals with disabilities gained less from training in terms of skills. 
Regression Results for Student Index 3 (Questions 14-19)

The largest differences by ethnicity occurred in Index 3 (Organizational Characteristics). Specifically, Asian Americans and Pacific Islanders (Asn) scores ranged from .59 to 1.06 points higher when compared to Hispanic Americans and other ethnic groups. African Americans (Af AM) ranged from .51 to .96 points higher and Caucasians (Cauc) scores were between .51 to .96 higher. These differences were statistically significant for most of the independent variables, excluding statements 14 and 15 for the Asian/Pacific Islanders, 15 for the Caucasians and 14 for the African Americans. This provides a strong indication that the ethnic groups, when compared to Hispanic Americans and others, perceived their workplace understanding of organizational characteristics to have changed the most following classroom instruction.

Table 4.14

Estimated Coefficients for the Statements

Comprising Index 3.

\begin{tabular}{lcccccccc}
\hline Statement & Asn & Cauc & Af Am & English & Yrwk dis & Disab & CA Cert & Web yes \\
Statement 14 & .59 & $.44^{* *}$ & .51 & -.17 & $.03 * *$ & $-.61^{* *}$ & -.08 & .06 \\
Statement 15 & .55 & .25 & $.71^{*}$ & $-.50^{*}$ & $.04^{*}$ & $-.43^{* *}$ & .15 & .29 \\
Statement 16 & $.69^{* *}$ & $.37^{* *}$ & $.85^{*}$ & -.46 & $.04 *$ & $-.47^{* *}$ & .17 & .10 \\
Statement 17 & $1.06^{*}$ & $.47^{* *}$ & $.87^{*}$ & -.25 & $.04^{*}$ & $-.49^{* *}$ & .17 & $.45^{* *}$ \\
Statement 18 & $1.05^{*}$ & $1.11^{*}$ & $.58^{*}$ & -.40 & $.04 *$ & -.14 & .09 & .01 \\
Statement 19 & $.95^{*}$ & $.50^{* *}$ & $.96^{*}$ & -.28 & $.04 *$ & $-.65^{* *}$ & $.35^{* *}$ & -.17 \\
\hline$* \mathrm{P}<.10^{* *} \mathrm{P}<.05$ & & & & & & & &
\end{tabular}

Similar to the other three indices; persons who spoke English as a first language scored lower on all statements when compared to their counterparts. As seen in Table 4.14 however, only in the results of statement 15 were the differences statistically 
meaningful. For those who reported being in a CA Cert program or taking the class via the Internet, significant findings were found in statements 17 and 19.

The other two most notable findings in this grouping of statements, from a statistically significant perspective, were the results of years working with people who have disabilities (Yrwkdis) and those who reported a disability (Disab). In almost every statement, statistically significant differences existed between those with disabilities and those without, as well as those who had worked with persons with disabilities and those who had not. These findings suggest that the knowledge of disability, from first hand experience, connotes a strong sentiment regarding changes in perception, and specifically from a negative perception, for individuals who have a disability as compared to persons who do not report having a disability.

Qualitative Data

Most student respondents provided answers to the qualitative section of the survey. Student answers were consistently positive as they articulated the value of training activities. Specifically, in responding to the open-ended questions shown in Table 4.15, student comments focused on an appreciation of their expanding knowledge of advocating for persons with disabilities, increased patience, people-first language, accessibility and integration.

Table 4.15

Student Qualitative Survey Questions.

21. What are three strengths that you demonstrate within your work environment that are a result of this class?

22. What three suggestions do you have to improve the curriculum and instruction of this class?

23. Other comments regarding the classroom instruction or curriculum?

24. Are you more likely to maintain your employment after completing coursework? 
25 . Following training, are you more likely to be promoted?

26. Are you offered rewards (e.g., tuition payment, promotion, etc.) for participating in coursework?

1. Are you more likely to pursue additional education following training?

Additional comments that you would like to make about the classes, instructor, instruction, curriculum or any other issue that you consider important.

Additional comments pertaining to the classes focused on communication skills and development of empathy for persons who have disabilities. One student wrote in the open ended question (number 21) that asked students to articulate 3 strengths developed in the classroom "a) Greater level of empathy and understanding of the needs and wants of pwd \{persons with disabilities\}; b) Better understanding of conditions surrounding various disabilities; c) Greater ability to discuss advocacy/rights and responsibilities with pwd". Additional comments focused on skill building and developing more positive attitudes regarding working with people who have disabilities and their efforts to lead fulfilling lives. For example, one student responded with “a) Being able to help consumers with their skills; b) I understand more about my clients and their needs; c) Change in a clients life starts with change in my way of thinking and understanding. In all, not only did the students believe the classes were beneficial, but those that answered the qualitative questions indicated that they had developed a more thoughtful perspective on key issues in the field of rehabilitation and how to work better with individuals who have disabilities.

Although there were many other noteworthy student comments, one in particular stood out that may seemed to sum up the entire experience. This particular student wrote, in response to question 21 of the survey:

a) I am much more comfortable in discussing a variety of issues concerning disability issues. I feel I have much more knowledge and knowledge is for 
sure, power; b) I also have a new sense of sensitivity towards vocational and employment issues; c) I also feel much improved in the area of directing individuals to resources and information. There is a lot of help out there when you know where to look.

The information derived from the students in the qualitative questions serve to reinforce the perspective offered by the quantitative sections of the survey. In fact, irrespective of the student's work environment, they reported a positive change in their perceptions of their skills, aptitudes and attitudes in their behavior towards persons with disabilities.

The supervisor respondents were also positive in their responses, although a few indicated that it was too soon after the students completed the class to voice an opinion. However, their overall statement to the qualitative questions in the survey were congruent with their quantitative responses. In responding to the questions, shown in Table 4.16, the statements generally focused on the classroom instruction and the learning exhibited by students. One particular supervisor responded favorably to question 21 "A) Better advocacy. B) Better communication. C) Better interaction with clients and co-workers." Table 4.16

Supervisor Qualitative Survey Questions.

21. What are the strengths demonstrated by the employee(s) that you could relate to classroom instruction?

22. What three suggestions would you recommend to improve the curriculum and instruction?

23. Other comments regarding the classroom instruction or curriculum?

24. At your agency, do employees taking the classes sponsored by the CRP-RCEP maintain their employment longer than those who do not take coursework?

25. Following training, are employees more likely to seek or gain promotions?

26. Are employees offered rewards and incentives for participating in coursework?

27. Are workers more likely to pursue degrees or certificates following their initial training?

Additional comments: that you would like to make about the classes, instructor, instruction, curriculum or any other issue that you consider important. 
Taken together, the data derived from the qualitative portion of the two surveys served to reinforce the quantitative data, in that both groups described the positive impact of instruction and the development of the their workplace skills, aptitude and attitudes. In particular, they focused on how the students had built an intrinsic and extrinsic awareness of issues that facilitate their working with individuals including persons who have disabilities as well as their coworkers, friends and family.

\section{Summary}

The qualitative and quantitative data generated and analyzed in this study provided clear answers to this study's three research questions regarding the perceived value of training by students and their supervisors. The first research question explored the perceptions of both groups regarding the value of the instruction provided by Interwork. Based on both the quantitative and qualitative findings, it was clear that both groups perceived the training to be beneficial. The second research question examined the differences between these perceptions. The result was that the students perceived themselves to have better workplace skills then their supervisors, in some cases by more than one-half of a point. The third research question considered the extent to which select demographic variables were able to explain variation in student responses. Although the regression models for the 4 indices and the 19 specific statements explained only a small portion in the student responses, some interesting findings emerged. Specifically, in Index 4, which aggregated all 19 statements, Caucasians and African Americans benefited more from the training than the omitted groups, Hispanic Americans and other ethnicities. In addition, persons speaking English as a second language received more benefit than those who spoke English as their first language, and persons who reported 
having a disability gained less from the training than those without disabilities. Students that took the Internet-based class and those enrolled in a certificate program also benefited more than their counterparts.

The largest differences occurred in the organizational section of the survey where over 50 percent of the estimated coefficients were found to be statistically significant. This suggests that the demographic measures explained more student variation regarding organizational issues than in any other section of the survey. As such, the results of the regression analysis indicate that the demographics play an important role in the perceptions of students regarding the value of the training activities sponsored by Interwork. 


\section{CHAPTER V}

\section{DISCUSSION}

\section{Introduction}

This study measured the perceptions of students and their supervisors related to the improvement of workplace skills, aptitudes and attitudes following training programs sponsored by the Interwork Institute. The research questions that guided this study involved measuring the benefits that accrued from the training, as perceived by the students and their supervisors, comparing those perceptions, and then using multiple regression analyses to examine the extent that select demographic measures helped explain variation in student responses. The subjects of this study were primarily Community Rehabilitation Programs (CRP) personnel working in either California or Nevada (Region IX).

Study Limitations and Biases

A number of limitations or potential biases may be attributed to this study. First, students may have been reluctant to provide an adverse opinion of the instruction they received, as training in this field is limited. Supervisors, in the same context, appreciated the fact that training was available for their employees at little or no cost to the organization and as a result, may have been reluctant to note negative perspectives about the training. Although careful attention was paid when developing the surveys to ensure that no questions were directed at the instructor, students might have considered the 
survey to be an assessment tool to measure instruction or the effectiveness of the instructor whom they may not want to disparage, thus overstating the positive aspects of the training. Along these same lines, supervisors may have been cautious about negatively assessing students' workplace skills in this type of format as it could have been considered a semi-formal means of evaluating their employees, thus creating personnel issues that were not a part of the study. The researcher was aware of these issues and proceeded with this knowledge, given the overarching goals of the research. Moreover, the overwhelming positive response regarding the benefits of the training suggested that the instruction was both useful and well received.

One other condition that changed during the study was the employment status of the researcher. Since the inception of the study, the researcher has become an employee of Interwork. In recognition of this fact, careful scrutiny was employed in all facets of collecting and analyzing the data. Reviews, edits, and examination by objective readers were used to minimize possible bias by the researcher. The main limitation of the study involved the size of the samples. If more observations of both students and supervisors had been made, the between-group variances might have been greater, resulting in a clearer picture of the differences between select groups. For this reason, future studies should incorporate larger samples to generate additional findings that confirm or refute the results of this study.

\section{Study Findings}

The two sample populations included 188 students and 20 supervisors. The typical student was female ( 81 percent), Caucasian (52 percent), and a high school graduate (64 percent) with an average age of 37 . She had 4.6 years of experience within her present organization and worked with persons who had disabilities for 8 years. The 
typical supervisor was also female (60 percent), Caucasian ( 75 percent), with a high school diploma (55 percent). Her average age was also 37 years and she had 7.3 years of experience working within her organization and 14.6 years working with persons who have disabilities.

Three research questions regarding the perceived value of training by students and their supervisors were addressed in this study. The first research question explored the perceptions of both groups regarding the value of the instruction provided by Interwork. Based on both the quantitative and qualitative findings, it was clear that both groups perceived the training to be beneficial. The second research question examined the differences between these perceptions. The result was that the students perceived themselves to have gained better workplace skills after the training than did their supervisors. In some cases, students perceived their skills to exceed their supervisors' scores of their skills by more than one-half of a point on a five-point scale. The third research question considered the extent to which selected demographic variables were able to explain variations in student responses. The findings that emerged required careful consideration of their relationship to the curriculum and instruction to include issues of ethnicity, language, disability, mode of instruction, and current enrollment in a specialized certificate program.

One issue that arose during the regression analysis was the differences in the benefit of training reported by various ethnic groups. Based on the results of the regression model, Caucasians and African Americans reported more benefit from some aspects of the training than did the omitted groups of Hispanic Americans and other ethnicities. This finding suggests that there is a between-group perceptual difference 
between ethnic populations. Along these same lines the regression analysis found that persons who spoke English as a second language benefited more than those who spoke English as their first language. Taken together these two issues suggest that additional attention might be required to meet the needs of the different ethnic groups within the classroom, or that the instruction may not adequately consider the needs of the many ethnic groups represented in the study.

Another issue indicated by the regression analysis was that persons who identified themselves as --having disabilities perceived less benefit from the training than did those without disabilities. This suggests that the curriculum or instruction may not fully meet the needs of the disabled students. Another consideration might be the access, or lack thereof, to accommodations necessary for successful learning. In either case, this was a provocative finding worthy of additional consideration and research.

Since the inception of this study, many researchers have explored issues regarding the effectiveness of Internet-based curriculum. This study found that students who took Internet-based classroom instruction rated the benefits more highly than persons who took the class in a traditional classroom setting. A number of issues might be considered. First, is there a difference between Internet-based education in the rehabilitation fields verses other less "hands-on" instructional areas? Second, and along these same lines, do discussion boards and the ability to interface with persons from different geographic areas within the same "classroom" provide students with a better educational experience? Finally, does the opportunity to receive instruction from many different instructors, verses the traditional one instructor per classroom, offer additional educational experiences that allow students to benefit from multiple experiential factors? This study 
only served to expose some differences between Internet-based and traditional instruction; clearly the exploration of these issues are areas for additional study.

Students enrolled in California disability-related certificate programs rated their experiences higher than persons who were not enrolled in certificate programs. This may simply be a demonstration of the students' focus, as students who were not enrolled in the certificate also reported benefiting from the educational format. Coleman (2002) reports that empathy can be a product of an educational process noting, "people find meaning in their connection and in their attunement with one another." Consequently, the similarities between what the students learn in classes regarding disabilities and subsequent rehabilitation practices may manifest in their learning more about themselves and their society.

The largest differences occurred in the organizational section of the survey where over 50 percent of the estimated coefficients were found to be significant. This suggests that the demographic measures explained more student variation regarding organizational issues than in any other section of the survey. This offers some insight into the potential needs of students to understand the organizations in which they work, including information about human resource functions, organizational hierarchy, grant funding and the mission of CRPs. This suggests that future curricular development might be warranted in the context of organization behavior, business management and related topics to provide organization competency training.

\section{Contributions to the Literature}

In reviewing the literature in rehabilitation education, a significant gap was found concerning the needs of entry-level personnel. The most prominent research in rehabilitation education was completed by Szymanski, who focused on the successes of 
Master's level rehabilitation counselors, rather than entry-level personnel, in facilitating employment for severely disabled individuals. Szymanski's work was used by the Institute on Rehabilitation Issues (1999) publication, in which the Comprehensive System of Personnel Development (CSPD) was published. The CSPD raised the educational requirements to a Master's degree in Rehabilitation Counseling for persons working as rehabilitation counselors in federally funded rehabilitation programs (e.g., Szymanski, 1991; Cook \& Bolton, 1992; Szymanski, Leahy, \& Linkowski, 1993; Mullins, Roessler, \& Bellini, 1997). The focus was the promotion of the skills, aptitudes and attitudes of individuals who provide support for persons with disabilities attempting to enter the workplace. This legislative address, however, did not include a requirement for persons in Community Rehabilitation Programs (CRP) to meet similar educational criteria.

Rehabilitation Services Administration (RSA instituted the CRP-RCEPs to "provide a broad integrated sequence of training activities that focus on the need of employed rehabilitation personnel" (2001 RRCEP grant application kit). Interwork and their cohort of CRPs developed a continuing education program to serve communitybased program personnel. The educational programs comply with the Rehabilitation Act and the overall need for qualified personnel to provide rehabilitative services.

As Interwork's instructional areas were designed in accordance with the CSPD, it was logical to explore methodologies for an entry-level training evaluation based on their programs and ideologies. Similar to the other nine regions, Interwork used a generic evaluation form and relied on its instructors and philosophical criteria to "stay the course." Interwork's educational directive stems from treating humans as resources or the Human Resources Development (HRD) model wherein the educational impetus 
focuses on the development of skills and abilities of adult learners that are respectful of their needs. The idea of adult learning first considers the human as a resource contributing to the work environment who requires consideration of their autonomy, who are task-oriented, self-supporting and pragmatic (Godlad as described by Shen, 1997). Interwork, recognizing these needs, uses the concept of a career ramp verses a career ladder to provide educational services. Within this conceptual and instituted format, individuals, depending on their needs, can access education in progressive educational steps that meet their individual needs (Sax, 1999). Simply stated, the career ramp allows the adult working student the opportunity to pursue and select multiple educational goals, including certificates, both academic and nonacademic, and degrees to include associate, bachelors, or masters; and even post-graduate units for various doctoral programs throughout the United States. The problem remained clear that Interwork had no clear direction or evaluation protocol for assessing the effectiveness of the students' training programs for entry-level educational programs without proven or tested programmatic curriculum with specific evaluative criteria.

Given the relationship between Interwork and the cohort of CRPs, the needs of both the student (adult learner) and supervisor were deemed important to Interwork's evaluation process. Thus, using an evaluation process that would compliment the HRD model was a priority. Based on the economy, validity and expediency of surveys as an effective method to "gather data about student knowledge, skill development, and job performance" (Osborn \& House, 1995 p.255) the survey method of evaluation was established. The evaluative protocols for this study were set to establish constructs that 
focused on the CSPD's criteria of the development of skills, aptitudes and attitudes within the workplace for persons who work with individuals who have disabilities.

Surveys impose a unique set of problems and factors that influence student perception (Fink, \& Kosecoff, 1995; Holcomb, 1997; Rea, \& Parker, 1997), including student grade point average, time of day, and student interest (Baldwin \& Blattner 2003). Efforts where made to minimize these issues by directing the survey toward the workplace and away from the classroom. Additional efforts were made in an attempt to elicit responses that were free from the "classic" educational evaluation biases and directed toward the workplace abilities of students who had completed training. Additional efforts were made, without success, to use methodologies from alternate fields on the effectiveness of training in a comparative format. This resulted in the utilization of CACREP's model that provided suggestions for a comparative format but offered few specific guidelines.

Taken together, the lack of information pertaining to the assessment of skills, abilities, and aptitudes for entry-level CRP personnel; the need for Interwork to stay their role as a leader in adult education; as well as the need to build an evaluative methodology that provides insight into program effectiveness and provides clear direction for future research. Areas of future research include curricular development focusing on the needs of different ethnic groups; better ways to meet the educational needs of students with disabilities, and the need for instructional focus in the context of organizational characteristics. In so doing, the development of CRP personnel that understand, recognize and participate in managerial functions as they relate to their role with their employment can become engaged members of the CRP that employs them. 


\section{Policy Recommendations}

Given the results of the two surveys, the apparent strength of the training programs was clearly demonstrated. These strengths included the students and supervisors' comments with respect to the training focus. Students reported a strong development of communication skills, person-first language, advocacy, and an understanding of the issues that permeate the field of rehabilitation. However, issues did arise that require redress based on the findings of the second and third research questions. For example, in the second research question the study found that students rated themselves up to one-half of a point higher than did their supervisors. This finding may indicate a need to discuss the expectations that supervisors hold for their employees and how to best tailor the curriculum to meet the immediate needs of the workplace while fulfilling academic goals. The third research question provided some insight into the specific between-group issues that influenced the educational process. These included the need for a careful examination of the curriculum with respect to the issues of Internetbased programs versus traditional instruction; the need to understand the learning requirements of persons with disabilities within the classroom; the realization that certain ethnic groups benefited more from the instruction than others; and the between-student differences in organizational awareness. However, given the overall positive responses, these issues do not appear to be "make or break" for any of the concerned parties. Rather they suggest the importance of revisiting the organizations served by Interwork to discuss how to better meet the unique needs of community rehabilitation personnel. Recommendations for Future Research

Many issues arose during the course of this study that present interesting topics for additional study. Although some of the issues are fast becoming "hot topics" in 
education, such as the benefits of Internet-based education verses traditional classroom instruction, the literature review did not find specific reference to the field of rehabilitation or the delivery of workplace skills as a topic for consideration. As such, the survey instrument developed in this study can be used in other studies to measure the effectiveness of training for CRP personnel in other venues and with other delivery mechanisms. In addition, the following research agenda may prove helpful in extending the results of this study:

1. Utilization of the open-ended questions from this study and answers to guide the development of a qualitative study on the best practices of workplace skills development for entry-level CRP personnel.

2. A longitudinal study that assesses students' workplace skills, aptitudes and attitudes at specific intervals $(3,6,9$, or 12 months) following training from the supervisor perspective to measure the inter-temporal changes in student performance.

3. A study that focuses on the specific program characteristics such as curricular content, instructional delivery and instructor effectiveness and what contribution these make to the overall experience of the participants.

4. A study that focuses on the ways in which the three possible delivery mechanisms for the training (Internet-based, traditional classroom instruction and a mixture of the two) influence the way in which different targeted populations benefit from training. 
5. This study could be improved simply by increasing the sample size for both groups, especially the supervisors who were underrepresented in this particular study.

Given these recommendations, the salient point is that this study was, in a sense, a wake up call in that Interwork could be doing more with respect to certain issue in the classroom. Overall, in the eyes of students and their supervisors, Interwork is doing an excellent job in providing educational programs for CRP personnel. This study demonstrated the importance that Interwork places on scrutinizing their own work for the betterment of the CRP cohort, and ultimately individuals with disabilities who receive the end benefit of the educational process undertaken by the organization.

\section{Concluding Statement}

There are many more tangential issues that should be considered in relationship to this study; after all, it is a study that pertains either directly or indirectly to the community of CRPs depending on one's perspective. First, from an organizational perspective, CRPs need to consider the importance of developing inter-organizational training programs that foster the development of humans as resources (Bowman \& Deal, 1997). Based on the disparity of student answers on the survey in this regard some work needs to be done in this area to advance the curriculum offered by Interwork in this area and within the organizations themselves. The importance of this focus within the workplace cannot be underestimated as it pertains to developing quality long-term employees.

Second, from the individual student perspective, their need for educational programs that are focused on skill building is clearly demonstrated and recognized by both groups of survey respondents. The responses to the qualitative sections of the survey 
reported the development of communication skills, the encouragement of individual autonomy and the appreciation for educational opportunities. Hence, the need for educational opportunities that provide insight, ethical and knowledgeable rehabilitation practices continues to require redress and thoughtful contemplation in order to facilitate positive educational experiences.

Third, and last, are the issues of future planning, development of additional governmental entities and social focus. Recently the Department of Labor has taken a more responsive and practical approach in the development of resources to facilitate employment for persons who have disabilities. As this focus grows, the attention by CRPs needs to become more receptive to individuals who have disabilities and are focused on work as a lifestyle choice. This will require sophisticated and educated CRP employees who are willing and able to meet the demands of the employer sector. No longer can we rationalize that the traditional social responsibilities will prevail and that employers will hire persons who have disabilities as a moral responsibility. The focus has turned toward working with the Department of Labor and other organizations that advance integrated community work, rather than sheltered workshops, congregate living or limited social opportunities that our society has grown accustomed to accepting. Studies such as this one and future studies on developing effective CRP personnel to meet the needs of the persons they serve must continue to provide for the future needs of persons with disabilities. 


\section{REFERENCES}

Association of Persons in Supported Employment (APSE). apse@apse.org. Ethical guidelines for professionals in supported employment. Supported Employment Quality Indicators. Toward Integrated Employment for all. APSE's Position on Segregated for people with disabilities.

Baker, S. B., \& Daniels, T. G. (1990). Systematic training of graduate-level counselors: Narrative and meta-analytical reviews of three major programs. Counseling Psychologist, 18, 355-423.

Baldwin, T., \& Blattner, N. (2003). Guarding Against Bias in Student Evaluations: What Every Faculty Member Needs to know. College Teaching 52, 27-32.

Billett, S. (1998). Ontogeny and participation in communities of practice: A sociocognitive view of adult development. In Studies in the Education of Adults, 30, 21-22.

Bowman, L. G., \& Deal, T. E. (1997). Reframing organizations: Artistry, choice and leadership $\left(2^{\text {nd }} \mathrm{Ed}\right)$. San Francisco: Josey-Bass.

Britton, D. (1996). The modern practice of adult education. New York: State University of New York Press.

The 1994 CACREP Standards. www.counseling.org/cacrep/cacrep_standards.

Caldwell, B., \& Fishbien, S. (1994). Development of an academic ladder program in psychiatric rehabilitation: A field initiative. Psychosocial Rehabilitation Journal, $18,55-67$.

Charlton, J. I., (1998). Nothing about us without us: Disability oppression and empowerment. Berkley: University of California Press.

Clark, R. E., Haiya, X., Becker, D. R. \& Drake, R. E. (1998). Benefits and cost of supported employment from three perspectives. The Journal of Behavioral Health Services \& Research, 25, 22-23.

Cook, D. W., \& Bolton, B. (1992). Rehabilitation counselor education and case practice: An independent replication. Rehabilitation Counseling Bulletin, 36, 37-42.

Coplin, W. D., \& O'Leary, M. K. (1998). Public Policy Skills ( $3^{\text {rd }}$ Ed.). Croton-onHudson, New York: Policy Studies Associates. 
CORE-Recognized Master's Programs in Rehabilitation Counselors Education 19992000 Academic Yearbook.

Cormier, S. (1990). Systematic training of graduate-level counselors: A reaction. Counseling Psychologist, 18, 446-445.

Danuck, M. M., Parker, R., \& Szymanski, E. M. (1991). Disability research and policy: Forging an alliance. Journal of Applied Rehabilitation Counseling, 22, 5-9.

Disability and Rehabilitation Curriculum Guidelines (1999). www.corerehab.org/guidelines 99.html

Fetterman, D. M., Kaftarian, S. J., \& Wandersman, A. (1996). Empowerment evaluation: Knowledge and tools for self-assessment \& accountability. Thousand Oaks: Sage.

Fink, A., \& Kosecoff, J. (1985). How to conduct surveys. Newbury Park, CA: Sage Publications.

Foddy, W. (1983). Constructing questions for interviews and questionnaire: Theory and practice in social research. Cambridge: Cambridge University Press.

Fowler, F. J. (1995). Improving survey questions: Design and evaluation. Thousand Oaks: Sage.

Gill, S. J. (1995). Shifting gears for high performance. Training \& Development, 49, $24-$ 32.

Gopal, G. C., \& Bailey, E. K. (1995). Empowering people with disabilities: Strategy and human resources. Organizational Dynamics, 23, 52-77.

Guba, E. G., \& Lincoln Y. S. (1989). Fourth Generation Evaluation. Newbury Park, CA: Sage Publications.

Harris and Associates survey (1988): disabled employment lags. Occupational Health \& Safety. Stevens Publishing Corporation.

Hirschorn, L. (1997). Reworking authority: Leading and following in the post-modern organization. Cambridge, Massachusetts. The MIT Press.

Holcomb, Z. H. (1997). Real data: A statistical Workbook based on empirical data. Los Angeles: Pyrczak Publishing.

Interwork Institute 1998 Annual Report. Interwork Institute: San Diego, California. 
Institute on rehabilitation issues, (1999). Achieving employment outcomes through VR counselors who meet the Comprehensive System of Personnel Development Requirements. Little Rock: University of Arkansas.

Kingbury, N. (2000). Program evaluations-studies helped agencies measure or explain program performance. Report to Congressional Committee. FDHC Government Account Reports.

Leahy, M. J., \& Szymanski, E. M. (1995). Rehabilitation counseling: Evolution and current status. Journal of Counseling and Development 74, 163-174.

Leahy, M. J., Szymanski, E. M, \& Linkowski, D. C. (1993). Knowledge importance in rehabilitation counseling. Rehabilitation Counseling Bulletin 37, 130-145.

Lee, C. (1998). The Adult Learner: Neglected no more. Training, Minneapolis; Minnesota

Lewis, S. \& Patterson, J. B. (1998). Training needs of rehabilitation counselors and rehabilitation teachers in state vocational rehabilitation agencies serving individuals with visual disabilities. Journal of Rehabilitation, 98, 46-51.

Linkowsky, C. L., \& Szymanski, E., M. (1993). Accreditation in rehabilitation counseling: Historical and current context and process. Journal of Applied Rehabilitation counseling, 24, 10-15.

MacKinnon-Slaney, F. (1994). The Adult persistence in learning model: A road map to counseling services for adult learners. Journal of Counseling \& Development, 94, 268-276.

McGuigan, F. J. (1983). Experimental psychology: Methods of research. Englewood Cliffs, NJ: Prentice Hall.

Mertens, D. M. (1998). Research methods in education and psychology. Thousand Oaks: Sage Publications.

Mullins, J., Roessler, R., \& Bellini, J. (1997). Improving employment outcomes through quality rehabilitation counseling. Journal of Rehabilitation, 63, 21-31.

National Organization on Disability (2000). www.nod.org/cont/dsp.html Employment Rates of People with Disabilities.

Oberman, C. (1967). A history of vocational rehabilitation in America. Minneapolis: T. $\mathrm{S}$. Dennison.

Osborne, J. L., \& House, R. M. (1995). Evaluation of counselor education programs: A proposed plan. Counselor Education \& Supervision, 34, 253-270. 
Parker, D.L., Shaw, S.F., \& McGuire, J. M. (2003). Program Evaluation for Postsecondary Disability Services. Journal of Developmental Education, 27, 2-4, $6,8,10$.

Rea, L. M., \& Parker, R. A. (1997). Designing and conducting survey research. San Francisco: Josey-Bass Publishers.

Rehabilitation Act Amendment of 1998, SEC. 7(5)(A-Q).

Ryckman, R., M. (1985). Theories of Personality. Brooks/Cole Publishing Company

Sax, C. (1999a). Diversity, Collaboration, Reflective Practices, and technology in professional education programs: Strategic choices for higher education.

Sax, C. (1999b). Region IX continued education program for providers of community rehabilitation.

Schon, D. A. (1983) The reflective practitioner: How professional think in action. New York: Basic Books.

Schraw, G. (1998). On the Development of Adult Cognition. Adult Learning and Development 89-106.

Shaw, K. (1998). Community Rehabilitation Organizations: Transition to what? American Rehabilitation, 24, 19-25.

Story, K. \& Certo, N., J.(1996). Natural supports for increasing integration in the workplace for people with disabilities: A review of the literature and guidelines for implementation. Rehabilitation Counseling Journal, 40, 62-67.

Szymanski, E. M. (1985). Rehabilitation counseling: A profession with a vision, an identity and a future. Rehabilitation Counseling Bulletin, 29, 2-5.

Szymanski, E. M. (1991). Relationship of the level of rehabilitation counselor education to rehabilitation outcome in the Wisconsin division of vocational rehabilitation. Rehabilitation Counseling Bulletin, 35, 23-36.

Szymanski, E. M., Leahy, M. J., \& Linkowski, D. C. (1993). Reported preparedness of certified counselors in rehabilitation counseling knowledge areas. Rehabilitation Counseling Bulletin, 37, 145-159.

Szymanski, E. M., \& Leahy, M. J. (1993). Prologue: Rehabilitation counseling credentialing: Research and practice. Journal of Applied Rehabilitation Counseling, 24, 3-4. 
Tabachnick, B. G., \& Fidell, L. S. (2001). Using Multivariate Statistics $\left(4^{\text {th }}\right.$ Ed.). Needham Heights: Allyn \& Bacon. National Clearinghouse of Rehabilitation Training Materials, Oklahoma State University (2000).

Weymeyer, M., L. (2000a). Riding the third wave. Focus on Autism \& Other Developmental Disabilities, 15, 106-117. 
Appendix A

Student Survey with Cover Letter 
Student Evaluation Explanation Form (07-29-03)

Your cooperation in completing this survey is appreciated. The survey was designed to measure your perceptions of your workplace skills following classroom activities.

Your individual answers will not be shared with others so that you can feel free to express yourself. Surveys will be destroyed when the study is completed in accordance with Interwork and San Diego State University's protocol.

The survey is divided into 5 sections. The sections are as follows:

Part 1-Questions1-7 assess perceived job effectiveness (skills)

Part 2-Questions 8-13 assess consumer support (aptitude and attitude)

Part 3-Questions 14-20 assess organizational competencies and course satisfaction Part 4-Questions 20-27 request information on your perceptions of the classroom instruction.

Part 5-Questions D1-D17 questions are the demographics

The survey should take approximately 10-15 minutes to complete.

With the exception of the comment and demographic sections of the survey a Likert scale is used. The Likert scale used in this survey is a five-point scale that ranges from "very strongly agree" to "no change" and relative points in between these two anchors. In this survey, we did not use a "not applicable" option, as only students who have participated in classroom activities are being surveyed.

Please answer every question.

If you have questions or concerns regarding this survey or would like to make comments you can contact Howard Twomey at 619-583-4561 or htwomey@interwork.sdsu.edu. You may also contact Interwork program coordinator Mari Guillermo at 619-594-4054.

Your assistance is greatly appreciated. Thank you for your help in advance. 
Part 1- Perceived job effectiveness following instruction (skills)

Check the box that represents your perception of the following statement based on your xperience in the class:

\begin{tabular}{|l|l|l|l|l|l|}
\hline Statement & $\begin{array}{l}\text { Very } \\
\text { strongly } \\
\text { Agree }\end{array}$ & $\begin{array}{l}\text { Strongly } \\
\text { Agree }\end{array}$ & Agree & $\begin{array}{l}\text { Some } \\
\text { What } \\
\text { Agree }\end{array}$ & $\begin{array}{l}\text { No } \\
\text { Change }\end{array}$ \\
\hline $\begin{array}{l}\text { I am more capable of completing assigned } \\
\text { work-related tasks following educational } \\
\text { activities. }\end{array}$ & & & & & \\
\hline $\begin{array}{l}\text { I am better able to participate in discussions } \\
\text { with coworkers about appropriate } \\
\text { rehabilitation strategies. }\end{array}$ & & & & & \\
\hline $\begin{array}{l}\text { I feel more comfortable discussing } \\
\text { rehabilitation strategies with coworkers. }\end{array}$ & & & & & \\
\hline $\begin{array}{l}\text { I discuss consumer empowerment issues } \\
\text { with supervisors. }\end{array}$ & & & & & \\
\hline $\begin{array}{l}\text { I am willing to share new skills with my } \\
\text { coworkers. }\end{array}$ & & & & & \\
\hline $\begin{array}{l}\text { I demonstrate a more thoughtful application } \\
\text { of knowledge in the work environment. }\end{array}$ & & & & & \\
\hline $\begin{array}{l}\text { Fóllowing instruction, I am better able to } \\
\text { establish performance goals for myself. }\end{array}$ & & & & & \\
\hline
\end{tabular}

Part 2- Consumer support and vocational/employment issues (aptitude and attitude) Please rate your ability to develop meaningful vocational objectives following coursework:

\begin{tabular}{|l|l|l|l|l|l|}
\hline Statement & $\begin{array}{l}\text { Very } \\
\text { Strongly } \\
\text { Agree }\end{array}$ & $\begin{array}{l}\text { Strongly } \\
\text { Agree }\end{array}$ & Agree & $\begin{array}{l}\text { Some } \\
\text { What } \\
\text { Agree }\end{array}$ & $\begin{array}{l}\text { No } \\
\text { Chang } \\
\text { e }\end{array}$ \\
\hline $\begin{array}{l}\text { I am better able to support/assist consumer } \\
\text { goals. }\end{array}$ & & & & & \\
\hline $\begin{array}{l}\text { 9. I am better at facilitating dialogue with the } \\
\text { consumer regarding their individual } \\
\text { assessment. } \quad\end{array}$ & & & & & \\
\hline I am better able to facilitate self-advocacy. & & & & & \\
\hline $\begin{array}{l}\text { 11. I am better able to facilitate the dialogue } \\
\text { with the consumer regarding living } \\
\text { strategies. }\end{array}$ & & & & & \\
\hline $\begin{array}{l}\text { 12. I am better able to facilitate employment } \\
\text { outcomes. }\end{array}$ & & & & & \\
\hline $\begin{array}{l}\text { 13. I am better able to facilitate the } \\
\text { establishment of visionary statements with the } \\
\text { consumer. }\end{array}$ & & & & & \\
\hline
\end{tabular}


Part 3- Organizational competencies and course satisfaction

Please rate your perception of your organizations ability to address each area.

\begin{tabular}{|l|l|l|l|l|l|}
\hline Organizational Characteristics & $\begin{array}{l}\text { Very } \\
\text { strongly } \\
\text { Agree }\end{array}$ & $\begin{array}{l}\text { Strongly } \\
\text { Agree }\end{array}$ & Agree & $\begin{array}{l}\text { Some } \\
\text { what } \\
\text { Agree }\end{array}$ & $\begin{array}{l}\text { No } \\
\text { Change }\end{array}$ \\
\hline 14. Resource utilization (financial) & & & & & \\
\hline 15. Respect of consumer needs & & & & & \\
\hline 16. Employee retention & & & & & \\
\hline 17. Accomplishment of set goals & & & & & \\
\hline 18. Organization of workload & & & & & \\
\hline 19. Decreased need for supervision & & & & & \\
\hline $\begin{array}{l}\text { I would recommend this class to } \\
\text { others. }\end{array}$ & & & & & \\
\hline
\end{tabular}

Part 4-Comment section

21. What are three strengths that you demonstrate within your work environment that are a result of this class?

1.

2.

3.

22. What three suggestions do you have to improve the curriculum and instruction of this class? 1.

2.

3.

23. Other comments regarding the classroom instruction or curriculum?

Please provide specific answers to the following questions.

24. Are you more likely to maintain your employment after completing coursework? (Why or why not)

25. Following training, are you more likely to be promoted? (Why or why not)

26. Are you offered rewards (e.g. tuition payment, promotion etc.) for participating in coursework? (Explain)

27. Are you more likely to pursue additional education following this class? (Why or why not)

Additional comments that you would like to make about the classes, instructor, instruction, curriculum or any other issue that you consider important. 


\section{Part 5-Demographics}

Please answer each question. The information in this context will not be shared with any person other than those that will be aggregating the responses.

D1. What is your BIRTH DATE?

D2. What is your GENDER?

_ Male_Female

D3. What is your ETHNICITY?

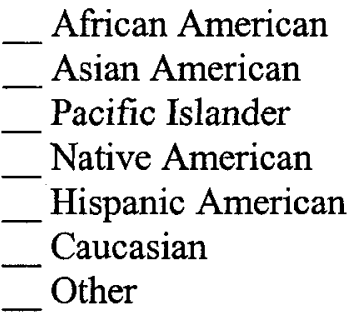

D4. Do you have a DISABILITY?

_ Yes _ No

D5. Are you a VETERAN?

_Yes_No

D6. EDUCATION: (check highest completed and specify degree) High School Diploma or GED

- AA or AS
BA or BS
- MA or MS
- Doctorate Degree
_ Other

D7. LANGUAGE: Is English your first or native language? _ Yes _ No If no, what is your first language?

D8. Who is your employer?

D9. Who is your supervisor?

D10. Present title or occupation?

D11. Starting title or occupation at your present employer?

D12. Years of service in your present organization?

D13. Years working with people who have disabilities?

D14. Number of Disability Services certificate or degree classes that you have attended?

D15. The name of the certificate program that you are in at the present time?

D16. I am in a degree program but not a certificate program. The degree program is called?

D17. I am not in either a degree or certificate program. I am taking this class to? 
Appendix B

Supervisor Survey with Cover Letter 


\author{
Howard D Twomey \\ Project Evaluator-SDSU/Interwork Institute \\ 3590 Camino del Rio North \\ San Diego, CA 92108 \\ Phone 619-583-4561
}

Dear Supervisor:

Enclosed is the survey instrument that Interwork is using to evaluate student outcomes following participation in class room instruction sponsored by the Community Rehabilitation Program-Regional Continuing Education Program (CRP-RCEP IX). Your help in collecting data on the ability of the CRP-RRCEP program to meet provide a meaningful workplace skill to the employees of your organization is appreciated.

The survey was purposely developed to be neither confidential nor anonymous. This was done so that we can develop inter-group dialogue regarding your perception of the training provided. If problems with the training program become apparent, following completion of data collection and interpretation, the staff at Interwork would like to follow-up with you and discuss your concerns.

You are in no way obliged to put your name on the document if this makes you uncomfortable. We will appreciate your input even if you decide not to make your name known.

The survey is broken into5 parts that explore your perceptions of the workplace skills and abilities of the of student(s) who have completed training activities. These areas are inclusive:

Part 1- Questions1-7 assess perceived job effectiveness (skills)

Part 2-Questions 8-13 assess consumer support (aptitude and attitude)

Part 3-Questions 14-20 assess organizational competencies and course satisfaction instruction.

Part 4-Questions 20-27 request information on your perceptions of the classroom

Part 5-Questions D1-D17 questions are the demographics

You are considered a valuable member of the evaluation process. Please complete each section of the survey and return it to my attention as quickly as possible. You can fax the completed survey to 619-583-0156.

If questions arise you may contact me directly at 619-583-4561 or e-mail at hdtassoc@cwo.com. You can also contact Mari Guillermo of Interwork at 619-594-4054

Sincerely

Howard D Twomey ABD, CRC

Program Evaluator 
Part 1- Employee job effectiveness following instruction (Skills)

Check the box below that represents your opinion of the following statement:

\begin{tabular}{|c|l|l|l|l|l|}
\hline Statement & $\begin{array}{c}\text { Ver } \\
\text { y Strongly } \\
\text { Agree }\end{array}$ & $\begin{array}{l}\text { trongly } \\
\text { Agree }\end{array}$ & gree & $\begin{array}{r}\text { S } \\
\text { ome What } \\
\text { Agree }\end{array}$ & $\begin{array}{l}\text { O } \\
\text { Change }\end{array}$ \\
\hline $\begin{array}{c}\text { Employee(s) are more capable of } \\
\text { completing assigned work-related tasks } \\
\text { following educational activities. }\end{array}$ & & & & & \\
\hline $\begin{array}{c}\text { Employee(s) appear to participate } \\
\text { in discussions with co-workers about } \\
\text { relevant rehabilitation strategies. }\end{array}$ & & & & & \\
\hline $\begin{array}{c}\text { Employee(s) appear more } \\
\text { comfortable discussing rehabilitation } \\
\text { strategies with coworkers. }\end{array}$ & & & & & \\
\hline $\begin{array}{c}\text { Employee(s) discuss } \\
\text { empowerment strategies with supervisors. }\end{array}$ & & & & & \\
\hline $\begin{array}{c}\text { Employee(s) are willing to share } \\
\text { new skills with co-workers. }\end{array}$ & & & & & \\
\hline $\begin{array}{c}\text { Employee(s) demonstrate a more } \\
\text { thoughtful application of knowledge to the } \\
\text { work environment. }\end{array}$ & & & & & \\
\hline $\begin{array}{c}\text { Following instruction, employees } \\
\text { are better able to establish realistic personal } \\
\text { performance goals. }\end{array}$ & & & & & \\
\hline
\end{tabular}

Part 2-Consumer support and employment issues (aptitude and attitude)

Please rate employee's ability to develop meaningful dialogue regarding vocational objectives

\begin{tabular}{|c|l|l|l|l|l|}
\hline Statement & $\begin{array}{c}\text { Ver } \\
\text { Agtree }\end{array}$ & $\begin{array}{l}\text { trongly } \\
\text { Agree }\end{array}$ & gree & $\begin{array}{r}\text { S } \\
\text { ome What } \\
\text { Agree }\end{array}$ & $\begin{array}{l}\text { o } \\
\text { Chang } \\
\text { e }\end{array}$ \\
\hline $\begin{array}{c}\text { 8. Employee(s) are better able to } \\
\text { support/assist consumer goals. }\end{array}$ & & & & & \\
\hline $\begin{array}{c}\text { 9. Employees appear better able } \\
\text { to facilitate dialogue with consumer } \\
\text { regarding their individual assessment. }\end{array}$ & & & & & \\
\hline $\begin{array}{c}\text { 10. Employee's are better able to } \\
\text { facilitate self-advocacy. }\end{array}$ & & & & & \\
\hline $\begin{array}{c}\text { 11. Employees appear better able } \\
\text { to facilitate the dialogue with the } \\
\text { consumer regarding living strategies. }\end{array}$ & & & & & \\
\hline $\begin{array}{c}\text { 12. Employees appear better able } \\
\text { to facilitate employment outcomes. }\end{array}$ & & & & & \\
\hline $\begin{array}{l}\text { 13. Employee's appear better } \\
\text { able to facilitate the establishment of } \\
\text { visionary statements with the consumer. }\end{array}$ & & & & & \\
\hline
\end{tabular}

Part 3- Organizational changes and competencies (organizational effect)

Please rate your perception of the student/employee's ability to understand each issue following coursework? 


\begin{tabular}{|c|l|l|l|l|l|}
\hline Organizational Characteristics & $\begin{array}{r}\text { Ver } \\
\text { y Strongly } \\
\text { Agree }\end{array}$ & $\begin{array}{r}\text { Str } \\
\text { ongly Agree }\end{array}$ & gree & $\begin{array}{r}\text { S } \\
\text { ome What } \\
\text { Agree }\end{array}$ & $\begin{array}{l}\text { o } \\
\text { Change }\end{array}$ \\
\hline $\begin{array}{c}\text { 14. Resource utilization } \\
\text { (financial) }\end{array}$ & & & & & \\
\hline 15. Respect of consumer needs & & & & & \\
\hline 16. Employee retention & & & & & \\
\hline 17. Accomplishment of set & & & & & \\
\hline goals 18. Organization of workload & & & & & \\
\hline $\begin{array}{c}\text { 19. Decreased need for } \\
\text { supervision }\end{array}$ & & & & & \\
\hline $\begin{array}{c}\text { 20. I would recommend this } \\
\text { class to others. }\end{array}$ & & & & & \\
\hline
\end{tabular}

Part 4-Supervisor Comment Section

Please provide three responses to each question. Write any additional comments on the back of the form.

21. What are the strengths demonstrated by the employee(s) that you could relate to classroom instruction?

1.

2.

3.

22. What three suggestions would you recommend to improve the curriculum and instruction?

1.

2.

3.

23. Other comments regarding the classroom instruction or curriculum?

Provide descriptive answers to the following questions. Write additional comments on back of page.

24. At your agency, do employees taking classes sponsored by the CRP-RCEP maintain their employment longer than those who do not take coursework? (Why or why not, explain)

25. Following training are employees more likely to seek or gain promotions? (Why or why not, explain)

26. Are employees offered rewards and incentives for participating in coursework? (Explain)

27. Are workers more likely to pursue degrees or certificates following their initial training? (Explain) 
Additional comments that you would like to make about the classes, instructor, instruction, curriculum or any other issue that you consider important. 
Part 5-Demographics

Please check the box(s) that apply to you:

D1. What is your Age?

D2. What is your GENDER?

_. Male _ Female

D3. What is your ETHNICITY?
African American
Asian American
Pacific Islander
Native American
_ Hispanic American
- Caucasian
Other

D4. Do you have a DISABILITY?

_ Yes_No

D5 Are you a VETERAN?

_Yes_No

D6.

_ High School Diploma or GED

- AA or AS

- BA or BS

- MA or MS

- Doctorate Degree

— Other

D7. LANGUAGE: Is English your first or native language? _ Yes _ No

If no, what is your first language?

D8. Type of EMPLOYER

_ State Vocational Rehab. Agency

- Client Assistance Program

- Other Employment Department

- Community Rehabilitation Program

Independent Living Center

Special education program

_ Protection and Advocacy Program

_- Other 
D9. Your EMPLOYMENT:

Program manager and/or fiscal and/ or personnel operations

Direct service delivery to consumers.

Both managing operations and providing direct services to consumers.

Support services to administration and/or

management and/or services delivery

personnel

Educator/staff trainer

Parent or family member

D10. OCCUPATION and number of employee(s) who have taken classes from Interwork (place a number by each job for the number of employees).

Job coach

Job developer

Support Specialist (clerical)

Classroom Support specialist

Administration Support Person

In home care provider

Rehabilitation Technologist

Rehabilitation counselor

Disability Manager

Other

11. Employer

12. (dspo) Years of service in this organization?

13. (dsysi) Years of Services working with people who have disabilities?

14. Name (optional).

15. Title

16. Starting title in this organization?

17. Present title in this organization? 


\section{Appendix C}

Student Responses to Qualitative Questions 
Survey Questions

21 . What are three strengths that you demonstrate within your work environment that are a result of this class?

22. What three suggestions do you have to improve the curriculum and instruction of this class?

23. Other comments regarding the classroom instruction or curriculum?

24. Are you more likely to maintain your employment after completing coursework? (Why or why not?)

25. Following training, are you more likely to be promoted? (Why or why not?)

26. Are you offered rewards (e.g., tuition payment, promotion, etc.) for participating in coursework? (Explain)

27. Are you more likely to pursue additional education following training? (Why or why not?) Comments: Additional comments that you would like to make about the classes, instructor, instruction, curriculum or any other issue that you consider important.

Survey Answers

Survey 1:

21. a) Confidence; b) People first language

22. None

23. None

24. The course was not a requirement for employment. However, having a better understanding will help prevent confusion and burn-out.

25. No

26. Reimbursement of tuition

27. Yes, continuing education in a changing world is a good investment to me.

Comments: None

Survey 2:

21. a) Health and well being ensuring consumer when health concerns are needed; b) Choices allowing decisions to be made and pursuing with confidence; c) Lifestyle with material on hand making readily available for consumers use and clarifying their.

22. a) Some material dealing with persons seeking to obtained consumers for the first time; $b$ ) How to start a home care giver service; c) What choices and agency you have to associate with to be a home care giver/provider.

23. Web exercise with researching was superb information and was very helpful.

24. This field will be maintained for self-employment purposes.

25. At my present location, I am not seeking promotion but knowledge and experience.

26. Certificate of completion from regional office.

27. HESC-110 for completion of required courses for regional office.

Comments: None.

Survey 3:

21. a) Ability to look at the bigger picture; b) Assessing needs and; c) Trying to allocate appropriately.

22. You will get out of it what you put in.

23. Curriculum was good, but it was, and is hard to access my grade.

24. This class did not directly affect my job, but it has helped me look at things in a different way.

25. Actually, I was.

26. Tuition reimbursement

27. Yes, I think that the class has motivated me to pursue other educational training, and not just in the Social Service field. 
Comments: The class was good, but the communication regarding grades could have been better. Still a few bugs to work out.

Survey 4:

21. a) I have learned to be more patient; b) advocated for people better, and c) I have a better understanding of people with disabilities.

22. I would not change a thing - it was great.

23. None

24. Yes, I think that if anything with this class and education, I will be able to maintain my job and even be able to be promoted.

25. I think so, because I have better skills that I have learned from this class.

26. No

27. Yes, because I want to major in disability service management/Nursing.

Comments: I found that Mari and Liz were dynamic. I learned so much from the both of you.

Thank you.

Survey 5:

20. A better understanding of how to interact with our consumers.

22. This was a good class. It was very intense though.

23. Very informative.

24. Sure

25. I don't think so.

26. Not sure

27. Yes I am

Comments: No

Survey 6:

21. a) I think that I learned many things about how to try the people with disabilities; b) How to make a better environment with more accessibility for these persons, and more important; c) What they need to have a total integration in the society and with this they will feel better.

22. I don't exactly know how to improve the curriculum of this class, because everything was ok.

23. Well, I consider it a good class. I only had some problem in the principle, because it was like my first experience in this. I never been in this kind of class and for me it was really interesting and important.

24. Yes, because I can obtain more skill and knowledge about how could integrate the people with disabilities in the world social and with a better quality of life.

25. Yes, because for me it was really nice, interesting and important, and I would like that others will learn all that I learned in this class.

26. I guess that yes, maybe with some publication in the newspaper about this interesting class and the important thing is to know about how to try the people with disabilities.

27. Of course, I would like so much to continue training me about the people with disabilities and more to eliminate all the architectural barriers that exist actually in my city, so that these people could be displaced for themselves.

Comments: I think that I said it all in the last questions. This class for me was really important and I never was any problem with the material of the class - well only except for my different language and I needed to translate everything of my homework. But it was a really nice experience for me.

Survey 7: 
21. a) Increased understanding of disabilities; b) Monitoring and Application of ADA; c) Better vocabulary and terminology of disabilities.

22. More mock scenarios and additional discussion topics.

23. --

24. Not applicable - took class to promote additional understanding.

25-Comments: No answers.

Survey 8:

21. a) I now use person first language, which shows my respect for people with disabilities; b) I feel more confident about helping others to set goals; c) I feel like I understand people with disabilities much better now.

22. a) I would liked to have learned more about how to work with people with behavioral issues which we didn't talk much about; b) I would have liked to see more discussion boards - they were beneficial to me and; c) I would have liked to learn more about how to manage a good balance with someone who is dual diagnosed with mental illness and developmental disabilities.

23. I would have liked to have the assignments graded in a more timely manner. Since this is an online course, I felt more feedback was needed in the beginning to let us know if the work we were submitting was what the instructor was looking for.

23. My employer did not know I was taking these classes. I took them to enable me to open up my own facility.

24. Yes, because I will be able to open my own facility and therefore be my own boss.

25 . No, but after completing these courses I am able to begin the process to open my own home, so that is a reward for myself.

26. Yes, I am very interested in learning more about people with disabilities.

27. I really enjoyed both the 110 class and the 150 class. Mari and Liz really understand the wants and needs of people with disabilities. Liz and Mari are very passionate about teaching others to respect the rights and feelings of people with disabilities.

Comments: None

Survey 9:

21. a) Awareness of "culture" measures within the differently abled communities; b) Stronger ability to recognize needs as well as resources (limited or otherwise) for each individual; c) A new found smile (now based on knowledge) for each client.

22. I liked the class. It seemed easy at first, however, the easiness of the class seemed to have allowed the knowledge to seep inside casually -- without effort changing how I see individuals. 23-27. No answers.

Comments: None

Survey 10:

21. I now know of more products that can be purchased for the type of students I work with.

22. I don't have any. Great class!!

23. --

24. I liked my job from the beginning. I wouldn't have changes.

25. No!

26. No. This is just for my own benefit.

27. Yes! I am going to take the next class that follows this one.

Comments: Get instructors.

Survey 11:

21. N/A 
22. I felt we covered what needed to be covered and the instruction was great. I really don't think there could be an improvement - everything was great. I learned a lot.

23. I loved the instructor, although we've never met, she answered all my questions that same day.

24. N/A

25. I am not working at the moment.

26. I am not offered any rewards.

27. Yes, I enjoyed learning about people with disabilities, and I want to help as much as I can, and the best way to do that is through training.

Comments: I learned a great deal and made a new friend with a disability thanks to this class!

Survey 12:

21. I'm not working right now.

22. I enjoyed the class a great deal.

23. --

24. Not at this time.

25. I am not working at this time.

26. No

27. I am not working at this time.

Comments: --

Survey 13:

21. a) I did not follow through and continue doing any work in this area, but I feel that the course better taught me how to speak up on behalf of myself and others with disabilities; b) I am also thankful that it gave me more knowledge of what is out there for people with disabilities (as far as resources, etc); c) I am also more aware of ways to better assist others (friends and the like) that I know with various disabilities.

22. I felt that the curriculum and instruction were fabulous. I have no suggestions for improvement.

23. None.

24. I have not followed through with the idea of working with the developmentally disabled. I have altered my career plan and now wish to teach special education at the elementary school level.

25. N/A

26. N/A

27. I will definitely try to take more courses regarding people with disabilities and how to assist them (if there are other courses offered). I am always trying to increase my knowledge of disabilities that exist.

Comments: I enjoyed the course and felt that it greatly helped to expand my knowledge of disabilities and ways in which the disabled are/have been treated by society in general.

Survey 14:

21. a) Advocacy; b) Respect; c) Leadership

22. I'm comfortable the way it is now.

23. Too many assigned tasks - not enough time.

24. Most likely, yes.

25. I'm working toward my goal to put up my Group Home.

26. Not applicable to me - I own my business.

27. In the future.

Comments: I can't think of any at the moment. 
Survey 15:

21-27. No answers.

Comments: --

Survey 16:

21. a) I can now deal with the people with disabilities without fear; b) I do now understand and feel with them; c) I have now an idea of finding how to meet their needs.

22. The need of hands on with the people with disabilities for those who have not the experience of facing them.

23. Excellent.

24. Yes, I enjoy working where I am now. I will be opening a board and care for the people with disabilities.

25. I doubt it.

26. Just the CEU, it will help to renew my LVN license.

27. I will think about it - at the present time I am busy to pursue any study.

Comments: None, everyone is great.

Survey 17:

21. a) Computer skills; b) People first reminders; c) Networking with others in the field.

22. a) I needed better computer skills to access documents; b) meet more with study groups.

23. I loved getting the feedback. This was all very new to me and I wanted to stay on track.

24. Yes, I've been doing this 21 years now.

25. No, I'm a lead Program Manager and want to continue with my hands-on caseload.

26. Tuition reimbursement.

27. Yes, finish classes for the certificate.

Comments: SLO facilitator was always ready to help and answer my numerous questions.

Survey 18:

21. a) Seeing the actions of the consumers as more logical from their point of view and not just stubborn; b) Thinking more about their rights; c) Trying different ways of communicating, breaking things down better.

22. I thought it was fine how it was. I liked the curriculum.

23. None.

24. Well, I've been there for nearly 10-years so I'm unsure if that will make a difference.

25. I'm sure it would help if I wanted to be promoted, but I like my work as job coach and have no desire to be promoted.

26. If we complete the whole series of courses our tuition will be paid for. If we have a $\mathrm{C}, \mathrm{I}$ believe.

27. I would be, except this is an exceptional trying period of my life and I have no extra energy. Theoretically I would, however, as I became aware through taking these two classes that it is an entire field of study which I had been pretty much unaware of.

Comments: I love the book "No Pity".

Survey 19:

21 - Comments: No answers.

Survey 20:

21. a) Advocacy; b) Assistive technology; c) Supported employment

22. a) More participation of instructors and facilitators at the discussion board; b) Extra reading materials/website page related to study course.

23. Well planned and easy to follow. 
24. I am not employed in the disability profession at this time.

25 . No, I am not employed in the disability profession at this time.

26. No, I am not.

27. Yes, for self-enhancement.

Comments: Thanks for all the support, guidance and time throughout the course. In my personal opinion, health science courses should be made a requirement for all vendorization purposes to achieve the best possible quality of life for people with disabilities. Secondly, some experience of working with people with disabilities should be initially considered prior to taking the health science courses for better gain of knowledge in understanding of what is being talked about.

Survey 21:

21. I am not working with disabilities yet.

22. None.

23. --

24. No, I would be more likely to go somewhere that deals with disabilities

25. If I were is a disabilities place.

26. Just a degree.

27. Yes, to get a degree.

Comments: -.-

Survey 22:

21. a) Greater level of empathy and understanding of the needs and wants of pwd; b) Better understanding of conditions surrounding various disabilities; c) Greater ability to discuss advocacy/rights and responsibilities with pwd.

22. I thoroughly enjoyed both the 110 and 150 courses. I felt I was given excellent information and plenty of time to complete my required projects!

23. -

24. No, because I have already made a commitment to my employer and the people I provide services for prior to taking the courses, and yes, because I feel more confident in my knowledge and abilities since completing the courses.

25. Yes, greater knowledge means I have more to contribute and am worth more to my employer!

26. Yes, we have an educational incentive program at work, where a pay raise is given for every

12 units of coursework completed.

27. Yes, I have continued from Grossmont's associate degree program into the BE program at SDSU, and have just finished my $2^{\text {nd }}$ year in the graduate program for Rehabilitation Counseling at SDSU.

Comments: The classes are phenomenal! The more I learn the more I need to learn more! All of my instructors were very knowledgeable and showed a genuine concern for the success of the students!

Survey 23:

21. a) Attitude; b) Responsiveness; c) Understanding and awareness.

22. Maybe a little more feed back from assignments. I really liked the course and don't see anything else I would improve.

23. Sometimes I was a little confused on assignments and was worried about doing them right.

24. Yes, I can provide better service to the people I serve.

25. I'm not sure.

26. No

27. Yes, I want to keep learning.

Comments: I liked working with Mari - she was very understanding when I was stuck or having trouble getting something to her. 
Survey 24:

21-27. No answers.

Comments: --

Survey 25:

21. Listening to people as they discuss their health issues.

22. Make the course longer, but keep the material the same. Working and family life really made it difficult at times to complete assignments on time. A week between assignments seemed too short, maybe because it's been a while since I was in a structured learning environment.

23. None.

24. Yes, I enjoy my present working environment and staff.

25. No, this is not required method for advancement.

26. No.

27. Unsure.

Comments: - -

Survey 26:

21-25. N/A

26. No

27. No

Comments: It's a lot of work

Survey 27:

21. -.

22. It has been a while since I took this class but if I remember correctly more discussion boards would have helped.

23. I got a lot out of the class. I took this class because it seemed interesting to me not for work. The book was great and I kept it (which I normally do not keep text books).

24. N/A

25. N/A

26. N/A

27. N/A

Comments: I highly recommend this class for anyone!!!

Survey 28:

21. a) I am able to have a better understanding of consumer concerns/needs; b) I recognize the importance of consumer input; c) I recognize my role as an advocate for consumers.

22. None at this time.

23. None at this time. It's been 4-years since I took the classes.

24. Yes, as I feel more comfortable with my role.

25. Yes, as my supervisors recognize the importance of training and education.

26. Yes, $2 \%$ raise upon completion. Job pays tuition.

27. Yes, I already have and it has benefited tremendously, allowing me to become a program manager where I work.

Comments: --

Survey 29:

21. Looking for ways to improve my client's lives.

22. Excellent as it is.

23. --

24. No more or less than before I took the course. 
25. No, limited promotional opportunities.

26. Tuition reimbursement

27. No

Comments: --

Survey 30:

21. How important it is to support each individual that I support at my work place.

22. None

23. --

24. Yes, I have always enjoyed working in the field.

25. --

26. No

27. I might look into it some more.

Comments: None

Survey 31:

21. a) I am better able to communicate with the consumers; $b$ ) I have a better understanding of their views, and; c) I am more informed to discuss issues with direct staff.

22. a) An actual class meeting at different divisions to better understand certain issues; b) A reflective correspondence with issues that are occurring currently (budget cut, consumer affect), and; c) More resources that are more easily accessible.

23. The class was a great outlet of information to a world that I am very seldomly exposed to. As an administrative staff, it has assisted me in discussing issues with both consumer and staff.

24. Yes. As mentioned before, the information and knowledge I have gained from the class has further my curiosity in developing a more intuitive exposure to the world of disability. Socially, it has given me a better understanding and better outlook than my egocentric state of mind before hand. This has enabled me to utilize different skills in order to assist people with disabilities and project a more mature demeanor with my peers.

25 . I don't think so, because I work more administratively.

26. Tuition payment is reimbursed because it is a course that directly reflects with my employment and its course.

27. I think more of further education in this field is more informative for me and my attitude towards society itself.

Comments: I really enjoyed the class and am very thankful for the direct comments and positive feedback provided by our divisional instructor, Dorena Martin.

\section{Survey 32:}

21. History of people with disabilities, "People First" language.

22. I had to take the class for San Diego Regional Center and Children with Developmental Disabilities. Most all of the information was based on adults without mental impairment, or limited impairment. The literature did not include care and supervision of this population, and did not cover teaching this population that respect is given to those to give respect. And that there needs to be accountability with all people, including those with disabilities.

23. LOVED the online format. I hated the question of who we would pick to die -- although it was very interesting to read the responses.

24. I own my own home. It does help me use the "looking at..." so that I can show my staff what the goal for every child should be.

25. Not applicable. However, I am opening another home. Everyone at Regional Center LOVES our program.

26. Not applicable. However, we will have staff attend the online classes when we promote them to manager. 
27. Not applicable. I am already seeking a Masters degree in Psy.

Comments: The online format was fairly hard to use at first. I took a while (and my computer skills are good). Mari was always available to speak with if my husband or my mother needed -this was nice.

Survey 33:

21. a) Patience; b) Understanding; c) Organization

22. a) More multiple choice questions; b) Less essay type questions, and; c) More frequent meetings of the class.

23. There should be more extensive comments about the work by the instructors.

24. Yes, because my interest has been tickled.

25. Probably so, because there is a huge turnover in this endeavor.

26. None whatsoever.

27. Yes, because I otherwise would not learn more about his particular field.

Comments: My hat is off to everyone that participated. You will never know how much you have affected my life and my behavior. Thank you.

Survey 34:

21. I am able to understand the difficulties some of our consumers have in terms of being striving for independence and getting a job.

22. In 206, there was a lot of work. It, at times, was very challenging, but there was just too much of it.

23. I really enjoyed the class.

24. Yes, because I now have a better understanding of our consumer needs and their desires.

25. It is possible.

26. Yes. If the classes are successfully completed, the company will reimburse for the books and tuition.

27. Yes I am. I am really enjoying these classes.

Comments: --

Survey 35:

21.--

22. --

23. Course content was great.

24. No. More or less likely than before taking the course.

25. No, limited opportunities for promotion.

26. Tuition payment.

27. I am currently a Junior at the Master's College.

Comments: --

Survey 36:

21. a) Being able to pass on information to staff that is current and applicable in our field or work; b) Teaching staff to ask the most important question first does the client wants to change their behavior; $c$ ) Building a report with a person will certainly give you the advantage of learning all about them and if what is being communicated is the change the person wants or the wish to be compliant (people pleasing).

22. I don't have any suggestions to give. I am very pleased with the information, the layouts, and the time and effort put into this class by the instructors and the facilitator.

23. Rebecca Bond and Mark Furia have been very good at being available and accessible during this class. I am very impressed with the class and will be encouraging my staff to take the series of courses. 
24. The coursework ensures that I stay on the cutting edge of a person centered mind set. Such ideas can only help one maintain employment.

25. No, I am at the top of my department.

26. Yes, tuition for the class is paid if you receive a "C" or better.

27. Yes.

Comments:--

Survey 37:

21. My knowledge regarding the communication skills have greatly improved since taking this class.

22. I feel the class was great the way it was.

23. I learned a lot on the online class, and the instructor was great.

24. My employment is why I am going for my degree in developmental disabilities, so I can gain the knowledge I need to insure that I can give them the best quality of life that I can.

25. After I get my degree.

26. My employment pays for all my tuition as long as I maintain a "C" average, which I have.

27. I'm not sure.

Comments: I was a little skeptical about an online class at first: My instructor was very good and the class curriculum was very educational and I learned a lot. I would encourage anyone in this field to take this class.

Survey 38:

21. I have been doing this work on the job and I have gained more insight into my role and view my paperwork as more than paperwork now -- the purpose is clearer.

22. I have none. I loved this class.

23. Great!!

24. Yes, because I feel like I know more of what I am doing.

25. No. I do not want to be promoted -- I love my current job.

26. Tuition

27. Yes, I was a little worried about going back to school, but this class really made me feel better.

Comments: I LOVED MY CLASS!!!!!!!

Survey 39:

21. I demonstrate skill when working on behavior plans at my volunteer site.

22. --

23. I really enjoyed this class. It made me think in depth about each subject.

24. Yes, I better understand things that may be affecting consumer's behavior that are not related to the program.

25. Yes, most programs want employees who have completed this training and are more likely to be interested in promoting such individuals.

26. No

27. Yes, I am working on completing my A.S. in disability services.

Comments: --

Survey 40:

21. a) Behavior management; b) Communication, and; c) Different teaching techniques.

22. None

23. No

24. Yes, most likely because I love my job.

25. No promotion 
26. No, just reimbursement.

27. Yes, to further my knowledge in the developmentally disabled field.

Comments: I enjoyed the learning experience.

Survey 41 :

21. a) Better communication of their needs; b) I find myself asking them what they want, than what I think they need; c) I see that I look and listen better than I did before so I am not just guessing what their needs are.

22. I don't have anything. I thought this class was great.

23. I thought this class was set-up for use to learn a lot about what people need to say without saying anything. I know that I have learned a lot. I thought the teacher did a great job.

24 . I would say yes. I really enjoy my job and the people that I work with.

25. I have been promoted to manager. I think they gave me a promotion because I have been there the longest and know the clients needs very well.

26. No, I am doing this on my own.

27. I hope to be a teacher some day.

Comments: I have learned a lot from all the classes I have taken so far. I have also learned a lot about myself. I am grateful to be able to meet other people that have the same interests as me.

Survey 42:

21. a) Able to help advocate; b) Know more about support plans, and; c) More about communications.

22. I think the class was perfect. I have no suggestions.

23. --

24. Yes, because I have more knowledge in the field.

25. Yes, because I have more knowledge.

26. Yes, reimbursement.

27. Yes, because I want to learn more in this field.

Comments: The class was very helpful, and I learned a lot.

Survey 43:

21. a) Knowing more of what an employer may expect of you and your group; b) Helping a person to choose a comfortable strategy to complete tasks; c) Helping a person to achieve goals they have set for themselves.

22. Have more handouts.

23. --

24. Yes, because I have gained more information and learned new strategies.

25. Maybe because now I have more knowledge.

26. --

27. Yes, because I am interested in this field.

Comments: -.

Survey 44:

21. a) The time I put in it; b) Patience; c) Hope.

22. Location

23. - -

24. Yes, this is why I'm taking this class - to get a degree and better job.

25. Yes, I will receive my RSS certificate.

26. No, the jobs I work at never talk about it to us.

27. Yes, I want a degree.

Comments: -- 
Survey 45:

21. a) Patience; b) The ability to help people.

22. None. I like it just the way it is.

23. N/A

24. Yes, because I will have my degree and it will open more job opportunities for me to apply for.

25. Yes, because having a degree increases my chances to start out at a higher position.

26. No

27. Yes, because I want to obtain my degree.

Comments: --

Survey 46:

21. a) Help set goal and keep them; b) That not all people are alike so need to get to know them as a whole; c) Advocate for those who can't.

22. I have no ideas. It is a great course.

23. -

24. Yes, I enjoy doing what I do. I would like to go as far as I can some day.

25. Yes, I already have been.

26. No.

27. Yes, I would like to be a teacher in this field.

Comments: --

Survey 47:

21. a) Improved ability to create team synergy; b) Increase team input and communication; c) More willingness to look at change as an opportunity.

22. a) Mix-up groups in: think, pair, and share; b) Consider reading assignments prior to the sessions (they can be helpful); c) Suggested reading list may be presented to the class.

23. Enjoyed breaking up info with discussion, videos, exercises. Enjoyed group activities.

24. Yes, this was my first management training I ever attended. Gives me a framework and some tools to work with.

25. Probably no. No higher tiers of management define between me and Exec. Director.

26. Tuition and mileage will be reimbursed.

27. Yes, I think education and training is a great way to increase skills and improve value to organization/employer.

Comments: --

Survey 48:

21. a) Positive thinking; b) To encourage play among staff member; c) Setting goals and ID timeline.

22. a) More problem solving; b) more thought sharing.

23. Excellent instructor and group interaction.

24. Maintain employment because there is so much $I$ have yet to work on and change about my work and personal life.

25. No, I like my job and believe there is a lot more to do yet.

26. No, I am interested in self-improvement.

27. Yes! This is fun and I got a lot out of the class.

Comments: This is one of the best training I have participated thus far. I believe I got to learn about my strength and weaknesses and able to see things differently. I will try to set personal and professional goals to help me see the big picture. This will also help me get where I most wish to be. 
Survey 49:

21. a) I've learned to look for new cheese, rather than relying on old cheese; b) its ok to have fun at work, but one must also regain professionalism; c) Listening actively and not multi-tasking provides reassurance.

22. None. Well received and good organizational skills utilized.

23. None

24. Yes, I like my job, the consumers, and my co-workers.

25. No, I am already the Departmental Director.

26. No

27. If I choose.

Comments: --

Survey 50:

21. a) Accept change; b) Clear communication; c) Be present with my 10 workers.

22. a) More team work; b) More video descriptions; c) Role playing (e.g., manager/worker).

23. -

24. Yes, I need money and I like my job.

25. No. No promotion is available.

26. No

27. No, I have a Masters. Maybe in the future.

Comments: --

Survey 51:

21. a) Better organization; b) Better communication with supervisor; c) Better communication with line staff.

22. --

23. --

24. Yes, I think the class has improved my ability to communicate with my superiors.

25 . No, at the present time budget deficits are affecting promotions and salary increases.

26. No

27. Yes, I have always wanted to complete my Masters and eventually doctoral.

Comments: --

Survey 52:

21. a) Able to communicate better; b) Understanding the need for team work; c) Able to better organize time (i.e., time management skills).

22. a) Possibly more reference books (I truly enjoy reading them); b) The videos are also very good (possibly more).

23. I have enjoyed this course. I felt that both instructors were wonderful and very easy to understand. I really like the examples that were given and the curriculum was very good as well.

24. Yes, I feel I have a better understanding on what I need to do to be more efficient, i.e., how to communicate.

25. I feel I have learned a lot. I would like to think that I could handle situations better by using the knowledge that I have gained (I think I could be promoted).

26. No, just more knowledge in the field, which is a reward in itself.

27. Yes, I have enjoyed this course and welcome additional education.

Comments: I really enjoyed the course. I felt the participation among the group was great. I feel I have learned a lot and will try to take it back to my office to share with co-workers. 
Survey 53:

21. a) Better communication skills; b) Work as a group to problem solve.

22. a) Start earlier and end class earlier; b) More total group participation versus small groups.

23. Enjoyed the interaction of Howard and Becky with the group.

24. Yes, training helps to understand what you are doing.

25. No, Director is next in line for me and I won't be working long enough to set that as a goal.

26. -

27. I'm always open to learning.

Comments: Howard and Becky make a good team.

Survey 54:

21. a) Communication; b) Being present

22. Confidentiality on survey (i.e., supervisor, birthdate, etc.)

23. --

24. Yes, a better understanding

25 . Yes, as the company grows the need for persons with more knowledge and ability to change are needed to fill positions.

26. Yes, VIP promotes training and additional knowledge by funding classes and transportation to conferences.

27. Yes, always been aware of the need for more education, but the discussions placed emphasis on what I do not know and can learn.

Comments: --

Survey 55:

21. a) Listening to others before speaking or making a decision; b) Having a positive attitude with all staff members, and; c) Being present.

22. A) Role playing; b) Maybe another video; c) More group activities.

23. Overall it was great.

24. Yes, because I've learned to always keep in mind our mission and to keep sharpening the saw.

25. Yes, because I have been training for a different position job duties.

26. Not from our organization, but personally I think I'm reward by gaining knowledge from this course.

27. Yes, because I love to learn and meet others and see their perspectives on different situations. Comments: --

Survey 56:

21. a) Communicate effectively; b) Importance of not doing 100 things at once (multi-task); c) Organizing workload.

22. a) Conflict resolution; b) Employee relations; c) Ethics.

23. Enjoyed working in groups, sharing ideas and solutions. Cheese book was good.

24. I will be looking for employment while still looking for the cheese.

25. No room for promotion, but according to the CEO every "new grant" is a raise. (I don't agree.)

26. The CEO lets some people go to school (time-off), but had made comments to me that "some" people will never make it. Negative remarks disappoint me.

27. Currently I have my MS and would like to pursue a doctorate - long term goal.

Comments: These sessions help me realize that I have been adapting to change but I want to look for change somewhere else. 
Survey 57:

21. a) Communication - evaluating and changing communication issues; b) Working with change - seeing change and making it an advantage; c) Lenses - recognizing our organizational (and personal penses) and addressing them.

22. More flexibility on choosing the dates for the class. Have mini projects or goals to see our growth. More participation from more of a diverse group.

23. Very useful, informative and fun!

24. I will maintain my employment. I will be able to take these principals/ideas back and apply them.

25. I would like to stay in my position and go back to school. A promotion will not allow that. 26. No

27. Yes, I have goals that extend beyond my current position and this class has again sparkled that interest.

Comments: --

Survey 58:

21. a) Communication with my co-workers; b) How to get some of my clients motivated; c) How to set realistic goals for myself at home and work.

22. a) Help enlighten each person with everything you have so that they can become a better person.

23. --

24. Yes, this is a place that I'm needed and I'm able to help someone and to make a difference in their lives.

25. No, you get internal rewards.

26. No, you get internal rewards.

27. If it's offered, I will.

Comments: --

Survey 59:

21. a) Adaptation to change - I have become more receptible; b) Listening skills - the knowledge that my personal improvement is necessary and making the efforts; $c$ ) Communicating and becoming more clear when communicating and letting others finish communicating before responding.

22. a) Possibly more books to read before attending the class; b) Group projects that involve hands on or role playing; c) Movies or even a couple clients providing information of how and what we can do to provide a better service to them.

23. Enjoyed every aspect of instruction and look forward to possibly more opportunities.

24. Yes, I enjoy my work and look forward to possibly furthering personally within my current employment.

25. Possibly. The following training and curriculum will improve knowledge and skills making me more valuable.

26. At this time it has not been mentioned. A personal satisfaction and growth is made.

27. It has opened my eyes to what is available when the time is right. It is very motivating.

Comments: Again, enjoyed every aspect of curriculum.

Survey 60 :

21. a) Demonstrate good rapport; b) Demonstrate great communication skills; c) Job assessment.

22. I felt that this instruction class was very satisfying and educational. No suggestions.

23. I'm sorry I missed the first day due to family death.

24. Yes, I enjoy my work and plan to grow in the future.

25. No at this point, but perhaps in the future. 
26. Yes, certificates.

27. Yes, to become better knowledgeable for myself.

Comments: --

Survey 61:

21. a) Better communication between myself and upper management; b) A greater sense of knowledge and security; c) An ability to think deeper on some issues of which I was not aware. 22. a) I would like to see more novels to read to go along with class; b) More movies to illustrate main points of curriculum; c) I would also like to see more assignments involving writing. 23. -

24. Yes, because you now have something invested in it and your investment or buy-in makes it likely you will want to remain employed.

25. Yes, you have more confidence and feel more secure and it shows and those with more training are likely to be moved up first.

26. Not financially. You gain internal rewards but our company does not offer any.

27. Yes, it's interesting and reminds me that I need to go back to school and get a Master's degree.

Comments: --

Survey 62:

21. --

22. a) Better detailed explanations of projects; b) Having professors email you back with 2-3 days; c) All assignments due on the same day of each week.

23. --

24. Yes, although I do not work in the rehabilitation field I do work at a doctor's office and they are very interested in my knowledge of issues concerning people with disabilities.

25. Not necessarily - my promotions are based on other work.

26. No

27. Yes, this just started my educational goals.

Comments: --

Survey 63:

21. a) Helping consumers with setting and achieving their goals; b) To help consumers with nonabandonment use of their technology, and; c) Use of proper assessment strategies.

22. a) Making sure that the discussion boards are posted on time; b) Making sure that the grading system is correct and on-time; c) Making sure that the web lectures are posted correctly.

23. The classroom instruction wasn't very clear on some homework. There were some unclear questions posted on the web exercises. Also, the responses for email are hardly replied. I would like to see more responses from the teachers. There were no comments regarding the homework grading.

24. Yes

25. No

26. Reimbursement

27. No

Comments: There was too much catching up to do and hardly any learning. Too much finding out and/or guessing what the teachers wanted for certain projects. There needed to be more samples to make the project clear. 
Survey 64:

21. a) To look at the person deeper and find out what they really want; b) To think about why I am doing this and is it for my own personal gain or to really help the individual; c) To speak up more for the individual.

22. a) Please....please...please don't have reading on the same weeks as a big project; $b$ ) Post grades a little faster; c) Post discussion questions on time.

23. Many of us have a full schedule (kids, jobs, more classes, and so on). The reading with the web exercises and then a large report was a little too much at once.

24. I was injured on the job and layed off...canned...during this class. I was an instructor of communications - primarily AT devices - and worked at a day program for 13 years.

25 . Not promoted but vocational rehabilitation is trying to set me up in my own business concerning AT.

26. No, only my own rewards.

27. Yes, I am currently signed up for three more classes.

Comments: None. I did enjoy the class and the textbook.

Survey 65 :

21. a) I think the things that I have learned are to listen to the opinions, needs and wants of the person I care for; b) I also have learned to help influence and inspire the man I take care of to use assistive technologies more to benefit him and for him to have more independence; c) I have also learned how to help him to live and have the best quality of life.

22 . I think that everything was great. I would not change a thing.

23. N/A

24. My course work doesn't affect if or if I'm not going to volunteer in taking care of the man I take care of.

25. N/A

26. N/A

27. Yes, I am working towards my associates degree in the Disability Service Management Program at Grossmont.

Comments: I just really enjoyed the class and I thought that the required text for the class was moving and inspiring. Thank you!

Survey 66:

21 - 27. No answers.

Comments: I enjoyed your class very much. Holly, thanks so much for your quick responses.

Survey 67:

21. a) Increasing my knowledge base of AT devices; b) Confidence in using the web for needed information; c) Wider base to stand on for supporting people with disabilities.

22. I think the MPT project should be discussed first. This would give the class a clearer view of where they are going with the information they are selecting and searching for.

23. The student feedback outline is totally wrong and was not updated in a timely fashion. There is Discussion Board points accounted for that do not exist. Board 7 and 8 are listed twice, each representing 5 points. Not assigning points for the MPT project for each section leaves a sense of subjectiveness on the part of the instructor. Some web exercises were combined, yet on the grade portion they were split as separate assignments - Chapters 3, 4,9 and 10. Leaving a score of 0 for chapters 4 and 9.

24. Gaining knowledge in your field always helps maintain employment.

25. No, I am at the top of my Dept.

26. Yes, with a grade of "C" or better the agency pays for the class.

27. -- 
Comments: Leaving the facilitators out of this class was a huge error. They have been our personal life line to you. When taking the course it is stressed at the importance of human content, no one is comfortable just using technology. Perhaps the instructors and Grossmont might want to take this class to help them understand what they have been teaching us and practice the lesson learned themselves.

Survey 68:

21. I am more aware of how to dig out information about the difference between my wants and the wants of the consumer.

22. a) I felt that the assignments were out of order and not clear. We spent a lot of time trying to figure out things; b) Less web searching and more directed sites to visit, like sites that people can use to find what they need. It was not until the webology was turned in did we realize it was for the MPT; c) The MPT research papers to help us did not because they should have been presented first, so our MPT project could go in order and all related work would have been more mentally applicable.

23. I liked the book. I did not like all the visits we had to do, but that's just personal.

24. I love my job and took these courses so I can offer more to the people I work with.

25. Do no want a promotion. I work at staying where I am. I am a person who likes hands on. 26. Tuition payments, but I did not except them. I wanted to pay for my own education - I want to feel like I own it.

27. Yes, I enjoyed going to school on-line. Most of the time I am up at 5 a.m. and can do work at my leisure or prepare ahead if I have things that are coming up.

Comments: This class was very confusing. I felt a lot of the time we were more focused on psychology rather than technology.

Survey 69:

21. N/A

22. The main problem was a lack of interaction. Little things, such as posting comments on the grade board go a long way.

23. --

24. No, more or less than I was before taking the course.

25. No, there are few opportunities for advancement in my organization.

26. Tuition is reimbursed upon satisfactory completion of the course.

27. I am pursuing my BA.

Comments: --

Survey 70:

21. Well, since I don't feel like I learned anything from this class, this is a hard question to answer.

22. Less work or more units. There was entirely too much work in an eight week period.

23. There needs to be a facilitator.

24. I will maintain my employment, but it has nothing to do with the coursework.

25. Nothing learned, so probably not.

26. No

27. Possibly as long as they aren't like this one.

Comments: I think if this class was offered during the fall or spring semester it would be better. The workload is out of control. The web exercises and discussion boards need to be worded in plain English. I felt like there were too many questions that I really didn't even understand after reading if 4 or 5 times. Having the website available at least a week ahead of time would be helpful as well to allow people to obtain the books and be able to get started on time, rather than waiting three weeks to get a book and then being behind and trying to play catch-up. 
Survey 71 :

21. a) How to and where to find technology for my consumers; b) Find the devices they need on the internet; c) How to advocate for the technology.

22. Have a class once a week for those who need help.

23. -.

24. I want to work at the home I work for until I feel that I am ready to move to a higher position. I am a manager at this home and I can't go any higher but administrator, and that is what the owner is, so that position is not open.

25. No, because this is the highest position there is for me at this home.

26. No, I am taking these classes to be at my best for the people I work for.

27. Yes, I want to be a teacher someday.

Comments: --

Survey 72 :

21. Unfortunately, I don't work with clients anymore - I am now in construction.

22. Change your due dates to Sunday instead of Friday - other than that this was a great first class.

23. None

24. No, I can make more money doing construction. This class did provide me with a new view of things that can be done around the house for my wife who is disabled.

25. No, sorry wasn't in a promotable job.

26. No, HGH does nothing to help train its RST's.

27. Very much so.

Comments: --

Survey 73 :

21. a) Advocate for the consumers; b) Listen to the needs of the consumers; c) Locate adaptive equipment on the internet.

22. a) Cut back on the workload... way too much! We as a group were so busy working, we had no time for discussion like in our previous classes; b) Include our facilitator because he brought us together for discussion and always answered our questions. When we had questions, we had to wait a long time, or never received the answer at all from the instructors.

23. Take into consideration that we want to improve and learn or we would not be taking these classes in the first place. However, we are working $40+$ hours a week in addition to this class. That does not leave us time to visit companies, etc. The workload was completely out of line and it only increased as the weeks went on. For instance, it was so incredibly difficult for you to expect us to complete not only one, but two exercises, a final exam and a discussion board the last week of class. The reason we did so well is simply because we "CARE" but it drained us and YES, we did out homework, but did not have the opportunity to learn as much as we could have. That is a real shame because I loved the book and we could have learned so much more if only we had the time to discuss, and not just do the busy work.

24. No

25. No

26. Yes, if we maintained a certain grade average, we will be reimbursed our tuition and books.

27. Yes, I have one more class for certification. If this had been the first class offered, I never would have completed the classes for certification and that is very sad to me. I feel anyone working in Social Services should understand adults with developmental disabilities, however, the amount of work would have turned me off and I would never have gone any further. I certainly hope the curriculum will be changed for possible future students because as it stands, I cannot recommend this class. 
Comments: When students email for help, I would hope the instructor would take the time to email back shortly thereafter. This was not the case. We never knew what our points were worth because (TBA) was seldom clarified. It took a very long time to know what points we were receiving, and most of us were failing the course up to the final week of the class.

Survey 74:

21. a) I am a better listener; b) A better facilitator; c) A better counselor.

22. a) More one on one contact with facilitator; b) More one on one contact with facilitator, and;

c) More one on one contact with facilitator.

23. More concise directions by the instructors.

24. Definitely yes - I'm stoked on learning all that I can about this job.

25. God only knows for sure.

26. None whatsoever.

27. True

Comments: Let's have a party.

Survey 75:

21. a) Looking at how the positives and negatives of a technology can affect an individual; b) Knowing now that the experience for someone with an acquired injury is very different from someone that was born with a disability; c) Being able to match a technology with the person through the assessment process.

22. a) The work load needs to be evaluated. For a 2-unit course, I was averaging 8-hours of homework a week. Is this normal? b) Try not having a discussion board the weeks that special projects are due; c) When interviews or site visits need to take place as part of the supplemental exercise, make it known at the beginning of the course. Sometimes it takes longer than 5-7 days to schedule an appointment, conduct an interview and answer the questions accordingly. The web exercise should be worth more than the discussion boards. Limit the web sites for finding 1-2 in the topics requested. Discussion boards should be posted by Monday of each week, not Wed. or Thurs.

23. Keep our facilitator in the loop so that he/she can assist us with any questions, especially if the instructors are not responding or explaining things properly. The whole MPT project was very confusing and was not explained well at all. The assessment should have been completed or due before we were looking for technology (webliography) because how else are we going to know what to look for.

24. No. After taking the certificated course as a whole I may be eligible for a raise, but this class is not making or breaking my job efforts.

25. I get a raise not a promotion necessarily, for completing 15 units related to my job.

26. Tuition payment.

27. Yes, continuing my general Ed. And going onto Human Services or Behavioral Science. Comments: Projects were not explained properly. I felt extremely left in the dark on several projects. When emailing the instructors I would rarely get answers and when I did they were very brief and to responsive or helpful to my questions. Many grades were left out to the last minute. When I inquired about such grades I got no response or reassurance that the assignment was even received. In the previous classes of this certificated course all assignments were sent to our facilitator also, and he would send them back to us so we knew for sure that assignments had been received. This class was so overloaded with work that it was hard to retain the information. The book was very good and enjoyable and I learned a lot from the book. The rest was tough, not because the material was difficult, just because it was so much and many assignments were not clearly explained. 
Survey 76 :

21-27. Did not complete questions.

Comments: -

Survey 77:

21. a) Disability knowledge; b) Behavior techniques; c) Disability culture.

22. N/A

23. N/A

24. Yes

25. Yes

26. Yes, $\$ 200$ bonus.

27. Yes.

Comments: --

Survey 78:

21. --

22. --

23. --

24. Yes

25. No

26. Yes

27. Yes

Comments: --

Survey 79:

21. a) Understanding client view-points; b) Explanations give to clients different; c) Organizing day better.

22. No

23. None

24. Yes, more knowledge of services needed to provide to clients.

25. Yes, increase position and pay.

26. Yes, repayed for classes.

27. Yes, turn into an AA.

28. Comments: --

Survey 80:

21. a) Consumer advocacy; b) How to support individuals/DD at worksite in a community effectively; c) Professionalism.

22. --

23. None

24. I've completed already. I'm with the same organization.

25. I believe so.

26. Yes

27. Yes, I am pursuing my Masters degree.

Comments: --

Survey 81:

21. a) Knowledge of disabilities and traits; b) Empathy for family members; c) Broader knowledge of solutions to behavior.

22. --

23. -- 
24. Yes, I have a better understanding for the environment.

25. --

26. $\$ 200$ for completion of courses.

27. Yes, struck an interest in the deaf world.

Comments: --

Survey 82:

21. a) I am better help with behavior plans; b) I understand and help the people I support; c) I learn new techniques and can apply them.

22. a) Ability to help work around work schedule; b) more on-line.

23. I think that it's all great.

24. Yes, it helps inform you and helps you understand behaviors and goals.

25 . Yes, in my field more education is better.

26. I get $\$ 200$ and $5 \%$ pay raise.

27. Yes, for more money.

Comments:

Survey 83:

21. a) Able to adapt skill vocationally; b) The handling of behaviors with alterative measures.

22. More East County classes.

23. None

24. The training was very well taught and has been a pleasure to have completed.

25. To better education levels.

26. None

27. It's possible.

Comments: --

Survey 84:

21. a) Self-starter; b) Better communication with consumers and family; c) Setting my goals.

22. None

23. None

24. Yes, to enable me to utilize what I learned and share it with others.

25. Yes, more confidence with myself.

26. Yes, a $\$ 200$ bonus check.

27. Yes, to broaden my knowledge.

Comments: --

Survey 85:

21. a) Choices for people; b) Advocation; c) Instruction

22. -

23. It was great - lots of information.

24. Yes, competency encourages people to go.

25. Certificate program.

26. Tuition reimbursement

27. I already have.

Comments:

Survey 86 :

21. a) Being more aware of consumers; $b$ ) need to do a better job; $c$ ) having consumers work more in depth.

22. None 
23. I'm pleased with on-line classes.

24. Yes

25. I'm happy with my position now.

26. Yes

27. Yes

Comments: --

Survey 87:

21. a) Communication; b) People skills.

22. --

23. --

24. --

25. Yes

26. Yes

27. Yes

Comments: --

Survey 88:

21. --

22. --

23. Really liked classes offered in a location nearby without having to pay for parking.

24. Remained in the field.

25. Possibly, if I apply.

26. Yes

27. Yes

Comments: --

Survey 89:

21. a) Setting objectives for people; b) Communicating better with people; c) Organizing job sites.

22. a) Having people with disabilities speak in class; b) More scenarios involving behaviors and how to cope; c) Course on adaptive devices.

23. I enjoyed the classes, but some were rather unorganized when I took them. I understand there are new instructors and some of the curriculum has changed.

24. Yes, I have had two promotions and took courses at SDSU.

25. Yes, understand paperwork and procedures better. Increased communication skills.

26. Will receive a $5 \%$ raise when completing 6 more units.

27. Yes, I need 16 units to finish my degree at SDSU.

Comments: --

Survey 90:

21. a) I am better able to work for the consumer by understanding how someone that uses an assistive device might feel about moving through a world that is built for non-disabled people; $b$ ) I am able to better understand how a person that uses a communication device might not want to use it because it is unable to keep up with regular conversations; $c$ ) There are some people that use an assistive device that might not like the way it looks or it might not be what the consumer wants.

22. a) The program needs to be able to be more organized - having alternate classes that can be taken instead of waiting a whole year to take a class; b) Having more class time outside of college location, like having more than HESC 110 or 150 offered; c) On-line classes are good but real 
classes are better because teachers seem to just pile work on the net. I'd rather ask questions directly or just have mandatory meetings throughout the semester.

23. -.

24. Yes, I am able to maintain employment by having some of the skills that are required to perform the job.

25. Yes, I can be promoted when an opportunity is made available.

26. There is tuition payment and education is something that is encouraged.

27. I am willing to follow-up on education because I think that I am motivated.

Comments: -

Survey 91 :

21. a) Setting goals (objectives); b) Better communication; c) Better understanding the purpose of center.

22. a) Purpose of having objectives and what RC looks at; b) How to interact with all consumers (different abilities); c) Consumer rights and how to help them exercise it.

23. --

24. --

25. Yes, promoted to Café Manager.

26. Classes paid for by SMSC.

27. --

Comments: --

Survey 92:

21. a) I'm able to handle a large group of consumers; b) I can teach classes to the consumers; c) I can be a stronger advocacy for the consumers.

22. More group activities for better understanding of class. I didn't have any other problems with the classes.

23. -

24. Yes, I enjoy the work I do working with the consumer who has a disability.

25. None as of now.

26. Yes, $2 \%$ raise.

27. Not at this time.

Comments:

Survey 93:

21. a) More leadership with peers and co-workers; b) More understanding of outcome; c) More understanding of purpose of goals.

22. More vocational skills training.

23. -

24. Yes, to best utilize skills gained.

25. Yes, due to utilize skills, knowledge and experience.

26. Yes, pay increase offered, promotions, and increased job duties.

27. Yes, to continue to learn how to better support the people I serve.

Comments: -

Survey 94:

21-27 Due to time, this section is too long to complete - sorry.

Comments: --

Survey 95:

21. Overview of functional assessments. 
22. Give more time.

23. Enjoyable.

24. Yes, the more education the better.

25. No, should stay the same.

26. No rewards. Receive the certificate upon completion.

27. Yes, always would enjoy more education.

Comments:

Survey 96:

21. a) Understanding the effects regarding down syndrome; b) Willing to gather more info on presenting sex ed.; c) Looking for signs that indicate that people may need assistance.

22. a) Maybe two days on this subject; b) more coverage of how meds affect people.

23. Instructor was knowledgeable regarding subject. Allowed leeway and allowed people to explore.

24. Yes, I like what I do.

25. No, as high as I can go right now.

26. No

27. Yes, you can never stop learning.

Comments: -

Survey 97:

21. --

22. This would be a good 2-day seminar!

23. -

24. This will not change things one way or another.

25. No

26. No

27. Maybe

Comments: -

Survey 98 :

21. a) A little more knowledgeable; b) More open to new ideas; c) More willing to start discussions.

22. --

23. -

24. Continuing education is crucial to reusing? competent and confident

25. No, promotion requires degree.

26. No

27. Currently working on Assoc. degree.

Comments: -

Survey 99:

21. a) Service to others; b) Job; c) Proud history.

22. a) Goals - person/client; b) Healthy, positive.

23. None

24. Why - I think it will help them.

25. Yes

26. No (I get to get to keep my job)

27. Yes, in November.

Comments: - 
Survey 100:

21. Safety - a great importance.

22. -

23. -

24. Yes, I really enjoy my job. If I can make a small effort to help one person, it's worth it.

25. No, any education is great, but advancement is not likely to happen.

26. Just a certificate.

27. Yes, all of the info I can get is great.

Comments: -

Survey 101:

21. A) Patience; b) Better listening skills; c) Compassion

22. Make this a 2-day course.

23. -

24. Yes, more understanding.

25. Yes, better education and understanding.

26. No

27. Yes

Comments: -

Survey 102:

21. a) Increased knowledge of subject matter; b) Share stories/experiences/statistics; c) Play devil's advocate/challenge stereotypes.

22. a) This particular class should be longer (2-days); b) Medication coverage - effect of meds; c) Symptoms/characteristics of other disabilities.

23. Tim Gust is great - thank you.

24. Absolutely - confirmed desire.

25. No, opportunities limited.

26. No

27. Yes, peeked interest.

Comments:

Survey 103:

21. --

22. 2-days

23. Was good.

24. Yes

25. No. No room up.

26. No

27. Yes, I like it.

Comments: -

Survey 104:

21.

22. Make it a 2-day class.

23. -

24. Yes

25. No

26. No

27. Yes, interested in learning as much as I can.

Comments: - 
Survey 105:

21. a) Advocacy; b) Self determination; c) "Normalization"

22. a) Expand employment strategies; b) Increase resource lists - options

23. -

24. No, funding limitations

25. No. No open positions/opportunities.

26. No

27. Possibly - I will continue to pursue the certificate.

Comments:

Survey 106:

21. a) Better assessment values for clients; b) Understanding client's needs; c) Political awareness and barriers for clients.

22. a) Need insight with Social Security; b) Break emotional and physical into 2-days; c) More open discussions.

23. -

24. Yes, better educational skills in dealing with the system and clients.

25. No, owner self-employed.

26. No

27. Yes, want to know more.

Comments: Great teachers. Thanks Howard.

Survey 107:

21. a) Listening; b) Advocacy; c) Reporting

22. Offer a Social Security administration (person) topic

23. Good use and visuals/handouts and class discussion.

24. Yes, increased ed. Helps make work easier to manage.

25. N/A. Self-employed. May find new ideas in work field.

26. N/A

27. Yes, always invigorating and stimulating.

Comments:

Survey 108:

21. --

22. -

23. -

24. Yes

25. Yes

26. Yes, advancement.

27. Taking classes.

Comments: -

Survey 109:

21. a) Communication with client and staff; b) Better understanding of client moods; c)

Understanding of different meds.

22. More handouts.

23. Very, very helpful.

24. Yes, I can communicate better with everyone involved. The more I learn the more interested I am in the field.

25. Not in the near future - new in field.

26. No 
27. Yes, there is so much to learn in this field.

Comments: -

Survey 110:

21. a) Better able to advocate for our consumers; b) Better able to view our consumers from a holistic standpoint.

22. No suggestions.

23. None

24. Yes, I am able to visualize myself in my current position or related as much as 10 years from today.

25. No, due to constrictive attitudes at this corporation.

26. No, nothing.

27. Yes, pending finances.

Comments:

Survey 111:

21. a) Better knowledge and understanding; b) Patience; c) Empathy

22. a) More frequency - maybe twice monthly; b) More information on the handouts

23. The classes are really nice and all of the instructors exhibited good teaching skills.

24. Yes, but it depends on how well I use the skills and knowledge I've achieved.

25. Maybe, because these training are part of the requirement for promotion.

26. No

27. Yes, because I have a hunger for more knowledge and these classes arouse my desires.

Comments: The classes are very informative and the instructors really try hard to make sure that everyone understands what they are being thought and why.

Survey 112:

21. a) Awareness; b) The ability to evaluate needs of persons served; c) The ability to speak with confidence about work performed.

22. a) More group activities; b) More group interactions; c) More group role play.

23. This class has been very educational

24. No

25. No

26. No

27. Yes

Comments: -

Survey 113:

21. a) Better communication; b) Better interaction with staff and co-workers.

22. a) More class discussion; b) More actual case scenarios.

23. -

24. Yes, have more knowledge.

25. Don't' know.

26. No

27. Yes, more knowledge is power!

Comments: -

Survey 114:

21. a) Active listening with consumers; b) Much better documentation; c) More understanding. 22. a) Integrate the coordinators, job coaches, case managers; b) Morning or evening classes, instead of 12-hours a day; c) Less breaks - stay on task. 
23. Case studies are good, but please limit them to presentation or presenters, not everyone in class.

24. Yes, not for the educational experience, but for enlightenment of our consumers.

25. No. No room for growth.

26. No

27. I would like to, but do not know where to begin.

Comments:

Survey 115:

21. a) Communication; b) Knowledge; c) Resourcefulness

22. Limit case by case conversations.

23. -

24. No. Supervisor is not capable of defending employees regardless of education and experiences.

25. No, same reason.

26. No

27. Yes! Inspirational! Fantastic information.

Comments:

Survey 116:

21. a) More comfortable communicating; b) Better advocate for client needs; c) Feel more knowledgeable.

22. a) More group activities; b) More group interactions.

23. Howard Twomey is great and so was this entire class.

24. No, I love my job and would stay even without this training.

25. No, just furthering my education.

26. No, I'm here because I want to learn more and appreciate my job for paying for it.

27. Yes, you can never get too much knowledge.

Comments: -

Survey 117:

21. a) Able to recognize situation quicker; b) Patience; c) Caring more.

22. None

23. None

24. Yes, because I have received a better understanding of this field.

25. I don't know

26. I don't know

27. Yes

Comments: -

Survey 118:

21. a) Better knowledge of client rights; b) Psychological understandings of the consumer; $c$ ) Better knowledge in helping clients get what they desire.

22. None

23. None

24. Yes

25. Yes, if a job opens up that requires the skills I learned in this class.

26. No, I just get the advice and knowledge from this class.

27. Maybe an Associates in this same field of mental retardation.

Comments: 
Survey 119:

21. a) Being able to help consumers with their skills; b) I understand more about my clients and their needs; c) Change in a clients life starts with change in my way of thinking and understanding.

22. a) More hands on activities; b) More visual material (not everybody learns vocally); c)

Shorter class time.

23. I would like to learn more about the laws dealing with this population.

24. Yes, I have a better understanding of people with developmental disabilities.

25. Nothing has changed.

26. No, just my own satisfaction.

27. Yes, it will help with my job and further my career.

Comments:

Survey 120:

21. a) More in-depth understanding of clients; b) Able to be more tolerant of client changes; c) Ability to ask better questions of clients to obtain better answers.

22. a) More in-depth interaction; b) More detailed knowledge; c) More ability to obtain research material.

23. -

24. No, the specific class had no bearing on my decision to stay.

25 . No, has little or no bearing on the issue.

26. No

27. Yes, to obtain more info in certain areas.

Comments: -

Survey 121:

21. a) Realizing the rights and needs of my clients; b) Ability to understand the constant obstacles that are presented; c) Keeping my obligation as far as true documentation for our team.

22. a) Break-up the classes into shorter, more thorough time slots; b) Gear towards the participants continued education.

23. -

24. Yes, helps keep me well rounded with my field.

25. Unknown, but I feel the more educated I am the more valuable I am to my company.

26. Yes, ORI pays for all of our classes as long as we keep a certain GPA.

27. Yes, education is the key to staying on top of your skill.

Comments: -

Survey 122:

21-28. No answers.

Survey 123:

21. Knowledgel

22. More movies

23. -

24. Yes

25. Yes

26. No

27. Yes

Comments: - 
Survey 124:

21-28. No answers.

Survey 125:

21. a) Advocacy for consumers; b) Training of consumers

22. -

23. -

24. Seeking better employment in the future. I have a desire for growth.

25. -

26. Yes, reimbursement for continuing education.

27. Yes, seeking a degree in human services.

Comments: -

Survey 126:

21. a) Better able to empower clients; b) Able to identify realistic/obtainable goals for clients; c) More professional in presentations.

22. a) Core more disorders (mental; b) More group interaction

23. -

24. Yes, I will be able to communicate better.

25. Yes, more education.

26. Tuition payment

27. Yes, to better serve my clients.

Comments: --

Survey 127:

21. a) Ability to rate clients more accurately; b) Knowledge of how they react to these meds; c)

Better able to see problems in clients if they occur.

22. Less breaks

23. Excellent - very informative.

24. Yes, I feel better - more knowledgeable of what I'm doing.

25. -

26. No

27. Yes, I feel I still have a lot more to learn so I can help my clients.

Comments: -

Survey 128:

21. a) I have a better understanding of the daily lives of most of our consumers; b) I understand the importance of addressing political issues regarding our consumers; c) I look at people with disabilities as equals rather than "those less fortunate".

22. a) Field trips to political rally's regarding issues about people with disabilities; b) The ability to interact or discuss class material, either by class meeting or computer; c) Additional resource material to better assist students who do not work directly with consumers.

23. The class was incredibly interesting and informative. The experience was indeed enlightening.

24. Yes, because the information I learned was for personal reasons, although it has helped me in the workplace.

25. No, again this was taken for personal reasons.

26. Yes, our class expenses were reimbursed.

27. Yes, I find the class material good for my own knowledge and contributes very much to my outlook in life.

Comments: - 
Survey 129:

21. a) Information based; b) Stronger knowledge base; c) Stronger knowledge of resources.

22. a) Lead time for ordering books; b) Facilitator in place for the whole class.

23. The fourth class seemed so unorganized. Communication seemed hampered and slow.

24. Yes, more knowledge $=$ more value.

25. No, I am at the top of my department.

26. Yes, grade of "C" or better and unit expense is reimbursed.

27. Yes, more knowledge - more value.

Comments: --

Survey 130:

21. a) Listening more to what the client desires; b) Understanding adaptive equipment and where to locate; c) How important a good rapport is.

22. a) Better communication between the students and the professor; b) Clear concise explanation involving assignment; c) Reduced workload and more discussion.

23. When all a person does is research and homework, it is mostly busy work. Although a reasonable amount of homework is understandable - too much decreases time to actually learn and discuss.

24. I felt I was very knowledgeable, but these classes enhanced my abilities and gave me quite a bit to think about.

25. I don't believe so, however, these classes enable me to confidentially talk to employers and help educate them.

26. Yes, and I think it is a wonderful opportunity to increase our knowledge in a field we love and enjoy.

27. Yes, this class has bolstered my confidence and self-esteem, so I want to continue my education.

Comments: --

Survey 131:

21. a) Better understanding of ADA laws; b) Understanding client's needs; c) Able to listen better.

22. --

23. --

24. Yes, because students will have more knowledge and know how when a situation arises.

25. Education is a strong background to have for any career advancement.

26. Yes, tuition reimbursement.

27. Yes, anyone can get or receive hands-on training, but when you combine on-the-job training and course work you have a stronger sense of what your job is.

Comments: --

Survey 132:

21. a) I feel more professional and more secure when I help the individuals; b) I understand their needs and I admire them more than before; c) There is always something that I remember from this class when I am working with them.

22. a) I'm so happy with this class; b) I never imagined how much I could get from this class; c) I think it is a very clear and complete course.

23. The instructor was very supportive and very clear explanations were given.

24. Yes, I think so now - I'm sure this is something I like to work in.

25. Yes, I think so, because I will be prepared to perform my job much better and I will be able to teach others what I have learned from this class. 
26. Well Project Independence paid tuition and gave us the necessary support to complete this goal. I think that is a kind of reward for us.

27. Sure, I would like to pursue additional education following training because I got the discipline necessary to follow instructions and I think this is a great opportunity being at home with my family and getting education on-line.

Comments: Excellent instructor. The development of the class was perfect. I liked the lectures very much. In general I like it.

Survey 133:

21. I am currently not in this field.

22. I thought this class was taught very well. I think I might have added more discussions.

23. Even though I am not currently in this field, this class has given me a better understanding of people with disabilities. It also has helped me see how important it is to give them every opportunity that anyone else has.

24. Does not pertain to my situation.

25. Does not pertain to my situation.

26. No

27. This is a very interesting field - I might continue education on it.

Comments: I think that this was a very helpful class. At first I wasn't really sure what this class was about and was going to drop out because I felt like this class wasn't for me, but I'm glad I did take it because it has taught me more about people with disabilities.

Survey 134:

21. a) Self motivation; b) Advocacy; c) Determination

22. None that I can think of.

23. I feel that anyone working in the disability field should take this class. It was very informative and helpful and so was the instructor.

24. Yes, because I feel that I am an asset to the disability field.

25. Yes, because I have received helpful training in the disability field.

26. Yes, I will receive a $2 \%$ raise.

27. Yes, I will be pursuing further education. I want an Associates degree in Disability Management.

Comments: I feel more valuable in this field now that I've taken this class. I am very grateful for this class and the instructor. Thank you Sheree Dickens.

Survey 135:

21-28. N/A

Survey 136:

21. a) Recognize disabled; b) Offer help

22. Have samples of each assignment

23. --

24. Yes, because I am a good worker.

25. --

26. --

27. Associates degree

Comments: --

Survey 137:

21. a) I demonstrate good organization; b) Excellent supervision, and; c) The ability to get the job done. 
22. a) Setting goals; b) Respecting consumers needs; c) Assisting consumers goals.

23. No

24. Yes, I like what I do and wouldn't change anything just because I did bad in this area - there is always need to improvement on my part.

25. In the years to come - I still have a lot to learn.

26. Yes, I get financial aid and work-study.

27. Yes, it allows me to build and learn more about the profession and myself.

Comments: I think you all did a very good job in teaching this course and I would recommend it to anyone who wants to try at it.

Survey 138:

21. a) Consistency; b) Patience; c) Projects delivered on time.

22. a) One on one with some of the classmates and/or subjects; b) More internet assignments due to the up and coming internet world; c) More immediate critique.

23. Should have more than one subject.

24. I am not working at present because I am a person with a disability.

25. Who knows if I can be hired at this time.

26. Yes, I needed three more units to fulfill my grant requirements.

27. Yes, I need to take an additional course to be able to work at home.

Comments: Sure am glad the instructor was not harmed in the recent fires or the students, but wished that her sub would have gotten us work to do while the world readjusted.

Survey 139:

21. a) Better communication with patients; b) A lot of patience; c) Ability to ask more questions.

22. a) More time for some assignments; b) More discussion boards; c) A research paper.

23. --

24. Maintain, because I love what I do.

25. Eventually, when I finish school into a RN position.

26. If I am working towards a degree that will benefit my job, they will help pay for school.

When I am finished some jobs will help to pay back student loans.

27. Pursue more education. I want to be a Nurse Practitioner. I just love what I do and I like to

help people.

Comments: --

Survey 140:

21. --

22. --

23. --

24. Yes, it is so rewarding helping individuals with disabilities.

25. Yes

26. No

27. --

Comments: --

Survey 141:

21. a) Better understanding of the challenges of the developmentally disabled; b) More realistic goals; c) Better appreciate small accomplishments.

22. a) Techniques for blind/vision impaired; b) Adjustments to screen materials to accommodate zoom text; c) JAWA and WINDO eyes.

23. a) Very well organized; b) Weekly assignments and resources easy to locate; c) Topics related to each other - good flow. 
24. Want to do better as an instructor. I will continue to teach.

25. My agency isn't structured for promotions. I plan to work with a teacher training program.

26. No incentives at all.

27. My goal is to earn the Masters degree in rehabilitation of the blind - teaching.

Comments: This class has been an eye-opening, learning experience for me. I knew nothing about these disabilities. I will be making adjustments to accommodate my students and recognize their accomplishments.

Survey 142:

21. a) Understanding of ADA; b) Organizational skills; c) More knowledge on setting consumer goals.

22. a) Do not add to the assignment once the assignment is given; b) When a deadline is given, stick to it, e.g., Sat. night was deadline for discussion board, then it was changed to earlier in the week if we wanted full credit.

23. Classroom meetings with the on-line course were very helpful and informative.

24. Yes, I like my job.

25. If I continue with courses, it's possible.

26. Tuition paid by my employer.

27. Yes, this class was kind of like a test for me to see if I could go back to school after so many years - and I now know that I can do it.

Comments: Our on-site instructor was a big help.

Survey 143:

21. a) Person centered planning; b) I have more knowledge of assistive technology; c) I am more aware of the way people with disabilities are treated with disrespect.

22. a) More info on State Regulations; b) More info on statistics; c) more info on Child

Development.

23. --

24. Yes, because I love working with people with disabilities.

25. Possibly, because they are going to know that I have more knowledge.

26. Yes, a wage increase, but right now we have a wage freeze.

27. Yes, I would like to get a teaching credential to teach Special Ed.

Comments: --

Survey 144:

21. a) The first strength that I demonstrate within my work environment is being able to communicate with my clients; b) The second strength is that I let my clients make some of there own decisions; c) The third strength is I give encouragement to them.

22. I felt that there was not anything that needed to be improved with the curriculum and the instruction of the class.

23. I do not have any other comments regarding the classroom instruction or curriculum.

24. I am more likely to maintain my employment after completing the coursework. I am in the medical field. My major is Nursing. I think that it is important to know about developmental disabilities.

25. Yes, following training I am more likely to be promoted. I am in the Nursing program and I think that I would make a great nurse.

26. No, I am not offered rewards for participating in coursework.

27. Yes, I am more likely to pursue additional education following training because I am in the Nursing program here at Grossmont College.

Comments: There are no additional comments that I would like to make about the classes. I

learned more than I knew before about people who have developmental disabilities. 
Survey 145:

21. a) More comfortable providing information relating to consumers self-advocacy; b) I feel more capable with conducting IPP's with consumers and really trying to see that their wishes are upheld; c) I feel more comfortable sharing new skills with staff and co-workers.

22. Maybe a little bit more on how to communicate with those who are developmentally disabled. 23. --

24. Yes, I learned a lot more about rehabilitation services and feel I could be more informative when speaking with parents or care providers about our services.

25. Yes, I am more comfortable with being able to explain different disabilities and in providing suggestions in what programs may or may not be suitable for certain individuals seeking services. 26. Tuition payment

27. Absolutely! I learned so much from this course and I am trying to receive my Disability

Services Management Certificate.

Comments: --

Survey 146:

21. a) I communicate with the people who have the developmental disabilities; b) I provide support; c) I interact with them.

22. I don't think that anything needs to be improved. I think that the curriculum was very helpful to me.

23. There are no other comments.

24. Yes, I am likely to maintain my employment after completing the coursework, because I enjoy working with people who have developmental disabilities.

25. Following training, I think that I would be more likely to be promoted because I provide skills that would allow me to become successful in helping others.

26. No, I am not offered rewards for participating in the coursework.

27. I am more likely to pursue more additional education following training because I am working toward my degree.

Comments: There are no additional comments. I really enjoyed being in the class.

Survey 147:

21. I don't work in the field as of yet.

22. --

23. The knowledge I have received in this class will be used when I work in the field.

24. --

25. --

26. -.

27. Yes, because one day I want to be a coordinator.

Comments: --

Survey 148:

21. I am not working right now. I am going through a vocational rehab program at Grossmont College.

22. This class was informative and I enjoyed it very much.

23. --

24. N/A

25. N/A

26. N/A

27. Yes, I am in the Disability Services Management program at Grossmont College. I plan on finishing the program and going on with my education. 
Comments: I enjoyed taking this class. I enjoyed the flexibility and the instructor was easy to access if I had questions or comments. Again, I would recommend this class to anyone interested in learning techniques.

Survey 149:

21-27. No answers.

Comments: --

Survey 150:

21. a) Teamwork, working together, openness, transparency in the workforce; b) Building good relationships with individuals we are serving by understanding where they are coming from, their needs, wants, likes, dislikes and preferences; c) Periodic review of individual with disabilities record to evaluate results of programs given them - where did we fail and why? What positive result was attained, and why? What needs follow-up or need more time to attain good results?; c) Find out the positive and negative result to be able to assess if the service/program is worthwhile pursuing.

22. a) For better understanding and better results, I would suggest that at the beginning of the class the instructor go over the syllabus with students and stress that they have to re-read for thorough knowledge of what they are expected to do and learn. We are all working and busy, given forward instruction is very essential so we go straight and give weight to the pointers taught us. Maybe I am speaking for myself - this is my first time to go on-line. Up until the $3^{\text {rd }}$ session, I did not get the whole picture of how it is to go on-line (in short, do not wait till the last moment to submit reading all posting from other students). I find very important giving me a lot of other insights about the subject matter. At first I just followed to give one comment, thinking I have fulfilled the requirements; b) To understand the deficiencies/mistakes/or omissions from the assignment submitted by students (to be able to improve the next assignment, PROMPT GRADING every assignment, submission will be of importance; c) I would say we are all aware of Murphy's Law, better communication between Santana School and Grossmont Staff or Administration. To cite the incident, we students all came last Nov. 11, 2003 and the instructor was there and so was the guest speaker. But there was no one to open the gate/school room for us. Instructor said she was made to understand at the very beginning of the class that we will be able to do classes on this day. Result, it was the student's unanimous vote to hold the class in the parking lot to save time as we cannot come for another day class extension - plus we do not like to miss the speaker. With the weather that we have to withstand, I am having a cold today. I will find out next meeting how my other classmates fared with that parking lot classroom. Just to let you know - this is important.

23. Class directory to be distributed to students, including their workplace and position. This will foster better camaraderie and closeness amongst each other. Good networking field and information center from whatever may arise/needs.

24. Honestly speaking, I am not working with people with developmental disabilities, but somehow maybe related. I am Activity Director of Hope ADHC. I don't deal with DD as we describe in this subject, but I deal with people with dementia $\left(1^{\text {st }} \& 2^{\text {nd }}\right.$ stages $)$ who have behaviors similar to people with developmental disabilities, maybe in a lesser degree. I deal daily with people who are elderly ranging from 80 to 94 years of age who have different ingrained characters of their own. But I find after my class here, I am very much interested working to support people with developmental disabilities.

25. I believe so, if I was working in any office for the developmentally disabled. I will be promoted because, my passion for caring is innate and with the knowledge I have gotten in this course. It has enhanced me in various aspects, not only caring, this course opened to me a deeper understanding of people with disabilities (specially that their bazaar behavior is a way of their communicating their wants, needs, likes and dislikes and is not just behavior). Looking at life 
quality gave me an understanding that they are people with emotions and feelings like us and should be dealt with with understanding, sympathy and love.

26. In my present work as ADHC Activity Director, my boss appreciated my studying the course. She knew that it will give me knowledge that I could use in our workforce, especially when I give in-service training. The things I have learned, I will tailor-fit to our need at ADHC (understanding the feelings, anxieties and frustrations of our participants, the elderly, who once were big bosses at their work, business owners, people who have freedom in all that they did, but now do not have that much freedom because of the limitations that their age dictates). This in-service will be of value to our staff assistants and aids. As a token of appreciation, I am allowed to take off from work 1-hour ahead to beat the traffic and be on time for my class, without deduction from my salary. A small thing, but the understanding and her appreciation of what I am studying counts. 27. Yes, that I would like to ask you advice on what other courses I can take to enhance my knowledge and to be able to work in that field as educator, program developer. I am a Bachelor of Arts (Pol. Sci. Major), law student up to $4^{\text {th }}$ year. I have worked with 200 people as a manager of an apparel company. I will appreciate your feedback (chitdomingo@sbcglobal.net)

Comments: My instructor is good, very knowledgeable of the subject matter, conduct classes in a vibrant atmosphere, always smiling. I wish we would be furnished list of books/material for the special people with mental retardation, autism, epilepsy and cerebral palsy that we could use.

Survey 151:

21-27. No answers.

Comments: --

Survey 152:

21. a) Help to provide a better quality of life to persons with disabilities; b) Provide better communication with them; c) Understand the many aspects of disabled persons in society.

22. Class is great but there is a lot of valuable material to be covered in such a short time. More time required! Try to work as a team in the discussion board instead of an individual basis. This will give more to discuss. Try to obtain more examples from real life situations. This will help the class a lot!

23. None! Class is great!

24. Yes, and I will continue to search for more classes like this that provide me more education.

25. Not yet!

26. Not working in the field at the moment.

27. Yes, these types of classes are very interesting - there are so many things to learn outside from classes too.

Comments: Instructor provides all the necessary information and makes the whole class work together.

Survey 153:

21. --

22. --

23. I really enjoyed this class and found it to be very informative.

24. Yes, but in June I will apply for an OTA position with the district.

25-27. No answers

Comments: --

Survey 154:

21. a) I can establish the communication level that is appropriate for each consumer; b) I can setup goals and tasks that the consumer can easily understand and follow; c) I can help family and others involved with a consumer understand the consumer's needs better. 
22. I think more input from the instructor as to how we are responding with our answers to the objective being taught. I never really understood at times if I was getting the point that was supposed to be understood.

23. I wished our grades were posted a lot quicker. I cannot tell if I am submitting my answers in the correct format that is expected. I am still waiting in the last week of the class for grades for assignments that are 3 weeks old. This does not help a student understand what he or she needs to put more work into. This part I am VERY unhappy with.

24. Yes, I work for myself and have 4 facilities. This class was so that I could enrich myself in the ability to understand how to meet in the needs of this very special and unique group of people. 25. This is not applicable to me.

26. N/A

27. Yes, always.

Comments: I did learn a lot from the course material. I just thought more feedback would have been nice. Also, the grading issue really bothered me. If you instruct the student body of the class from the beginning that they must answer 2 discussion boards before the deadline each week of Saturday evening, then this should be what is expected. Whether or not I answered both of my discussion boards in one day or spread them out over that week, really is not and should not have been an issue. As long as I was not late, which I was not, I should get the full credit for my participation. Also, of course, being on topic is important and answering any other questions that you post on that discussion board should be answered. I did all of this, yet I was given feedback that I did not get all of the points for my participation because I answered both discussion boards on the same day. Well, I do not think this should have been an issue at all. I answered the discussion board two days before the cut-off (Sat. night). Do not forget that some of us have large facilities already that we run quite successfully. I am successful because I work 18-19 hours a day and am hands-on at every facility everyday. Just fitting this class in at the end of a long day and entering the quality work I did is quite an accomplishment for me. Docking me for a dual entry in one day was almost like a slap in the face. After all, this was not criteria posted for everyone to follow, that we could not make a dual entry in one day. Anyway, this is just my criticism of this particular part of this instructional team. Otherwise, I was happy with this class. Thank you for being interested in our HONEST opinions.

Survey 155:

21. I now look around for entities that could aid handicapped people so I guess that would be perception. Another would be tolerance for their needs and maybe gaining more patience. Anther strength would be to be more attentive at work due to the discussions.

22. More discussions. I really have no other recommendations. I had no problems or disagreements with the curriculum.

23. No

24. I do not think so because that usually depends on the employer or the situation I'm in uncomforting, lack of interest in the job.

25. Maybe I do not believe a class based upon health and disabilities would really up my chances at being promoted.

26. No, I do not receive any rewards that I am aware of unless you mean moral, and in that case, I do not.

27. -

Comments: I thought the class was great in its organization of the assignments.

Survey 156:

21. a) Better listening skills; b) More knowledge; c) An ability to meet challenges from day to day that require immediate decisions. 
22. a) One class meeting with the professor and facilitator; b) Study groups and teams to do projects; c) More time to discuss questions that we may have.

23. I think that the facilitator should not be focused on what he/she has to get accomplished to pass their classes, when they are on our class time teaching us. More education on getting to websites and homework. A facilitator that is willing to go to any lengths to help you achieve what you want out of these classes.

24. Absolutely, I don't think I would be very nice to be around if I did not get to see my students everyday. I love my job, my boss, everything about the place. When I wake up in the morning I don't dread going there, I look forward to it! I love it when I get greeted with the big smiles, the pat on the back, and a friendly rub on my shoulder. You couldn't get any better than that.

25. I probably will because I'm recognized as an exemplary employee - loyal and trustworthy. I know I will definitely be getting a raise after June - we are on a raise freeze due to the budget cuts.

26. Yes, my company will help with my schooling and the cost of books. They feel that I'm a good investment.

27. Probably, it is what I love to do. I will need additional education to further my career. I also have a passion for school and learning something new.

Comments: I'm sorry I was later on a couple of things, but the fire caused me to be very emotionally upset and in need of counseling over what I had witnessed (don't worry, it's been taken care of). The following week I got sick from cleaning up the debris and ash, and on top of that I got the flu a couple of days later. WHEW! I really did have a fun time in this class, and it was very hard at time to get my homework being since my computer went down 1-week prior to starting class. Thank you for all your help. I would really like to meet you in person. Take care.

Survey 157:

21. a) Knowing ADA considerably more than I did; b) Advocacy; c) Organizational skills. 22. -

23. Very helpful having a meeting with instructor at SMSC - especially not having been in school for so many years. Some of us needed that extra help and explanations.

24. Yes, I like my job very much.

25. Well, I will be more capable and knowledgeable and be more sure of myself, so who knows maybe later after I complete additional classes.

26. Yes, my tuition is paid to take this class and I believe I will get a $2 \%$ raise. Surely I didn't do it for $2 \%$.

27. Yes, I enjoyed taking classes. At first I was thinking "why did I do this", then after I had a little more confidence and decided I could do it, I really enjoyed the class.

Comments: Very interesting class. I really needed the extra help I received from the instructor at SMSC, as did a lot of us who had not been in school for several years. Thank you.

Survey 158:

21-27. No answers.

Comments: I think the class was great - I learned a lot.

Survey 159:

21. a) I am much more comfortable in discussing a variety of issues concerning disability issues. I feel I have much more knowledge and knowledge is for sure, power; b) I also have a new sense of sensitivity towards vocational and employment issues; c) I also feel much improved in the area of directing individuals to resources and information. There is a lot of help out there when you know where to look. 
22. It is difficult for me to think of three suggestions to improve this class, but if I have to say I think having an assignment in which we had to be "disabled" (if we aren't already) ourselves if only for a few hours.

23. I totally enjoyed and learned a lot from this class. The discussions gave a big diversity of opinions which was very interesting and informative. Mari was great as a teacher and quick to respond to any questions or email sent.

24. Yes, I am more likely to maintain employment after completing this class because I feel more comfortable with the subject.

25. Yes, I am more likely to be promoted because the more you know the more responsibility is given to you.

26. Yes, tuition will be payed if it pertains to learn more about this subject.

27. Yes, because now that I am learning more other interests and opportunities are appearing. Comments: I love that you have offered this as an on-line class. I love to do on-line classes and seem to learn more that way.

Survey 160:

21. I do not work at the present time. I am in a vocational program at Grossmont College Disability Services Management. I learned a great deal from taking this class.

22. I think this class was very well done and I can't think of anything I would change. I enjoyed it very much.

23. No other comments.

24. N/A

25. N/A

26. N/A

27. Yes, I am going on with my education of disability services management. First I am going to complete my vocational training program. Second, I plan to pursue my educational goals. Those goals include obtaining a degree at SDSU.

Comments: Our instructor was very good. She would answer any questions I had about the course. I felt she was in touch with what was important for a beginning course in disability and society. I would recommend her highly to anyone who might be considering this course.

Survey 161:

21. a) Much more aware of words I use to describe people who have disabilities; b) More involved in making sure those I know in that situation are being taken care of; c) Much more informed and able to inform others about what help exists out there.

22. I was very confused in the beginning about how to get started and when or what to turn in. It took me a little while. I think there should have been a slide show for every section. I think that the discussion boards might be a little more organized with the topics in one area and people's comments in another.

23. Nothing negative. I really enjoyed this class.

24. Yes, I now know the importance of my employment and I am much better prepared to do the work required of me. I feel strengthened in my position.

25. Yes, I think that training and the experience I gained here will definitely help me in a promotion.

26. I think that extra payment is offered for such coursework, but I did not know about it so I did not receive any.

27. Yes, I do feel like I have learned a lot but there is always more to know.

Comments: This was a good class. I am glad that I took it. 
Survey 162:

21. a) Better understanding of others needs; b) Understanding how the society plans to help with the disabled; c) How people view each other and why.

22. A little more direction on the discussion board.

23. -

24. Yes, because I feel as though I'm contributing to society by working with autistic children.

25. No, not sure.

26. No

27. Yes, to further educate myself.

Comments: -

Survey 163:

21. a) I am more understanding of the great detail needed to explain things to people with disabilities; b) My manager and myself have noticed I am more patient while assisting people with disabilities, and; c) I have been speaking with the owner of the business so that we could make the work place more comfortable for the disabled.

22. I had mentioned that I would love to spend an entire day with the child I had interviewed for our homework and observe her interactions with others among different ages and races.

23. I found this class to be very interesting and personally helpful. The curriculum given, made us put our own thought and opinions into our work, which would actually evaluate our personalities. This is my first on-line class and it was a positive experience.

24. Yes, I am in sales and I get the chance to personally deal with a variety of people. Sometimes I get discouraged with some customers, however, there are those who appreciate your help and express their gratitude.

25 . No, in my office there are only three workers, myself and two ladies whom are the owner's sisters; however, I am treated as family and I am given the same respect and treatment they do. 26. No, my work has no rewards for my coursework. I do appreciate the fact that my hours are very flexible and always change as my school schedule changes every semester.

27. Yes, I have always been fascinated by people with disabilities. For some reason the different disabilities and diseases have always caught a special interest to me.

Comments: -

Survey 164:

21. a) I am able to recognize and address the needs of others; b) I have gained knowledge of alternate resources; c) I am able to talk to people with disabilities more comfortably, knowing that they are as strong as me and I don't have to feel sorry for them.

22. I think more videos would be helpful and interesting. I also think that if the book is really necessary for the class, there should be more assignments in the book.

23. For an 8-week class, I think this was very well organized. There were enough assignments to give us a good understanding of the subject. The workload was not overwhelming and the time given for each assignment was very reasonable,

24. I don't think my work relates to the coursework.

25. No, not related to work.

26. None

27. Not sure

Comments: -

Survey 165:

21. Person Centered Planning - a) I am more aware of the respect shown for the people that I work with; b) I am more interested in making sure that the consumers are able to have assistive devices and what one is appropriate for the individual. 
22. I would like to see the class have more information on the programs available to people with disabilities, some statistics on a regional basis; like there are $1,000,000$ people with DD being served in CA, and so on. The last area that might be interesting to learn is about how the new regulations in CA are going to affect the people with DD in CA.

23. I loved being able to do all the work whenever I got a chance, however, I missed the one on one interaction with the teacher.

24. Yes, this is what I do. I love working with people with disabilities.

25. I sure hope so! Why? Because I care about the people, have a lot of experience, and I have a lot of knowledge about Developmental Disabilities.

26. I believe that we can get a percentage raise, however, because of the budget cuts, our wages are frozen.

27. Yes, I would like to teach Special Ed.

Comments: -

Survey 166:

21. Thank you. If I would not have taken this class I would never have been the struggles and hurdles that disabled individuals face even today. Wonderful class.

22. I wish it was longer. I think that there are a lot more issues to cover, but in the amount of time I had, I learned so much.

23. -

24. Yes, I feel that I have equal opportunities and will continue to have them.

25. No, I was not taking this class to be promoted.

26. No, I took this class on my own.

27. Yes, I would one day like to become an accountant.

Comments: -

Survey 167:

21. a) People first language; b) Understanding of history of disability rights movement; c)

Knowledge of assistive technology.

22. a) Have students read the entire "No Pity" book; b) Have a final exam rather than a final project; c) More instructor input on discussion boards.

23. Good way to ease into the field. Good beginner topics.

24. I am not sure, as I had already been working with people with disabilities for 3-years prior to taking this course. For me it was a good review with some new information.

25 . No, the requirements for promotion are extensive.

26. Reimbursement by employer.

27. Yes, to better advocate and serve people with disabilities.

Comments: Instructor was very nice.

Survey 168:

21. I don't work in the field yet.

22. I really like the instruction of this class.

23. This class is perfect.

24. I don't work in the field yet.

25. -

26. -

27. -

Comments: -

Survey 169:

21. a) Better advocate; b) Confidence; c) Respect 
22. None

23. Very informative

24. Yes, I feel I will be able to maintain my job due to the new skills that I have learned.

25. Yes, I believe I will eventually receive a promotion due to my disability awareness skills that I have received from taking the Disability Management courses.

26. This course was offered by my employer as a reward, tuition free and also a raise.

27. Yes, I will be pursuing additional education. I would like to receive a degree in the disability field.

Comments: I feel that Mari was very informative in the instruction that she provided during this course.

Survey 170:

21-28. No answers.

Survey 171:

21. a) Using people first language; b) Self advocacy; c) Observant.

22. Field trips and hands-on assignments.

23. I like the class a lot. I learned a lot, feel better equipped and realized I have a lot more to learn.

24. I am better equipped to start my social work degree.

25. No

26. No

27. I am pursuing a degree in Social Work at SDSU with children.

Comments: Feel like more people should be encouraged to take this class so they will learn and have open eyes and hearts.

Survey 172:

21. a) I understand the individual needs much better; b) I'm more secure when planning goals with them; c) I have a very wide knowledge about all kinds of devices that I didn't know before this class.

22. I would like to have more information about resources in general. Something that is very important for me is to have the experience to initiate the plan of work with an individual. To learn a little bit more about recreation.

23. I never thought about having a class on-line. At the very beginning I was scared about the discipline we should have to keep track on the assignments. I thought I was going to be bored, but I found out my class was so interesting that kept my attention and enthusiasm - it is the most wonderful thing that has happened to me lately. The instruction was very clear and the development of the curriculum was perfect. Our instructor was always ready to answer our questions right away.

24. Sure, because with this course I'm more confident myself. I love people more than before because I understand their needs and now I can perform my job much better.

25. Yes, I'm a community support specialist with the experience of 2-years working with people with disabilities and the training I'm having, I will be able to be promoted anytime since I will be more professional for the organization.

26. I work for Project Independence and I really couldn't believe when they offered us these courses. That was something that I was looking for and the barrier was the time to go to College and the money to pay tuitions. I never thought about having these classes on-line either and that Project Independence pays everything and offered us the support we needed in order to complete these classes. I think that is a kind of reward. I'm so happy working to PI.

27. Yes, of course. I would like to know what other classes we are going to have and when they will start. 
Comments: Thank you for all the support, for the materials, the lectures, the examples. In general, everything was just perfect for me.

Survey 173:

21. The three strengths that I demonstrate within my work environment that are a result of this class are: a) Being a caring person; b) Helping others accomplish their goals; c) Sharing my knowledge of skills with others.

22. I don't think that any improvements are needed for the curriculum and instruction of this class. I think that the curriculum and the instruction were well taught.

23. I learned a lot from the classroom curriculum.

24. Yes, I am more likely to maintain my employment after completing the coursework, because my employment will give me the skills that I will need to use when I become a nurse.

25 . Following training I think that I would be more likely to be promoted because my supervisor would see that I am doing a great job.

26. I am not offered rewards, tuition payment, for participating in the coursework.

27. Yes, I am more likely to pursue additional education following training because I am in the medical field, and because I would get more training to be prepared for the medical field.

Comments: I learned a lot by being in the classes that I have taken. The instructor taught the class well. The instruction and curriculum was good. I understood everything.

Survey 174:

21. a) Showing good work skills; b) Being a team player; c) Good quality care.

22. I have no suggestions to improve the curriculum. I feel like the curriculum was very useful.

23. There are no other comments regarding the classroom instruction or curriculum.

24. Yes, I am more likely to maintain my employment after completing my coursework because I enjoy working with disabled people.

25. Following the training I am most likely to be promoted because I have been asked to do care for another client in a different program.

26. No, I am not offered awards.

27. Yes, I am more likely to pursue additional education following training. I am in the RN program here at Grossmont.

Comments: There are no more additional comments.

Survey 175:

21. a) Interest; b) Compassion; c) Fulfillment

22. Needs no improvement the way I feel.

23. People in this field should be required to take classes like this to help the disability movement.

24. Yes, because I love this field. I can be apart of a great movement.

25. Yes, because if I get a certificate in disability training and perform my job to the standards of my place of employment, I will climb the ladder.

26. Pay raise and opportunities to get promotions.

27. Yes I will. I always wanted to get a College degree, but I never found a field I liked. I'm 45 and found it.

Comments: I'm glad I took it, but I'm sorry I was late in homework.

Survey 176:

21. None

22. None

23. Great course. I enjoyed it and learned a lot.

24. No, this has nothing to do with my job. I am pursuing higher education for myself only. 
25. No, this has nothing to do with my job. I am pursuing higher education for myself only. 26. No

27. Yes, seeking degree in Anthropology.

Comments: This survey does not apply to me at all, really. Just checking off the box for GE requirements at SDSU. It was a great course. I found it interesting and I learned a lot.

Survey 177:

21. a) Have more knowledge about disability rights movement; b) Not afraid to ask questions about a person's disability; c) More aware that a person's attitude towards a person with a disability is important.

22. I really don't have any suggestions to improve the class. I think that the class is pretty straight forward and for a web class, it's easy to access.

23. -

24. This question doesn't really apply since I'm not employed at the moment.

25. N/A

26. N/A

27. N/A

Comments: -

Survey 178:

21. a) I'm better able to talk to co-workers with disabilities and find it easier to be around them. Before this class I was always a little discouraged to go up to them and talk but now I will usually stop and say Hi and talk a little bit with them; b) I find myself discussing topics of disability with my boss and different things that we could do to make this a more normal environment for these people with disabilities; c) I ask other co-workers what they think about the disability situation that we have here at work and I find myself talking to different individuals about their opinion as well.

22. I don't really think that there are three things that could be done to make this class better. It was already a great class and had everything that a normal class would, except you pretty much get to make your own schedule. The discussion boards were a great way to make everyone in the class participate, and some of the other assignments involved researching some things. So all in all, it was a great class.

23. Great class - thank you Mari.

24. Yes, I would say that I am more likely to maintain my job since completing this course because at first I didn't really like working in a bigger work environment because there was such a big diversity of people. But after taking this class, I realize that they are all just the same as me. 25. I really do think I am, because it is such a big industry that I have talked to my boss and asked if there was room for advancement following training and he said definitely.

26. I'm not really sure on this one, but I don't think so.

27. Yes, I do believe that I am still going to go to school following training to further my education and try to advance in my career.

Comments: -

Survey 179:

21. a) Ability to recognize problems at work; b) Advocacy; c) Self actualization.

22. No improvements needed - very well put together class.

23. The text was very interesting and helpful.

24. Yes, this class motivated me even more to continue in the direction I am going in life.

25. No, to be promoted I will need a higher degree.

26. Yes, tuition reimbursement.

27. Yes, I am working on an AS degree. 
Comments: None at this time.

Survey 180:

21. --

22. -

23. I really enjoyed it and found it to be very informative!

24. Yes, but in June I will apply for an OTA position within the district.

25- No answers.

Survey 181:

21. a) Knowledge of consumer's rights; b) Understanding the history of the struggle; c) Respect of consumer needs.

22. No suggestions - everything was great and I learned a lot.

23. None

24. Yes, I will maintain my employment. I took the class because it was a Regional Center requirement. I love this field and I enjoy what I do.

25. There are no promotions involved. I am already the administrator of the group home. I am looking to open up a second group home.

26. No, I am not offered rewards for participating in coursework.

27. I love to take some more classes in this field. I would be a better employee for the organization, be better equipped to deal with a higher level facility and be a better employee for the consumers. I am also taking some local classes at the hospital for CEU units for additional training.

Comments: I do not have any additional comments.

Survey 182:

21. a) Know more about ADA/Civil rights movement; b) Consumer rights; c) First people language.

22. Nothing

23. None

24. Yes, enjoy working with people with disabilities.

25. Most likely be promoted because of the experience and courses I took regarding people with disabilities.

26. No - non-profit organization. SMSC pays for my class.

27. Yes, to better myself.

Comments: No

Survey 183:

21. Awareness of the needs of people with disabilities.

22. I can't think of any because it is good as it is right now.

23. I would highly recommend this to my peers.

24. Yes

25. No, because this is totally different from my current job.

26. No, this came from my own pocket.

27. Yes, but undecided yet what would be the next and when.

Comments: Mari, you are the BEST - keep it up!

Survey 184:

21. a) Happier; b) More knowledgeable; c) More informed and ready to help.

22. None at this time.

23. Great class! 
24. Yes

25. Yes

26. Yes

27. Yes

Comments: Great professor! She's very bright!

Survey 185:

21. a) I have better knowledge about the disabled people; b) I know what they went through to get the rights movement started; c) I understand their feelings better than I did before. With knowledge of this I can respect and be more understanding of a disabled persons needs.

22. The course was so fast and straight to the point. I cannot really think of any suggestions. I can just speak on what is already in place for this course. The contact with the students was great. I always received an email concerning the class, which made me feel good because I knew the teacher was in contact with me.

23. The instruction was very specific in detail of what was needed. Everything was on the website in order. It was very sufficient.

24. I am not for sure of my employment right now because I am on disability from my position. When I return to work, I don't know if they will accommodate me with another job or if I am going to have to find me another one.

25. On disability right now, however, if I am working in an environment where I may qualify to be promoted I will certainly not pass it up. I feel after the training I am able to be promoted.

26. No

27. Yes, I am probably going to try to complete the major for becoming a disability worker. I have the personality that is needed out in the world. I love to help people - that has been my line of work since I was a teenager.

Comments: I really enjoyed learning from this on-line course. It is very convenient for me. The course was taught very good because it is in order, no confusion, and the teacher was very clear and specific about what she wanted.

Survey 186:

21. a) Consumer choice; b) Accessibility; c) Communication

22. More towards developmental disability.

23. Great instructor! Thank you for letting me take your class.

24. Yes! I love my job. I have worked for the same agency for 13 years. This class just helped me get back on track.

25. No, I run a very successful day program and this is where I want to stay.

26. Yes, but I never put in for the reimbursement. I wanted to take the class myself.

27. Yes, I would like to take the next class that follows this one.

Comments: It's great to complete this course on-line. You feel like you have the support as you do in classroom settings. Plus you can do it on your time table.

Survey 187:

21. a) The assignment website was very user friendly. I like the links to related subjects that were often included; b) I also liked how we got feedback on all of our assignments; c) Lastly, the coursework was challenging and not overwhelming, which is a good thing.

22. None. I enjoyed this class very much.

23. I learned quite a bit. The history of disability rights was very interesting to me.

24. Yes, I work with the public. It is helpful to learn to deal with all sorts of people more effectively.

25. Yes

26. No 
27. Yes, you can never learn too much.

Comments: -

Survey 188:

21-27. No answers.

Comments: -- 
Appendix D

Supervisor Responses to Qualitative Responses 


\section{Questions}

21. What are the strengths demonstrated by the employee(s) that you could relate to classroom instruction?

22. What three suggestions would you recommend to improve the curriculum and instruction?

23. Other comments regarding the classroom instruction or curriculum?

24. At your agency, do employees taking the classes sponsored by the CRP-RCEP maintain their employment longer than those who do not take coursework?

25. Following training, are employees more likely to seek or gain promotions?

26. Are employees offered rewards and incentives for participating in coursework?

27. Are workers more likely to pursue degrees or certificates following their initial training?

Additional comments

That you would like to make about the classes, instructor, instruction, curriculum or any other issue that you consider important.

\section{$\underline{\text { Answers }}$}

\section{Survey 1:}

21. A) Better understanding and awareness of the needs of their assigned group. B) Behavior management understanding.

22. Unknown

23. -

24. Possibly, although he/she may not stay with our organization - they stay in the field of developmental disabilities.

25. No, lack of financial resources.

26. Yes, can lead to a slight promotion depending on amount of coursework. May received certificates, recognition from employees, employer, etc.

27. Unknown

28. -

Survey 2:

23. A) People seem to have a better grasp of abuse and neglect. B) Some people are more able to talk about vocational goals and how to reach them.

24. The feedback I have received is that people value instructor information more than peer information limiting life experience discussions and increasing instructor information.

25. -

26. We hand picked employees who had already demonstrated longevity.

27. Some of the people we sent were already interested in promotions, for others there was no change.

28. In our job culture, there is some prestige attached to being chosen to take special classes. The certificate offered is also an incentive to staff.

29. Some employees were very interested in getting the certificate.

30. I hope that these classes continue, as more and more people move to supported employment, we will need employees capable of effectively supporting them.

Survey 3:

23-30. No answers.

Survey 4: 
23. A) Understanding of people's rights. B) Making plans using person's goals. C) Knowing what is abuse and neglect.

24. A) Limit life experiences - focus more on lecture information. B) Encourage different agencies to commit to participate. C) Use of PowerPoint (actually) using it.

25. -

26. We took only employees who were employed for 3-years or longer to initially take the courses to see if they would benefit.

27. If there were openings, I feel they would seek a promotion.

28. No, although I think if funds were available some kind of incentive program could be setup.

29. No, I do not think my employees are likely to pursue degrees.

30. -

\section{Survey 5:}

23. A) Openness to learn and understand. B) Teamwork philosophy being exercised.

24. More time allotted for instructor information as opposed to peer stories - tend to miss out on valuable info when stories happen.

25. Howard is a good source of information - the guest speakers were outstanding.

26. We chose the employees who would attend, and they tend to be long-term employees already.

27. Some, it depends on the person. There are some we sent to get information, while others asked to go.

28. No, nothing set-up at this time within the agency.

29. No, our employees tend to attend what they're asked to, but rarely seek out info on their own.

30. N/A

\section{Survey 6:}

23. A) Communication; B) Support; C) Dependability

24. A) Environment; B) More hands-on; C) I cannot think of anymore - I find the curriculum to be very good.

25. None

26. I am not sure - I've only been with the agency for 6 months.

27. I doubt it - promotions seem very hard to come by.

28. No

29. I believe so. I plan on pursuing my AA. With all the info I'm receiving I am inspired to go back to school.

30. -

Survey 7:

23. A) The ability to hold an in-depth conversation regarding rights. B) Staff becoming advocates in the community. C) Acquired self-assurance of using the websites.

24. A) Increase lead-time for ordering books. B) Keep the facilitators in place during all five classes. C) Remembering that facilitators take high tech and make it personable.

25. The class meeting once a week as a group with the facilitator not only helped to exercise what was being taught, but also encouraged a sense of bonding.

26. This is the first time that on-line classes have been offered.

27. I can see where the employees would be more likely to pursue promotions.

28. A grade of " $C$ " or better and the class unit costs are reimbursed.

29. Most all who enter our field are interested in learning. Having a certificate to prove your knowledge becomes incentive to pursue your education. 
30.

Survey 8:

23. A) Increased awareness of respectful language. B) Confidence sharing ideas to personalize support. C) Broader awareness of support systems to people with DD.

24. Perhaps an assignment involving doing a presentation to a small group outside of class setting (i.e., a staff meeting or with a support team).

25. -

26. Too soon to tell. Most employees who have taken class are already long-term employees of our agency.

27. Too soon to tell, but I hope so.

28. At this point, we are only able to offer reimbursement for costs for all who complete.

29. Too soon to know, but I hope so.

30. -

Survey 9:

23. Better understanding of person first language.

24. -

25. -

26. Not enough time has passed to answer this question.

27. Not enough time has passed to answer this question.

28. Yes, payment for course/materials after successful completion - group recognition.

29. Not enough time has passed to answer this question.

$30 .-$

Survey 10:

23-30. No answers.

Survey 11:

23-29. No answers.

31. Volunteered to take this class for personal gain.

Survey 12:

23. A) Better interaction with clients and co-workers. B) Better communication.

24. A) More group activities. B) More real-life stories.

25. -

26. Yes, because they really enjoy the training.

27. Depends on the individual if interested.

28. No

29. Unknown.

30. -

Survey 13:

23. A) Better advocacy. B) Better communication. C) Better interaction with clients and coworkers.

24. A) More group participation. B) More group role playing. C) Having instructors like "Howard Twomey".

25. Howard is great - he's upbeat and never boring and he keeps everyone's interest.

26. Yes, it gives them more knowledge and better tools to effectively do their job.

27. Yes, for the same reasons listed above. 
28. No, if the person wants to increase their knowledge and/or further their education they can participate.

29. Yes, well I would hope everyone wants to further their education cause you can never know too much since this field is constantly changing.

30.

Survey 14:

23-30. This area is too long to complete due to time needed - sorry.

Survey 15:

23. A) Capable of implementing classes with minimal instruction. B) Well-grounded confidence with assigned tasks. C) Enthusiasm with consumers.

24. I have not participated in the classes myself, therefore poorly equipped to answer this question.

25. Survey answers are based upon only two individuals. My guess is that individuals who enroll in these classes are self-motivated and regard their job as a career.

26. Both employees have advanced within SMSC job ranks. Both exceed 5-years employment.

27. Yes, seeking a promotion and increased pay was part of the motivation for enrolling in classes.

28. Yes, I believe a $2 \%$ increase follows completion of programs.

29. Yes, one of my past employers that have attained a certificate is nearing completion of their AA degree.

30.

Survey 16:

23. A) Improved dialogue with supervisors. B) Improved understanding of meeting needs of consumers. C) Improved desire to advocate for consumers.

24.

25. -

26. Yes, as they feel more committed to working with consumers. They understand purpose behind it all.

27. Yes, as they feel they have more understanding of expectations as well as feel they can contribute.

28. Yes, $2 \%$ raise upon completion of 15 -unit course.

29. So far three have gone on to get AS or BS - others were content with what they got.

30.

Survey 17:

23. A) They see the individuals more as people. B) They want to learn more about the people they serve.

24. A) More focus on vocational skills training. B) More focus on various day program instruction.

25. - -

26. Yes, they have a better understanding of their role in the person's life that they serve.

27. Yes, they tend to want to fully use the knowledge that they gained.

28. Yes, they are offered a wage increase for obtaining certificate in Disabilities Management.

29. Sometimes - it depends on how far they want to go in the organization.

30. - 
Survey 18:

23. A) Public speaking; B) Applying knowledge learned.

24. A) More classroom participation; B) Homework that is applicable to program.

25. -

26.

27. More

28. Yes

29. Yes

30. -

Survey 19:

23. A) Openness to new situations; B) input about consumers; C) consumer/disabilities (knowledge of)

24. Have more assignments related to what $\mathrm{CO}$ does.

25. Have heard no complaints.

26. Yes, more committed.

27. One was - one wasn't

28. Yes, $\$ 200$ for certificate.

29. It seems like it - one going on to pursue more schooling.

30.

Survey 20:

23. A) Increased knowledge/awareness of person centered issues/supports. B) Better able to see "big picture" in terms of quality lives.

$24 . \quad-$

25. -

26. No, rate of pay, issues about workload, benefits.

27. More likely to seek, more confident, knowledgeable.

28. Yes, for 15-unit certificate, and for every 24-units accumulated.

29. No

30. 